\section{$Y-12$}
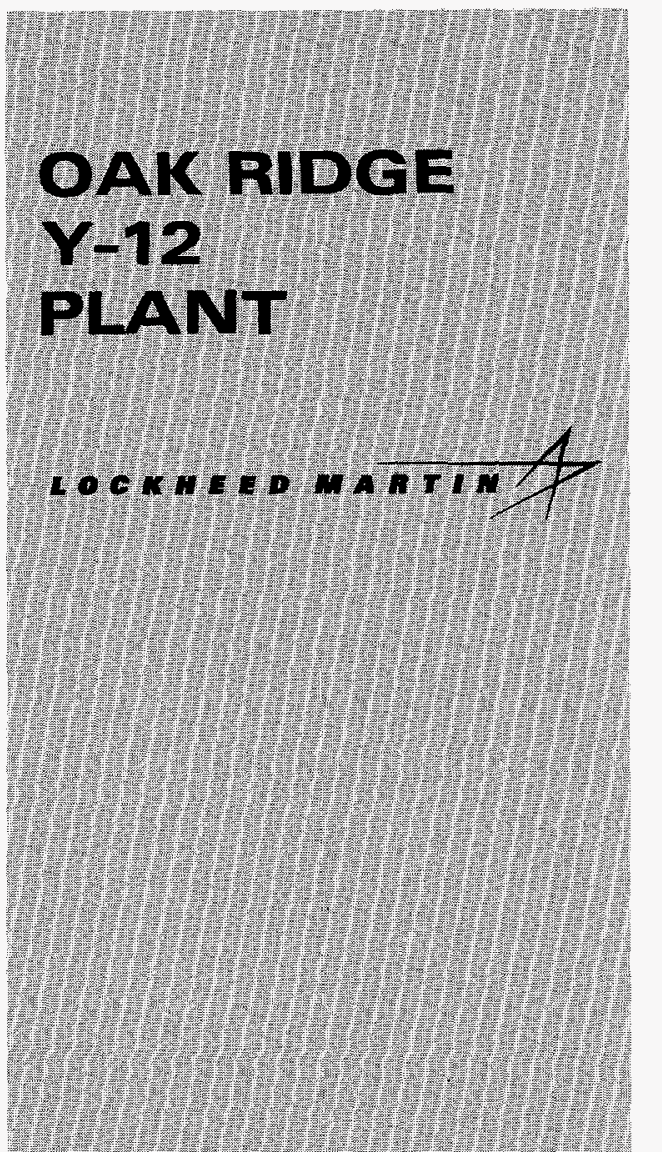

\section{- MANAGED BY} LOCKHEED MARTIN ENERGY SYSTEMS, INC. FOR THE UNTED STATES DEPARTMENT OF ENERGY

\section{RECFIVED \\ Nก: 301998}

USTI

Y/TS-1732

\section{TOXICS RELEASE INVENTORY EXPANSION RULE PHASE 3 (TRI-P3)}

September 1998
R. A. Evans

Environment, Safety, and Health Organization Y-12 Plant

\section{A. D. Saunders}

Office of Environmental Protection Lockheed Martin Energy Research

G. G. Worley

Emergency Management Program Organization Y-12 Plant

Prepared by the Oak Ridge Y-12 Plant

Oak Ridge, Tennessee 37831 managed by

Lockheed Martin Energy Systems, Inc. for the U.S. DEPARTMENT OF ENERGY Under Contract No. DE-AC05-84-OR21400 


\section{DISCLAIMER}

This report was prepared as an account of work sponsored by an agency of the United States Government. Neither the United States Ciovernment nor any agency thereof, nor any of their employees, make any warranty, express or implied, or assumes any legal liability or responsibility for the accuracy, completeness, or usefulness of any information, apparatus, procluct, or process disclosed, or represents that its use would not infringe privately owned rights. Reference herein to any specific commercial product, process, or service by trade name, trademark, manufacturer, or otherwise does not necessarily constitute or imply its endorsement, recommendation, or favoring by the United States Government or any agency thereof. The views and opinions of authors expressed herein do not necessarily state or reflect: those of the United States Government or any agency thereof. 


\section{DISCLAIMER}

Portions of this document may be illegible in electronic image products. Images are produced from the best available original document. 


\title{
TOXIC RELEASE INVENTORY EXPANSION RULE PHASE 3 (TRI-P3)
}

September 1998

\author{
R. A. Evans \\ Environment, Safety, and Health Organization \\ Y-12 Plant \\ A. D. Saunders \\ Office of Environmental Protection \\ Lockheed Martin Energy Research \\ G. G. Worley \\ Emergency Management Program Organization \\ Y-12 Plant
}

\author{
Prepared by the \\ Oak Ridge Y-12 Plant \\ Oak Ridge, Tennessee 37831 \\ managed by \\ Lockheed Martin Energy Systems, Inc. \\ for the \\ U.S. DEPARTMENT OF ENERGY \\ Under Contract No. DE-AC05-84-OR21400
}




\section{TABLE OF CONTENTS}

$\underline{\text { Page }}$

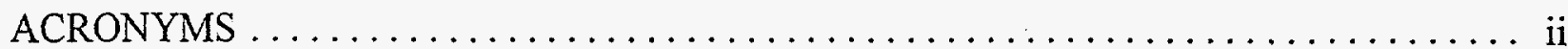

EXECUTIVE SUMMARY $\ldots \ldots \ldots \ldots \ldots \ldots \ldots \ldots \ldots \ldots \ldots \ldots \ldots \ldots \ldots \ldots \ldots \ldots \ldots$ iii

I. TASK 1 - REGULATORY REVIEW AND INTERPRETATION $\ldots \ldots \ldots \ldots \ldots \ldots$ 1-1

II. TASK 2 - APPLICATION O]: TRI-P3 TO A 1997 TRI CHEMICAL ........... 2-1

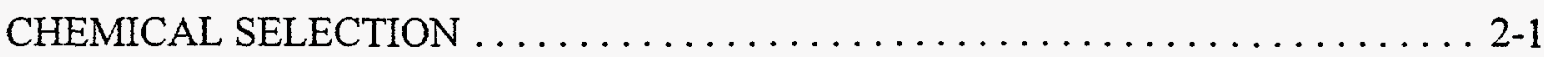

ORR CHEMICAL USE REPORTING OF LEAD $\ldots \ldots \ldots \ldots \ldots \ldots \ldots \ldots \ldots .2-1$

TRI-P3 CHEMICAL USE FORMS FOR LEAD $\ldots \ldots \ldots \ldots \ldots \ldots \ldots \ldots \ldots \ldots \ldots \ldots$

SUMMARY REPORT (LEAI)) AND GENERAL COMMENTS $\ldots \ldots \ldots \ldots \ldots .2-3$

III. TASK 3 - APPLICATION O $\approx$ TRI-P3 TO A NEW CHEMICAL $\ldots \ldots \ldots \ldots \ldots 2-5$

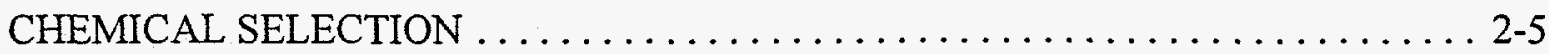

ORR “OTHERWISE USE” FOR CHROMIUM METAL $\ldots \ldots \ldots \ldots \ldots \ldots \ldots .2-6$

TRI-P3 CHEMICAL USE FCIRMS FOR CHROMIUM METAL $\ldots \ldots \ldots \ldots \ldots 2-6$

SUMMARY REPORT (CHROMTUM) AND GENERAL COMMENTS . . . . . . . 2-7

IV. TASK 4 - WORKER EXPOSURE MONITORING $\ldots \ldots \ldots \ldots \ldots \ldots \ldots \ldots \ldots \ldots \ldots$

APPENDIX A: DATA PACKAGE FOR LEAD $\ldots \ldots \ldots \ldots \ldots \ldots \ldots \ldots \ldots \ldots \ldots$

APPENDIX B: DATA PACKAGE: FOR CHROMIUM $\ldots \ldots \ldots \ldots \ldots \ldots \ldots \ldots \ldots$ B-1

TABLE 1 - OAK RIDGE RESERVATION (ORR) CHEMICAL USE OF LEAD . . . . . . 2-2

TABLE 2 - ORR CHEMICAL USE OF CHROMIUM $\ldots \ldots \ldots \ldots \ldots \ldots \ldots \ldots \ldots \ldots \ldots$ 


\section{ACRONYMS}

\begin{tabular}{|c|c|}
\hline ANPR & Advance Notice of Proposed Rulemaking \\
\hline CFR & Code of Federal Regulations \\
\hline DOE & U.S. Department of Energy \\
\hline DOE-ORO & U.S. Department of Entergy, Oak Ridge Operations Office \\
\hline $\mathrm{EO}$ & Executive Order \\
\hline EPA & U.S. Environmental Protection Agency \\
\hline EPCRA & Emergency Planning and Community Right-to-Know Act of 1986 \\
\hline ETTP & East Tennessee Technology Park \\
\hline HEPA & High-Efficiency Particulate Air (Filter) \\
\hline HMIS & Hazardous Materials Information System \\
\hline NPDES & National Pollutant Discharge Elimination System \\
\hline ORNL & Oak Ridge National Laboratory \\
\hline ORR & Oak Ridge Reservation \\
\hline OSHA & Occupational Safety and Health Act of 1970 \\
\hline RCRA & Resource Conservation and Recovery Act of 1976 \\
\hline $\mathrm{SIC}$ & Standard Industrial Classification \\
\hline TRI & Toxic Release Inventcry \\
\hline TRI-P3 & Toxic Release Inventory-Phase 3 \\
\hline TSCA & Toxic Substances Cortrol Act of 1976 \\
\hline TURA & Toxics Use Reduction Act \\
\hline WOD & White Oak Dam \\
\hline
\end{tabular}




\section{EXECUTIVE SUMMARY}

The Emergency Planning and Community Right-to-Know Act of 1986 (EPCRA), Section 313, requires Toxic Release Inventory (TRI) reporting by industries in specified Standard Industrial Classification Codes (SICs). Executive Order (EO) 12856 extends that reporting requirement to all federal facilities, regardless of trpes of work performed. The Environmental Protection Agency (EPA) has been expanding the scope of TRI reporting in a three-phased series of regulatory revisions, as described telow:

1. Phase 1, October 1996, added 286 additional chemicals to the list of reportable chemicals;

2. Phase 2, May 1997, required seven additional industry groups to file annual TRI reports; and

3. Phase 3, as announced in an October 1996 Advance Notice of Proposed Rulemaking (ANPR), would require reporting of additional materials accounting data at reporting facilities.

Prior to finalizing TRI Phase 3 (TRI-P3), the EPA is studying the burden that it would place on industry, as well as the feasibility for reporting facilities to provide chemical use data on expanded TRI reporting forms, such as are already used in the states of Massachusetts and New Jersey.

The Department of Energy (DOE) is among the industry groups participating in TRI-P3 pilot studies, and the Oak Ridge Reservation (ORR) was one of the DOE reporting facilities identified to carry out the reporting process p:ior to final rule promulgation. ORR TRI reporting personnel, through DOE Oak Ridge Operations (DOE-ORO) staff, have frequently commented during the public comment period on the anticipated impact of proposed rules. This pilot project has 
provided the opportunity to apply and comment on the rule's impact, while simultaneously benefitting the EPA in their final rulemaking agenda.

The ORR [East Tennessee Technology Park (ETTP), Y-12 Plant, and Oak Ridge National Laboratory (ORNL)] is considered a single facility for reporting by the DOE prime contractors. The processing, manufacturing, or "otherwise use" Section 313 chemicals are combined to determine TRI reportability.

Such is the case with lead metal, which is one of two chemicals for which reporting forms were prepared in this pilot study (Task 2). The lead shop at ORNL exceeded the reporting threshold, causing a lead activity at a Y-12 machine shop and lead in waste at ETTP to be reportable. TRI-P3 report preparation time for lead totaled 36.5 hours. The second chemical investigated and reported (chromium) also required nearly a man-week for report preparation and documentation by experienced TRI personnel. The ORR TRI report typically includes about six chemicals, so an estimate of the TRI-P3 incremental reporting burden for ORR would be six weeks for experienced personnel and two/three man-months for first-time ORR preparers.

TRI-P3 is aimed at clearly defined jroduction/manufacturing processes causing a complication for ORR reporting. There are few clearly defined processes involving Section 313 chemicals, yet there is no exemption from reporting in "otherwise use" activities--which may exceed the reporting threshold of 10,000 pounds. Chemical mass balance through a production plant is the ideal TRI-P3 reporting scenario, and mass balance becomes extremely difficult when numerous, unrelated, nonmanufacturing activities on the ORR become reportable (as determined months after closing the reporting year). 


\section{Task 1 - Regulatory Review and Interpretation}

TRI reporting at the DOE-ORR encompasses about 34,516 acres of contiguous land and involves operations at three separate facilities: ORNL, the Y-12 Plant, and ETTP (formerly the $\mathrm{K}-25 \mathrm{Site})$. Each is a vast industrial complex separated from the others by a distance of 5-10 miles, with little commonality in the work performed. The ORR reports as a single facility, primarily under EO 12856 as there are very few manufacturing/production activities that would be TRI reportable based on SIC codle. The Y-12 Plant is the only true "production" site; however, its primary process involves the enrichment of uranium, a non-TRI chemical. The primary processes at ETTP are remedial waste management activities, largely exempt from TRI, and hazardous waste incineration, which has resulted in some inadvertent "manufacture" of TRI-reportable chemicals.

On the ORR, the "otherwise use" criteria (10,000 pounds) usually causes the reporting threshold to be exceeded through aggregation of unrelated chemical usage. The easiest explanation is the rule of "the whole is greater than the parts." EO 12856 requires ORR reporting of these chemicals when the specified threshold is exceeded (even though there is no SIC code limit). So when one site of the ORR reaches a chemical usage close to the threshold, the other parts/sites of the ORR end up reporting (even small, normally exempt measurements) causing the whole itself to go over the threshold.

TRI-P3, being primarily aimed at specific production processes in a "cradle to grave" atmosphere, is not geared to this aggregate situation. The ORR "otherwise use" activities will have to be force-fitted into the rule and onto the form. The following, Task 2, illustrates this point. 


\section{Task 2-Application of TRI-P3 to a 1997 TRI Chemical}

CHEMICAL SELECTION. As proposed in the Statement of Work, the chemicals submitted on an actual TRI report represent an iceal departure point for this pilot study: TRI report preparation is complete (shortening the study period) and the time required for TRI-P3 can be isolated and quantified. Accordingly, lead was selected for reporting in Task 2 of this pilot study.

ORR CHEMICAL USE REPORTING OF LEAD. Lead was reported on the ORR 1997 TRI reports. The lead activity responsible for exceeding the reporting threshold was the melting ("otherwise use") of 236,000 pounds of lead at the ORNL lead melt shop in a recycling/reuse effort. Table 1 shows a summary of the ORNL and other ORR lead activities reported on the Form Rs and how each is being hardled in TRI-P3. Two related processes are reportable by ORNL; one Y-12 activity, although unrelated to the ORNL process, is able to be classified as a chemical use process for TRI-P3 reporting. The Y-12 "process" involved a machine shop that drilled holes in a single lead plate for use at the plant. Lead activities at ETTP, also reportable on TRI because of threshold exceeclance at ORNL, were related to remedial waste treatment activities, and current state of Massachusetts reporting instructions exempt these activities from Form S reporting. The New Jersey instructions and forms make provision for chemical ingredients in waste, and lead contained in the waste treated at the ETTP incinerator is reportable. Other "out-of-process" remedial waste management activities at ETTP would be extremely difficult to fit into the chemical use reporting process, and it appears that New Jersey would not require reporting beyond the waste management entries on the Form $\mathrm{R}$.

TRI-P3 CHEMICAL USE FORMS FOR LEAD. Enclosed are completed Massachusetts Toxics Use Reduction Act (TURA) Report Form Ss and pertinent sections of the New Jersey Release and Pollution Prevention Report Forms for lead (Appendix A). Since regulatory compliance involves much more time, effort, ard documentation than just entering numbers onto a form where appropriate, some of the rationale and thought processes involved in researching and 


\section{Production Units \& Processes / Other Form $\mathrm{R} L E A D$ Activities}

\begin{tabular}{|c|c|c|c|c|}
\hline Establishment & $\begin{array}{l}\text { Production } \\
\text { Unit }\end{array}$ & $\begin{array}{l}\text { Related } \\
\text { Process }\end{array}$ & $\begin{array}{l}\text { Out-of-Process } \\
\text { Activity }\end{array}$ & $\begin{array}{c}\text { Chemical Use Report } \\
\text { Status }\end{array}$ \\
\hline ORNL & $\begin{array}{l}\text { LEAD Melt Shop } \\
(236,000 \mathrm{lbs})^{*}\end{array}$ & & & Form S prepared \\
\hline \multirow[t]{4}{*}{$\cdot \ldots$} & & $\begin{array}{l}\text { Off-site shipment } \\
\text { of raw material }\end{array}$ & & Included on Form $\mathrm{S}$ \\
\hline & & $\begin{array}{l}\text { LEAD in } \\
\text { stormwater }\end{array}$ & & $25 \%$ on Form $\mathrm{S}$ \\
\hline & & & $\angle E A D$ in stormwater & $\begin{array}{l}\text { Unrelated release; } 75 \% \\
\text { overlooked } \\
\text { (Ref. p. 17) }\end{array}$ \\
\hline & & & $\begin{array}{l}\text { Off-site remedial } \\
\text { waste shipments }\end{array}$ & $\begin{array}{l}\text { Unrelated releases; } \\
\text { overlook (Ref. p. 17) }\end{array}$ \\
\hline \multirow[t]{4}{*}{ Y-12 Plant } & $\begin{array}{l}\text { Machine Shop } \\
\text { ( } 10 \text { lbs used })\end{array}$ & & & Form S prepared \\
\hline & & & $\begin{array}{l}L E A D \text { in liquid } \\
\text { organic waste }\end{array}$ & $\begin{array}{l}\text { Unrelated waste } \\
\text { treatment; overlook } \\
\text { (Ref. p. 17) }\end{array}$ \\
\hline & & & $\begin{array}{l}L E A D \text { in storm \& } \\
\text { wastewater }\end{array}$ & $\begin{array}{l}\text { Unrelated releases; } \\
\text { overlook (Ref. p. 17) }\end{array}$ \\
\hline & & & $\begin{array}{l}L E A D \text { in landfill \& } \\
\text { off-site remedial } \\
\text { waste shipments }\end{array}$ & $\begin{array}{l}\text { Unrelated releases; } \\
\text { overlook (Ref. p. 17) }\end{array}$ \\
\hline \multirow[t]{5}{*}{ ETTP } & & & $\begin{array}{l}\text { LEAD in waste at Toxic } \\
\text { Substances Control Act } \\
\text { Incinerator/Central } \\
\text { Neutralization Facility }\end{array}$ & $\begin{array}{l}\text { New Jersey } \\
\text { form prepared }\end{array}$ \\
\hline & & & $\begin{array}{l}\angle E A D \text { in TVS } \\
\text { remedial waste }\end{array}$ & $\begin{array}{l}\text { Unrelated waste } \\
\text { treatment; overlook }\end{array}$ \\
\hline & & & $\begin{array}{l}\text { Repackage/store } \\
\text { processed waste }\end{array}$ & $\begin{array}{l}\text { Unrelated releases; } \\
\text { overlook (Ref. p. 17) }\end{array}$ \\
\hline & & & $\begin{array}{l}\text { Off-site remedial } \\
\text { waste shipments }\end{array}$ & $\begin{array}{l}\text { Unrelated releases; } \\
\text { overlook (Ref. p.17) }\end{array}$ \\
\hline & & & $L E A D$ in stormwater & $\begin{array}{l}\text { Unrelated releases } \\
\text { overlook (Ref. p. 17) }\end{array}$ \\
\hline
\end{tabular}

*denotes threshold activity ${ }^{* *}$ State of Massachusetts, TURA Reporting Instructions, page 17.

Table 1. Oak Ridge Reservation Chemical Use Reporting of LEAD 
completing each form entry are included. The documentation is typical of that prepared and maintained to demonstrate compliance, even where there may be $N O$ form entry or perhaps even $N O$ report required. DOE burden forms were use to track the TRI-P3 report preparation time, and those forms are also enclosed.

\section{SUMMARY REPORT (LEAD) AIND GENERAL COMMENTS.}

1. The primary reporting establishment, ORNL, obtained the information and prepared the forms and documentation in 20 hours; whether the Massachusetts form or the New Jersey form, it is not entering data onto the form that takes the time, but rather it is data compilation and documentation that is time consuming. Since the Y-12 Plant is part of the single ORR reporting facility, a one-time lead drilling process was reportable under TRI-P3, and it required an additional 12.5 hours. This is 12 hours longer than it took to drill the holes in the lead plate, and it might be representative of the simplest process and the minimum time required for a single TRI-P3 report. ETTP lead activities pertained to waste management processes, for which the reporting forms are not well designed; the Massachusetts guidance to "overlook" unrelated waste t:eatment processes was applied in this task, while the New Jersey form, where applicable, was completed for the ETTP incineration process in 4 hours.

For our own planning purposes, we conclude that each TRI chemical reported could require an additional week for TRI-P3 reporting by experienced TRI personnel. TRI-P3 reporting of more complex scenarios (inclucling chemicals in waste) by less experienced personnel (or personnel less familiar with the TRI documentation) could require 2 weeks per chemical, and our usual 5-6 chemicals could require up to 3 additional man-months per reporting year.

2. Although we've applied the Mcssachusetts option to "overlook" waste management activities unrelated to the process/operation/product being reported on (reference Massachusetts 1996 Form S Reporting Package, p.17), that is NOT the kind of guidance that will suffice for regulatory compliance. TRI-P limits of applicability must be more clearly defined, and if 
there are no limits defined, then form preparation and compliance documentation is going to be quite difficult for people with "otherwise use" activities. Direct communication with the state of Massachusetts confirms that (a) their forms are not intended for chemicals in waste (only chemicals used to treat waste), and (b) their reporting instructions have not yet addressed the "otherwise use" chemicals in off-site waste, i.e., TRI-P2, which became effective January 1, 1998. The New Jersey form was easily completed for the incineration process; however, the value of the few completed entries is questionable, and it is not altogether clear whether unrelated out-of-process inventory and waste management activities are to be excluded from the forrn. If not, the otherwise use process information for a chemical would be quite distorted by bits and pieces of unrelated waste information from other site activities, if ingredient information is even available (our incinerator waste ingredient tracking system is much more detailed than required for most other waste management activities).

3. An objective review of the comments from those preparing the forms clearly indicates that the proposed regulation and forms are targeting certain information that is somewhat irrelevant to the ORNL, Y-12, and ETTP reported processes. This exercise and report did not provide good information on chemical use, nor does it identify an opportunity for reduction of toxic chemicals used in a prccess. It is felt that existing pollution prevention (P2) programs are more effective at quantifying and targeting problem chemicals. The ORR P2 programs have been active and highly successful, and in general they have not been guided by TRI reports, nor will useful information be obtained from the TRI-P3 report.

4. Data misuse. Form entries such as the byproduct/emissions reduction aspects of TRI-P3, were quite difficult to address and probably "not applicable" for this application, but that could not be concluded. After attempting a report entry, we must then be concerned about what the public will infer from our reporting of 6,503 pounds of lead byproduct (no explanation offered here, because the reporting form doesn't allow for an explanation). 
5. Data availability. Site-wide chemical inventory information is generally available via the ORR Hazardous Materials Information System (HMIS); however, it requires a high level of manual attention to be reliable and personnel resources for this type of administrative burden are on the decline. Additionally, HMIS does not provide information on chemicals in waste, and that can be a large part of the inventory at a treatment, storage, and disposal (TSD) facility. TSD waste records are as detailed as required to satisfy the Resource Conservation and Recovery Act (RCRA) regulations.

In this lead reporting project involving "otherwise use" activities, it was discovered from the sites that in performing a routine or one-time support activity, rather than a production activity, there is no strong basis for generating "otherwise use" records, especially where the chemical may have been an ing:edient in a previously manufactured article.

6. The New Jersey form provides several exit points, and that is very important when the preparer is struggling with scenarios that do not fit well into the TRI-P3 mold. Those who design the forms must consider not just the ideal reporting scenario, but a broader range of possible scenarios being brought about by TRI expansion, as well as by EO 12856 .

\section{Task 3-Application of TRI-P 3 to a New Chemical}

CHEMICAL SELECTION. As proposed, an "otherwise use" chemical in waste was targeted in Task 3, in order to apply the TRI-P2 definition of "otherwise use" and involve the ETTP hazardous waste incinerator along with Y-12 and ORNL. Numerous chemicals are candidates for reporting (there are more than 150 tracked in the waste), but very few are "otherwise used" in sufficient quantity to exceed the reporting threshold. For example, the primary waste ingredient for which the incinerator is permitted, i.e., polychlorinated biphenyls, is being received from off-site facilities, and, if selected, would involve $O N L Y$ the ETTP site. Recognizing that chemical quantities in off-site waste could change in the future, reporting thresholds could 
change in the future, and/or activities at another part of the ORR could trigger the reporting requirement, a chemical (chromiur! metal) was selected for purposes of this project.

Note: the current usage and the nurabers appearing on the forms would not have required reporting in the pilot project (reference year, 1997).

ORR "OTHERWISE USE" OF CHROMIUM METAL. Chromium is a very minor constituent in waste handled at the ETTP hazardous waste incinerator, and only about 2 percent of the chromium in waste came from off site in 1997. This breakout of off-site vs. on-site waste is not compiled for any other purposes, sc the "otherwise use" amount was not known at the time of chemical selection (even though suich data can be calculated from the information in the waste tracking database). At the Y-12 Plant, an electroplating process (reportable activity) involved the "otherwise use" of chromium metal as an ingredient in a plating solution. At ORNL there was chromium as "otherwise use" as ar ingredient in welding rods, which lost their article exemption upon use. The pilot reporting exercise was completed at ORNL to be representative of similar activities at the other plant sites, and after the fact, it is very difficult to know whether or not the "otherwise use" was for an exempt activity. ORNL attempted to complete the forms, operating under the assumption that the welding was performed for nonexempt applications. An overview of ORR chemical use reporting for chromium is shown in Table 2.

TRI-P3 CHEMICAL USE FORMS FOR CHROMIUM METAL. Enclosed are completed Massachusetts TURA Report Form Ss and pertinent sections of the New Jersey Release and Pollution Prevention Report Forms for chromium (Appendix B). Supplemental material is provided to explain and document each form entry, along with the time required to compile the information. 
1. Report preparation time. The reporting of "otherwise use" chemicals depends heavily upon the availability of past records. If personnel time and/or computer resources are not devoted throughout the year, no amount of time by the report preparer will recreate some of the information that is needed solely for chemical use reporting; rough estimation or incomplete reporting are the likely outcomes. For the Y-12 Plant, personal interviews revealed information about the chromiurn plating activity, although it is an example of an activity that nobody expected to be reportable throughout the year. It is difficult, then, to generate detailed chemical ingredient information after the fact. Estimates were made and the reporting forms prepared in 12.5 hours; an estimated 5 additional hours would have been spent to investigate the use of chromium in activities unrelated to the electroplating process.

In the case of "otherwise use" chemicals in waste, there could be some extremely difficult scenarios involving minor chemical constituents. The ETTP hazardous waste incinerator, however, maintains a detailed vaste tracking system that was accessed by a system specialist. For a single chemical, there were 6 hours devoted to obtaining the information and preparing the forms, and an estimated 5 alditional hours would have been spent to investigate the use of chromium in unrelated site activities. In order to develop the software that would provide chemical use data (as defined by TRI) for all chemical constituents in waste incinerated, a 40-hour development effort is estimated.

With no clear-cut process involving chromium to report on, ORNL addressed the problem of chromium in welding rods (which lose their exempt status upon use) to be representative of the time and effort that would be required at Y-12 and ETTP. Information was obtained for estimating usage, and the forms were prepared in 5 hours. In summary, much like the report preparation time for lead, it too $\mathrm{s}$ a total of 35.5 hours to prepare the chemical use forms for chromium. An additional softwrare development effort of 40 hours is foreseen and an 


\section{Production Units \& Processes / Other CHROMIUM Activities}

\begin{tabular}{|c|c|c|c|c|}
\hline Establishment & $\begin{array}{l}\text { Production } \\
\text { Unit }\end{array}$ & $\begin{array}{l}\text { Related } \\
\text { Process }\end{array}$ & $\begin{array}{l}\text { Out-of-Process } \\
\text { Activity }\end{array}$ & $\begin{array}{c}\text { Chemical Use Report } \\
\text { Status }\end{array}$ \\
\hline \multirow[t]{5}{*}{ ETTP } & Waste Incinerator & $\begin{array}{l}\text { Neutralization } \\
\text { facility }\end{array}$ & & Form S prepared \\
\hline & & & $\begin{array}{l}\text { Soldering and } \\
\text { welding }\end{array}$ & $\begin{array}{l}\text { Insufficient use data; } \\
\text { refer to ORNL report }\end{array}$ \\
\hline & & & $\begin{array}{l}\text { Off-site remedial } \\
\text { waste shipments }\end{array}$ & $\begin{array}{l}\text { Unrelated releases; not } \\
\text { reported on Form S }\end{array}$ \\
\hline & & & $\begin{array}{l}\text { Chromium in } \\
\text { stormwater }\end{array}$ & $\begin{array}{l}\text { Unrelated releases; not } \\
\text { reported on Form S }\end{array}$ \\
\hline & & & $\begin{array}{l}\text { Chromium in other } \\
\text { wastes }\end{array}$ & $\begin{array}{l}\text { Unrelated activities; not } \\
\text { reported on Form S }\end{array}$ \\
\hline \multirow[t]{4}{*}{$Y-12$ Plant } & Chrome Plating & & & Form S prepared \\
\hline & & & $\begin{array}{l}\text { Soldering and } \\
\text { welding }\end{array}$ & $\begin{array}{l}\text { Insufficient use data; } \\
\text { refer to ORNL report }\end{array}$ \\
\hline & & & $\begin{array}{l}\text { Chromium in } \\
\text { stormwater }\end{array}$ & $\begin{array}{l}\text { Unrelated releases; not } \\
\text { reported on Form S }\end{array}$ \\
\hline & & & $\begin{array}{l}\text { Chromium in other } \\
\text { wastes }\end{array}$ & $\begin{array}{l}\text { Unrelated activities; not } \\
\text { reported on Form S }\end{array}$ \\
\hline \multirow[t]{3}{*}{ ORNL } & & & $\begin{array}{l}\text { Soldering and } \\
\text { welding }\end{array}$ & $\begin{array}{l}\text { Form S prepared with } \\
\text { limited data }\end{array}$ \\
\hline & & & $\begin{array}{l}\text { Chromium in } \\
\text { stormwater }\end{array}$ & $\begin{array}{l}\text { Unrelated releases; not } \\
\text { reported on Form S }\end{array}$ \\
\hline & & & $\begin{array}{l}\text { Chromium in other } \\
\text { wastes }\end{array}$ & $\begin{array}{l}\text { Unrelated activities; not } \\
\text { reported on Form S }\end{array}$ \\
\hline
\end{tabular}

Table 2. Oak Ridge Reservation Chemical Use Reporting of Chromium 
undetermined amount of time and personnel resources could be applied throughout the year to generate "otherwise use" records, which ideally would be available for TRI-P3 compliance.

2. Burden on state agencies. Whi e seeking instructions for completing the Massachusetts TURA Form S, it became evident that their staff was too overloaded in 1997 data collection to be aware of the full effects of TRI-P2 (already in effect) on their data collection in the future. As for the affected industries in Massachusetts, undoubtedly many in September 1998 do not know of the need to inc.ude chemical ingredients in off-site waste in threshold determination for calendar year 1998 compliance reporting. This illustrates excessive regulatory and administrative burden. Furthermore, when further automation is relied upon as the solution, it implies more chances for data misuse by the public.

3. As in Task 2, our data collection efforts in Task 3 seemed to be misdirected by TRI-P3 toward activities that are quite insignificant compared to the real pollution issues at the plant sites. On the ORR, this has been brought about by the wide scope of coverage of EO 12856, by broad definition of "facility" as it pertains to more than one reporting establishment, and particularly, by the inclusion of "otherwise use" activities in chemical use reporting. Each regulatory add-on has taken us farther away from the reporting of meaningful data while increasing the reporting burden. The challenge for TRI-P3 is to highlight significant opportunities for source reduction without significantly increasing the administrative burden and causing unintended consequences.

\section{Task 4 - Worker Exposure Monitoring}

In the ANPR, the information proposed to be collected consists of
a. Total number of workers at the facility,
b. Number of workers potentially exposed to the chemical being reported, and
c. Whether exposure assessment was/is being performed for the chemical. 
For the ORNL lead shop, that information is $a=7, b=7, c=$ Yes (if the facility is considered only to be the lead shop). An "Overview of the Lead Shop Operation" (Attachment 1) was presented to the TRI-P3 project interviewer by a representative of ORNL Industrial Hygiene. The presentation had previously been prepared and presented to an Occupational Safety and Health Act of 1970 (OSHA) audit leam that visited the ORNL lead shop, where an ongoing monitoring program consists of both breathing airspace monitoring and medical (worker blood) sampling. There have been no exceedances of OSHA standards in and around the lead shop, and routine air monitoring in the remainder of the ORNL facility reveals no lead levels approaching the action level of 30 micrograms per cubic meter. Except as special short-term projects on activities may dictate, there is no further facility-wide lead exposure assessment program at the individual worker level.

It is rather apparent that, by operating in full EPA and OSHA compliance, the ORNL lead shop has little or no worker exposure information of value to report, and all facets of the monitoring program document that the "workers potentially exposed" are in fact NOT exposed at any regulatorily established limits. Thus, any reported worker exposure information would be available for misuse, and the problem of "facility" definition has not yet been addressed.

The worker exposure information above is based only on the ORNL lead shop facility. Under the EPCRA definition of facility, the CIRNL workforce should include the total workers at the facility, even though it has been ill sstrated and documented that there are no exposures either inside or outside of the lead shop. To let the administrative burden and the numerical totals extend from a totally compliant lead melting process involving seven workers, to the remainder of the ORNL facility and the Y-12 Plant and ETTP is clear evidence of a troublesome regulation with ill-defined limits. The dilemra for the reporting facility is whether to wander off into the compilation and nearly impossible reporting of further extraneous numbers (in the thousands at ORR), or to report just on the production process at hand and perhaps be vulnerable to a nearly impossible interpretation by an auditor or inspector. 
The Y-12 Plant has an extensive and comprehensive Ambient Air Monitoring and Worker Protection Program. Specified maintenance jobs are reviewed on a case-by-case basis for any possible need for biological (blood; or air workspace monitoring. The lead activity reported at the Y-12 Plant did not include persınnel monitoring simply due to the pre-existing controls established via job hazard analysis.

At ETTP, the site of the Toxic Substances Control Act (TSCA) Incinerator and other hazardous waste management activities, there is an extensive ambient air and personal monitoring program, but not driven by EPCRA TRI-repcrtable chemicals. The perimeter air monitoring program satisfies state air monitoring requirements and monitors metals in waste at the incinerator. The summary sheet (Attachment 2 ) illustrates that the ambient air levels are consistently below the level of detection.

Industrial hygiene air monitoring summaries at ETTP, and specifically at the TSCA Incinerator, are shown in Attachments 3 and 4, respectively. To illustrate how little monitoring information the TRI-P3 program would capture lead monitoring in 1996 constituted approximately 2 percent of the total industrial hygiene effor. To report that as potential exposures, regardless of the number of workers involved, when the actual program documented no exposures in nearly 7,000 samples, would significantly misrejresent an active program in full OSHA compliance. Time spent to isolate information for a TJUI-reportable chemical, known locally to be a nonissue, could be more effectively applied toward potential worker health issues that have been identified to the health professionals and their regulating agencies. 


\section{Attachment 1}

ORNL Overview of the Lead Shop Operations 


\section{OVERVIEW OF THE LEAD SHOP OPERATION}

13 Lead Shop Operation (Building 7005)

- The lead shop supports research activities at ORNL by fabricating lead for shielding against radioactivity.

- The fabrication of lead is accomplished by the following activities:

- burning, melting, pouring, cutting, machining, and welding.

- The equipment utilized for fabrication of lead is as follows:

- Four furnaces for melting lead

- two small with $1000 \mathrm{lb}$ capacity

- two large with $50100 \mathrm{lb}$ capacity

- Dewalt saw for cutting lead

- Radial arm drill for drilling lead

- Lathe for machining arld milling lead

2 Exposure Assessment

- Breathing zone air sampling has been conducted to assess exposures to lead

- Hygiene facilities have also been monitored for lead dust (surface sampling)

- Facility surveys and work evaluations are performed periodically.

3C Controls

- Engineering controls for worker health \& safety

- Equipment controls:

- local exhaust ventilation and safety cut-off valves on the furnaces.

- Dewalt saw with loca exhaust ventilation

. use of coolant during machining/drilling

- local exhaust ventilation for welding/cutting

- Facility controls:

- regulated area to prevent unauthorized entry

- use of HEPA vacuurr to prevent lead in the shower and launch area

- positive pressure venilation for the lunch room

- Periodic ventilation evaluations to ensure adequacy of the system

- Covered storage area for lead to minimize oxidation 


\section{Controls (cont'd)}

- Administrative controls are as follows:

- Lead compliance plan (work guidelines)

- Safety Work permit

- Work practices to minimize exposure to lead include:

- no eating, drinking, smoking, application of cosmetics, etc., in the regulated area

- washing hands and face, or showering prior to eating

- showering at the end of the work shift

- no dry sweeping or blowing with compressed air

- HEPA vacuuming prior to entry in non-contaminated areas

- Personal protective equipment utilized at the lead shop is as follows:

- Company issued c cothing and/or disposable clothing

- Safety glasses

- Respirators

- Gloves

- Steel-toe shoes

\section{Training}

- Initial lead training is provided to all employees who work at the lead shop.

- Refresher training is provided to all employees who have exposures at or above the action level.

5 Medical Surveillance Program

- ORNL Health Division is responsible for the medical surveillance program.

- All employees at the lead shop participate in the medical surveillance program.

\section{$6 \bigcirc$ Conclusion}

- ORNL lead shop has recycled 480,000 pounds of lead since 1995 and saved approximately 1.5 million in purchase and disposal costs.

- All the lead work was performed in accordance with 29 CFR 1910.1025 requirements. 


\section{Attachment 2}

ETTP Ambient Air Monitoring Averages 

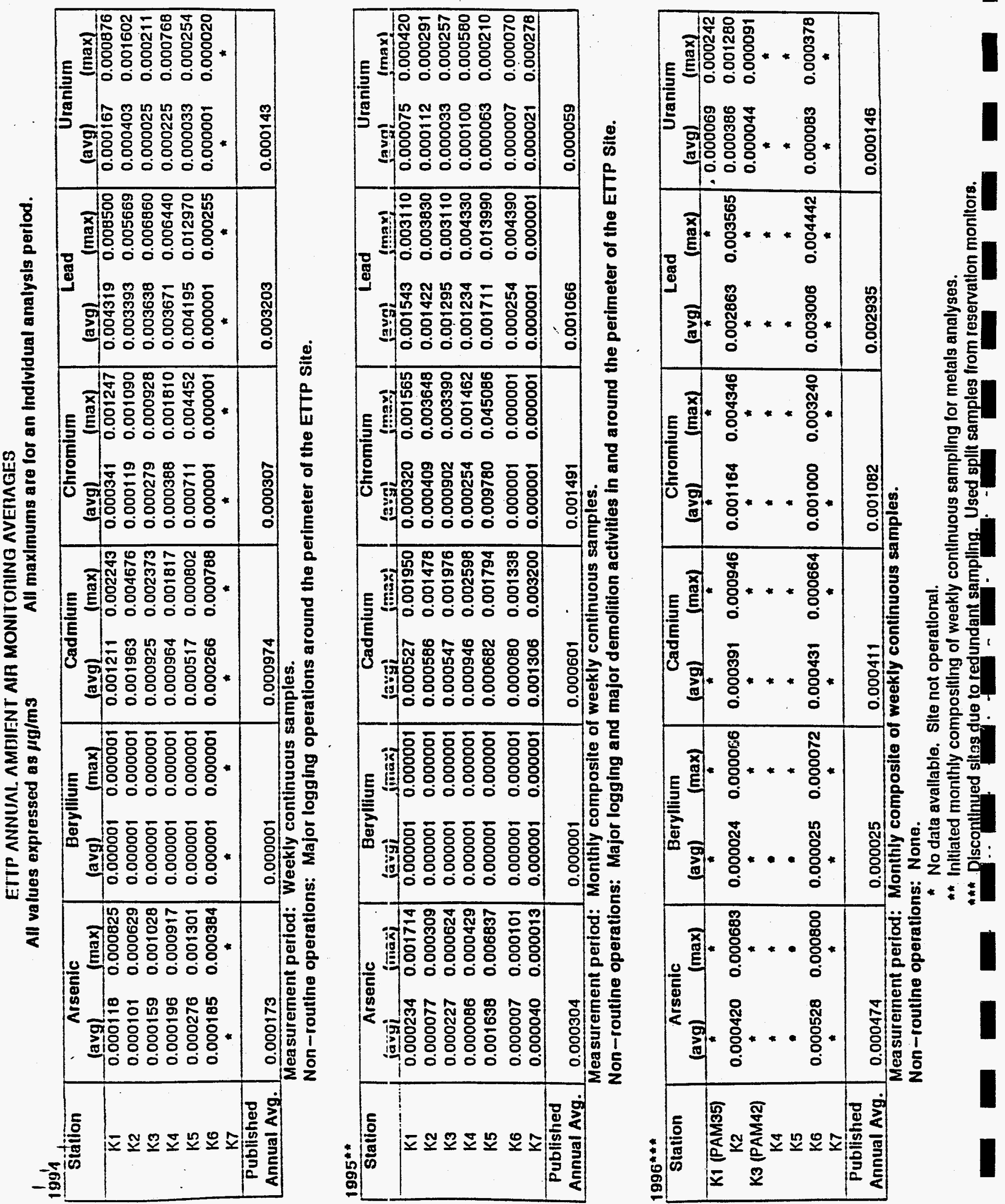


\section{Attachment 3}

ETTP Industrial Hygiene Air Monitoring Summary 
NUMBER OF SAMPLES

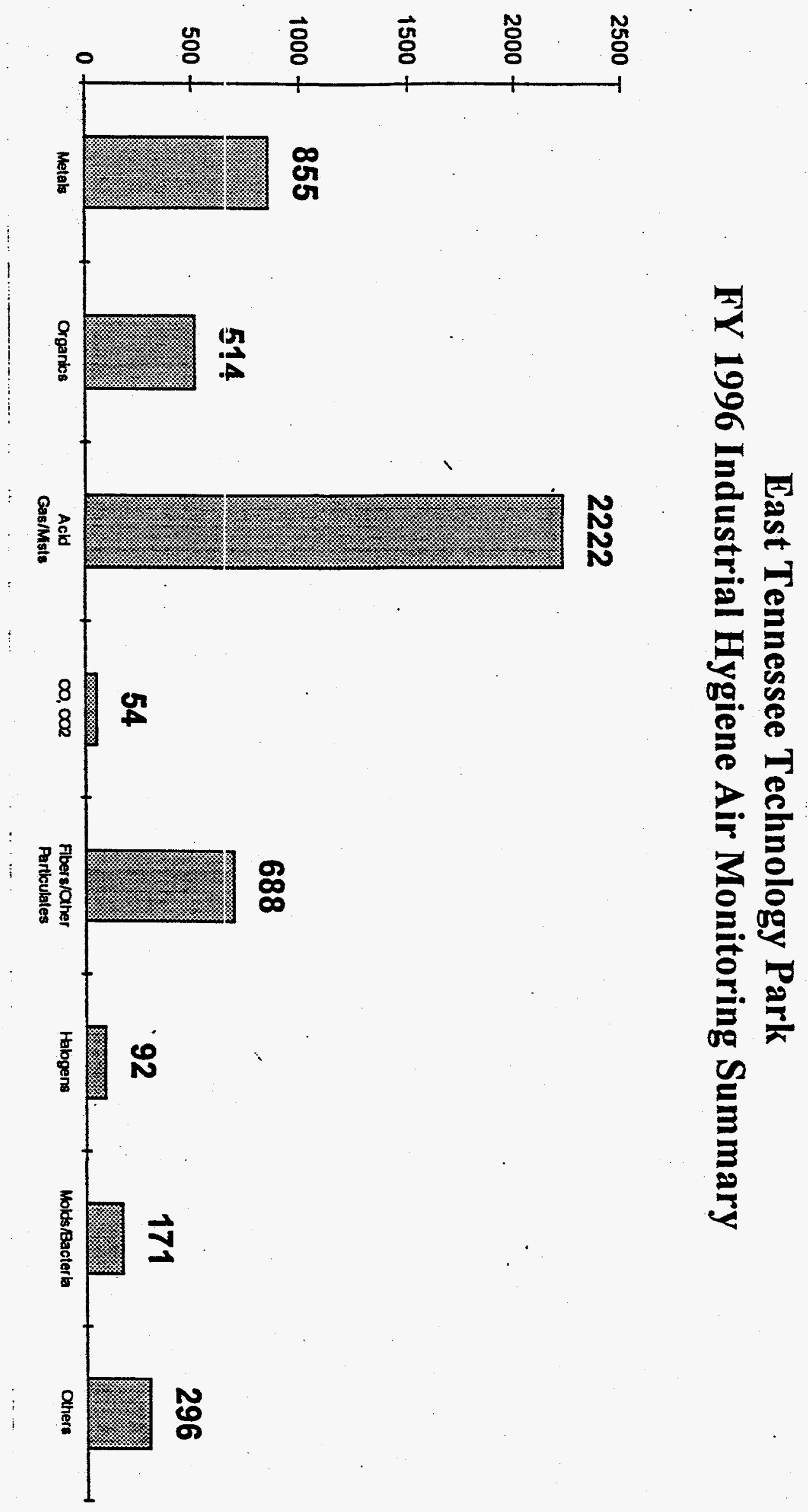




\section{Attachment 4}

ETTP TSCA/Waste Management Air Monitoring Summary 
NUMBER OF SAMPLES

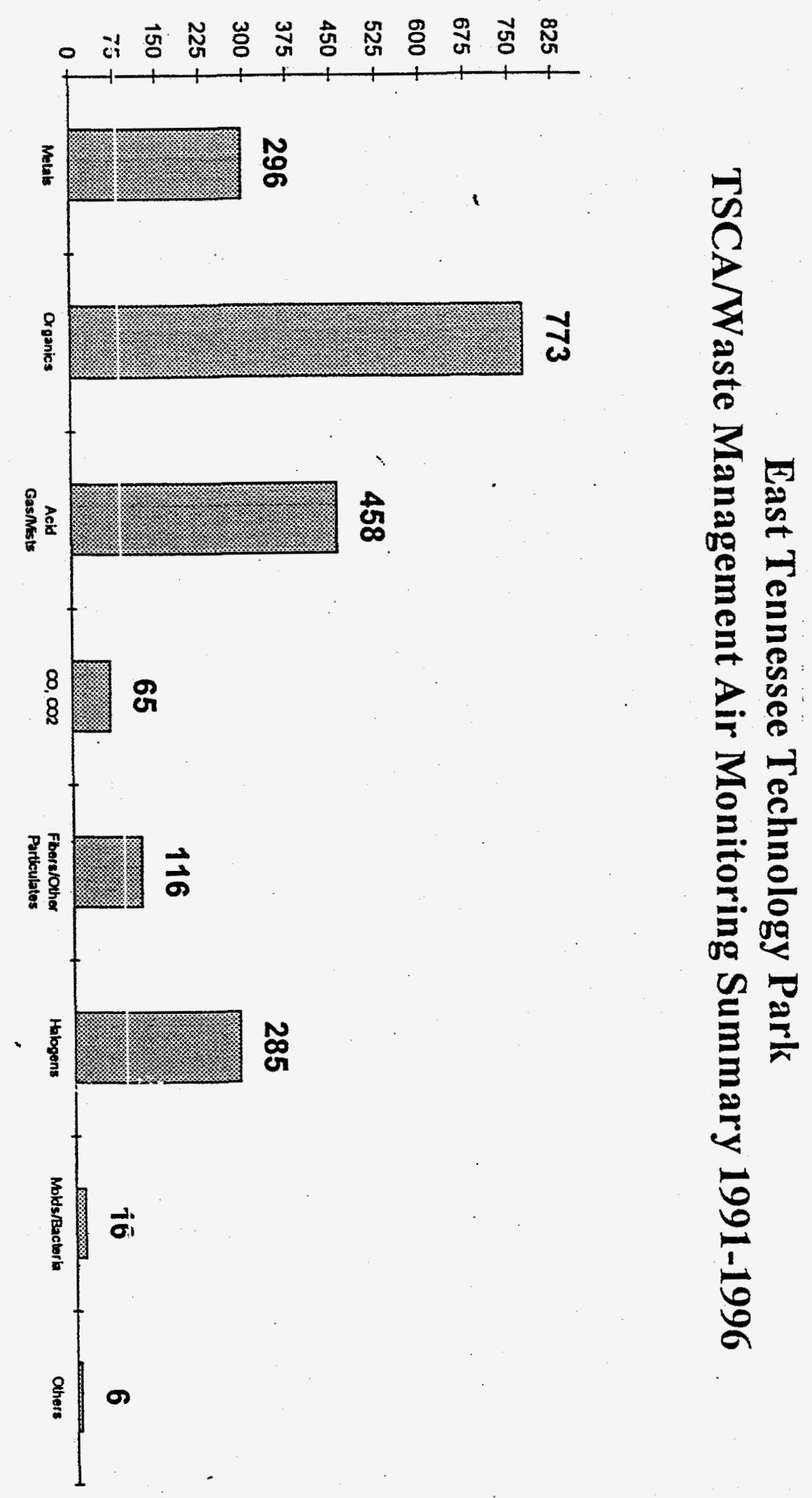




\section{INTENTIONALLY BLANK}




\section{APPENDIX A}

\section{Data Package for Lead}

A-1 
Page 1 af 2

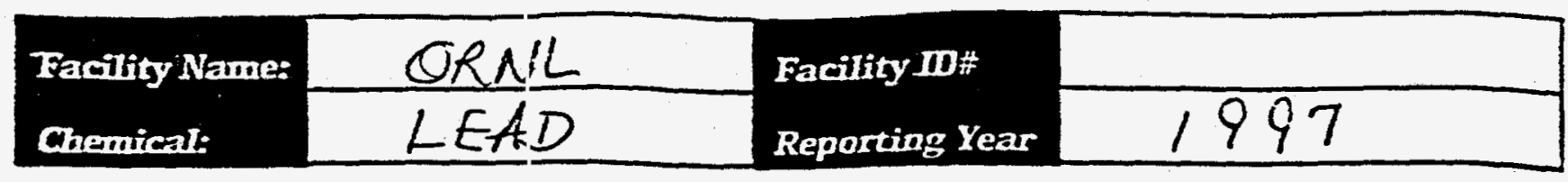

Massacherietss Deparment of Envirommental Protection

TURA REPORT - FORM S

Toxics Use Reduction Act - Chemical Usage Facillty-Wide \& by Production Units

Section 1: Facility-Wide Usage of Lisied Chemical

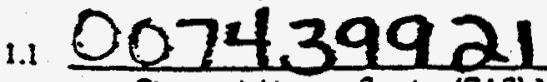

Chernieal Absuract Service (CAS) Number (if applicable)

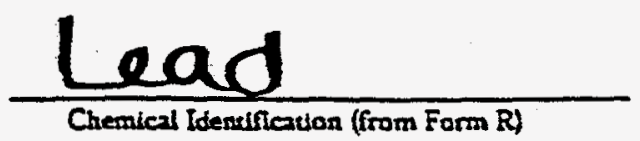

12 Facillty-Wide Usage of Chemical Identified la 1.1 above. Enter wal amount (In POUNDS) for each applicable Category. NOTE: Bypraduce (ltern 1.2d) generallv means all wastes cantaining the listed chemical before the waste is treated or recycled. Read the instructans carel ully, hawever, befare completing this section.

1.2. Manufaciured:

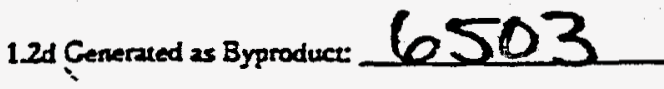

$1.2 \mathrm{~b}$ Processed:

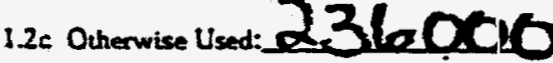

12e Shipped in or as Product:

1.3 OPTIONAL QUESTION. When thit amounts reported in 1.2a, 1.2b, and $1.2 \mathrm{c}$ are added together, the sum will -- in many cases - - equal the sum of $1.2 d$ and 1.2e. In other words. the left and nght columns will often form a "materials balance." the two columns are not in approximate balance, you may use this block to explain why. Mark all the reasons that apply, or indicate the number of pounds in the appropriate block below. (1.e- 4,000 Chemical was held in inventory).

209497 Chemical was recycled on site. Chemical was consumed or transfarmed.

Chemical was held in inventory. Chemial is a compound.

Ouher (expiain):

1.4 OPTIONAL QUESTION: Did anything non-saitine occur at your factlity during the reporting year which affected the data reporied?

YES NOIf YES, you may use this space to comment:

\section{Section 2: Chemicals Used in Waste Treatment Units}

2.1 Is chis chemical used to treat waste or coneral polludion? YES_ No

If YES. enter the quantity of chemical code for the amount used to treat waste or control pollution: $L$

OPTIONAL - You may enter the amoune

Section 3: TURA Report on Production init\#: (Enter from the Form S Cover Sheet.)

3.1 Base Year: 1995

3.2 Quantity or Chemical Code:

3.3 Toxies Use Reduction Techriques Cods:
3.4 Bypradua Reduction Index:

3.5 Emissions Reduction Index

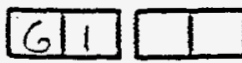

If there has been a change from one separting year to the cucrent year in a (1) base year, and/or (2) estimating meethods (that significantly alier previousiy reponed data) fix this PRODUCTION UNIT REPORT. describe the change: 


7. $\frac{O R N L}{\text { FACILITY NAME }}-\frac{19 \varepsilon 7}{\text { TOWN or TURA IDI }}$ Page $\frac{2}{2}$ of

FORM S COVER SHEET (continued)

Section 4: Facility-Wide Listing of Prodiction Units

A PRODUCTION UNIT is best thought of as the combination of the process (or activitles) used to produce a product or service and the producs or service. In this block, please identify the PRIJDUCTION UNITS at the facllity, then use the production unit number to report on chemical usage in the attached Form S. If there is a substantial change in a PRODUCTION UNIT from one reporting year to the next. the PRODUCTION UNIT must be given a new, unique number.

Prnduction Unit t:

This Production Unit (Process/Pnxduac Combination) is: Describe the Process: The le ad Shop in inelto and pouns Ilead bricrs and other. Btyles. Reuce is tue process Describe the Pratuct lead brizes and Atyces fu vadiological Bherding

Enter the four-digit SIC Code(s) that best describe(s) the product:

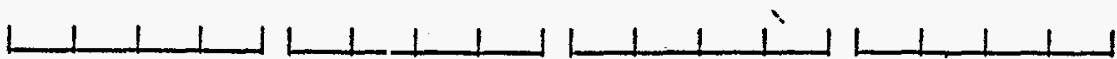

Describe the Unit of Product:

(Please specify if the Unit of Proiluct has been changed since the previous reporting year.)

\section{PRODUCTION PROCESS STEP INFORMATION FOR THIS PRODUCTION UNIT}

Enter the production process code(s) to identify the process step(s) that involves a TUR-reporable chemical(s) as an input, output or throughpul. (See the reporting guidance document for the list of production process codes and instructions on when a given code needs o be listed.)

1. $1+1+1$

2.1

6.

5.

List below, the TURA-reporible chemicals associated with the production unit. If a chemical is associated with ALL the process steps identinted abovi, check the ALL block. If the chemical is associated with some but not all of the process steps. put the relevant code(s) (from above) next to the chemical

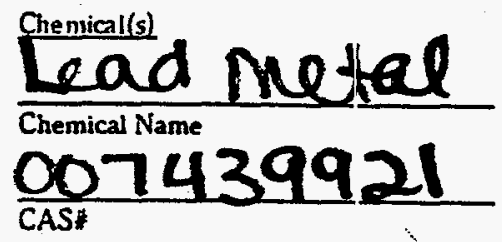

Chemical Name

CAS:

Chemical Name

CAS\#
Production Process

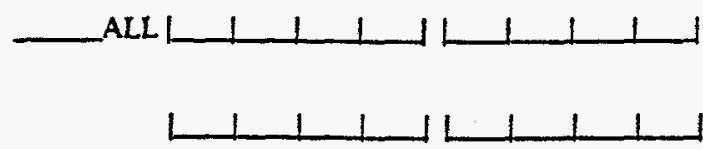

ALL

$111+111$

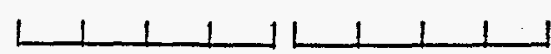

ALL
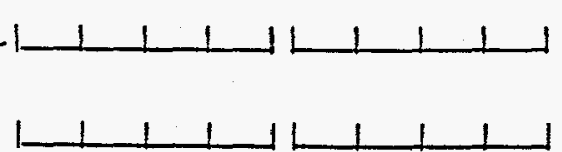
of 


\section{TURA Report - Form S}

\subsection{CAS No.}

007439921

\section{Chemical Identification}

Lead

$1.2 \mathrm{a}$

0

$1.2 \mathrm{~b}$

0

$1.2 \mathrm{c}$

Only looked at the one process at ORNL. The Lead Shop takes lead items on Site to melt and pour lead bricks and other styles. Melting and pouring the lead IS the Process. The newly poured bricks and other styles are used on Site for radiological shielding. The Lead Shop melted $236000 \mathrm{lbs}$ of lead in CY 97.

\section{$1.2 \mathrm{~d}$}

$6500 \mathrm{lbs}$ of slag was generated from melting $236000 \mathrm{lbs}$ of lead at the Lead Shop in CY 97

Lead to air from melting at the Lead Shop

Per Air Pollutant (AP) 42 Emission Factors for Secondary Lead Processing for Refining/Casting indicates that 0.01 pounds/ton +0.00104 pounds/ton (fugitive) $=0.011$ pounds $/$ ton is the factor to be used for lead emissions. The furnace at the Lead Shop vents to one of several stacks.

Air emissions $236000 \mathrm{lb} * 1$ ton/2000 lb * $0.011 \mathrm{lb} /$ ton $=1.3 \mathrm{lb}$ for lead melted in CY 97

The Lead Shop is located inside a building with no patent drains to the Stormwater System. However, a portion of the lead that is slated for melting at the Lead Shop is stored outside. Assumed that $25 \%$ of the lead to White Oak Dam is attributed to runoff from lead that is destined for the Lead Shop. 
Lead in Stormwater

Received WOD information (flow across WOD) from Melinda Salmons. Talked with Wes Goddard on 4-16-97 and he indicated that ORNL used 3-5 MGD supply water which is exempt from reporting.any additional water contribution to WOD would be a result of groundwater and stormwater. Made the following assumptions: Added the twelve sampling events for lead at WOD for CY '96 and averaged (0.1)017 mg/l); Because ORNL uses 3-5 MGD supply water calculations subtracted out 4 MGD from total flow at WOD. Due to issuance of a new NPDES Permit ORNL is no longer required to monitor for lead. Operations have not changed over the last calendar year that should affect lead concentrations in storm water. Used ' 96 lead numbers and the ' 97 measured flow at WOD. Based upon discussions with Melinda Salmons, Charlie Valentine, and Wes Goddard amount of lead in storm water is a function of storm events.

$(4 \mathrm{MGD}) *(3.7854 \mathrm{~V} / \mathrm{gallon}) *(365$ days $/ \mathrm{yr})=5526684000$ liters $/ \mathrm{yr}$

CY 97

$(13957.50 \mathrm{E} 6 \mathrm{l})-(5526684000 \mathrm{l})=8430816000$ liters

$(8430816000 \mathrm{l}) *(0.0017 \mathrm{mg} / \mathrm{l}) *(\mathrm{~g} / 1000 \mathrm{mg})=1.46 \mathrm{E} 4 \mathrm{~g}$

$(1.46 \mathrm{E} 4 \mathrm{~g}) *(2.205 \mathrm{E}-3 \mathrm{lb} / \mathrm{g})=30.8 \% \mathrm{lbs}$

Assumed that only $25 \%$ is attributable to the Lead Shop operations

$(30.87 \mathrm{lbs})(0.25)=8 \mathrm{lbs}$

Assumed that $\sim 25 \%$ of the $8 \mathrm{lbs}$ is due to lead melted in CY 97 or $2 \mathrm{lbs}$

$6500 \mathrm{lbs}+1 \mathrm{lb}+2 \mathrm{lbs}=6503 \mathrm{lbs}$

\subsection{Optional Question}

$229497 \mathrm{lbs}$ of lead was recycled on site. Our process IS recycling or reusing lead by melting into needed configurations for radiological shielding on site.

\subsection{Did anything non-routine occur...}

No

2.1 Is the chemical used to treat waste or control pollution

No

Section 3 Production Unit \#01 


\subsection{Base Year}

Exceeded a reporting threshold for lead in CY 95 due to resumed Lead Shop operations. Lead had been reported previously. The Lead Shop only resumed operations on 10-24-95. The lead melted, byproducts, and emissions are very low due to the limited operations in CY 95.

\subsection{Quantity of Chemical Code}

C ( $>10000 \mathrm{lbs})$ Melted and poured $236000 \mathrm{lbs}$ of lead at the Lead Shop.

\subsection{Byproduct Reduction Index}

$\mathrm{BRI}=100 * \mathrm{~A}-\mathrm{B} / \mathrm{A}$

$A=$ Byproduct quantity in the base year/\# of units of product produced in the base year

$\mathrm{B}=$ Byproduct quantity in the reporting year/\# of units of product produced in the reporting year

$\mathrm{BRI}=$

(100)( $5680 \mathrm{lbs}$ of slag/44150 lbs of lead melted $-6500 \mathrm{lbs}$ of slag/236000 lbs melted)/ 5680 $\mathrm{BRI}=1.8 \mathrm{E}-3$

Melted 44150 lbs of lead at the Lead Shop in CY 95 (see 3.1)

Did not really reduce slag generated between CY 95 and CY 97 because melted more lead. Our reduction was melting and pouring the lead into usable styles for shielding rather than disposing of the lead as a hazardous or mixed waste. Could consider that our reduction was the $236000 \mathrm{lbs}$ melted $-6500 \mathrm{lbs}$ siag $-1 \mathrm{lb}$ to air $=229499 \mathrm{lbs}$ of lead reused. Avoided disposal or the cost associated with finding a user for the lead and shipping costs. Do not believe that this fits well with the question or intention of this section on the form.

\subsection{Emission Reduction Index}

$\mathrm{ERI}=100 * \mathrm{~A}-\mathrm{B} / \mathrm{A}$

$A=$ Emission quantity in the base year/\# of units of product produced in the base year

$\mathrm{B}=$ Emission quantity in the reporting year/\# of units of product produced in the reporting year

The limit of detection for analytical cata for $C Y 95$ versus $C Y 97$ would account for reductions in emissions. Did not really reduce emissions between CY 95 and CY 97 because melted more lead. Our reduction was melting and pouring the lead into usable styles for shielding rather than disposing of the lead as a hazardous or mixed waste. Could consider that our reduction was the $236000 \mathrm{lbs}$ melted $-6500 \mathrm{lbs}$ slag $-1 \mathrm{lb}$ to air $=229499 \mathrm{lbs}$ of lead reused. Avoided disposal or the cost associated with finding a user for the lead and shipping costs. Do not believe that this fits well with the question or intention of this section on the form. 


\section{TURA Report Cover Sheet}

\section{Section 4}

\section{Production Unit}

\#01

\section{Process Description:}

Only looked at the one process at ORNL. The Lead Shop takes lead items on Site to melt and pour lead bricks and other styles. Melting and pouring the lead IS the Process. The newly poured bricks and other styles are used on Site for radiological shielding. The Lead Shop melted 236000 lbs of lead in CY 97.

\section{Product Description:}

The Lead Shop takes lead items on isite to melt and pour lead bricks and other styles. Melting and pouring the lead IS the Process. The newly poured bricks and other styles are used on Site for radiological shielding.

\section{Unit of Product:}

Pounds of lead melted in a calender year

\section{Production Process Step Information:}

None identified. Appendix $\mathrm{H}$ did not have codes that accurately described our process. The lead at the Lead Shop is melted NOT smelted. The lead is poured to form bricks or other styles. The configuration of the lead is changed ror radiological shielding purposes.

\section{Chemical:}

Lead Metal

CAS No. 007439921 
SEGTON B. FACLTY.LEYEI SUESTANCE.SPECAFIC INFORUATOA

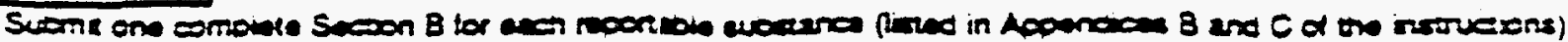

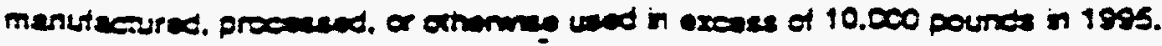

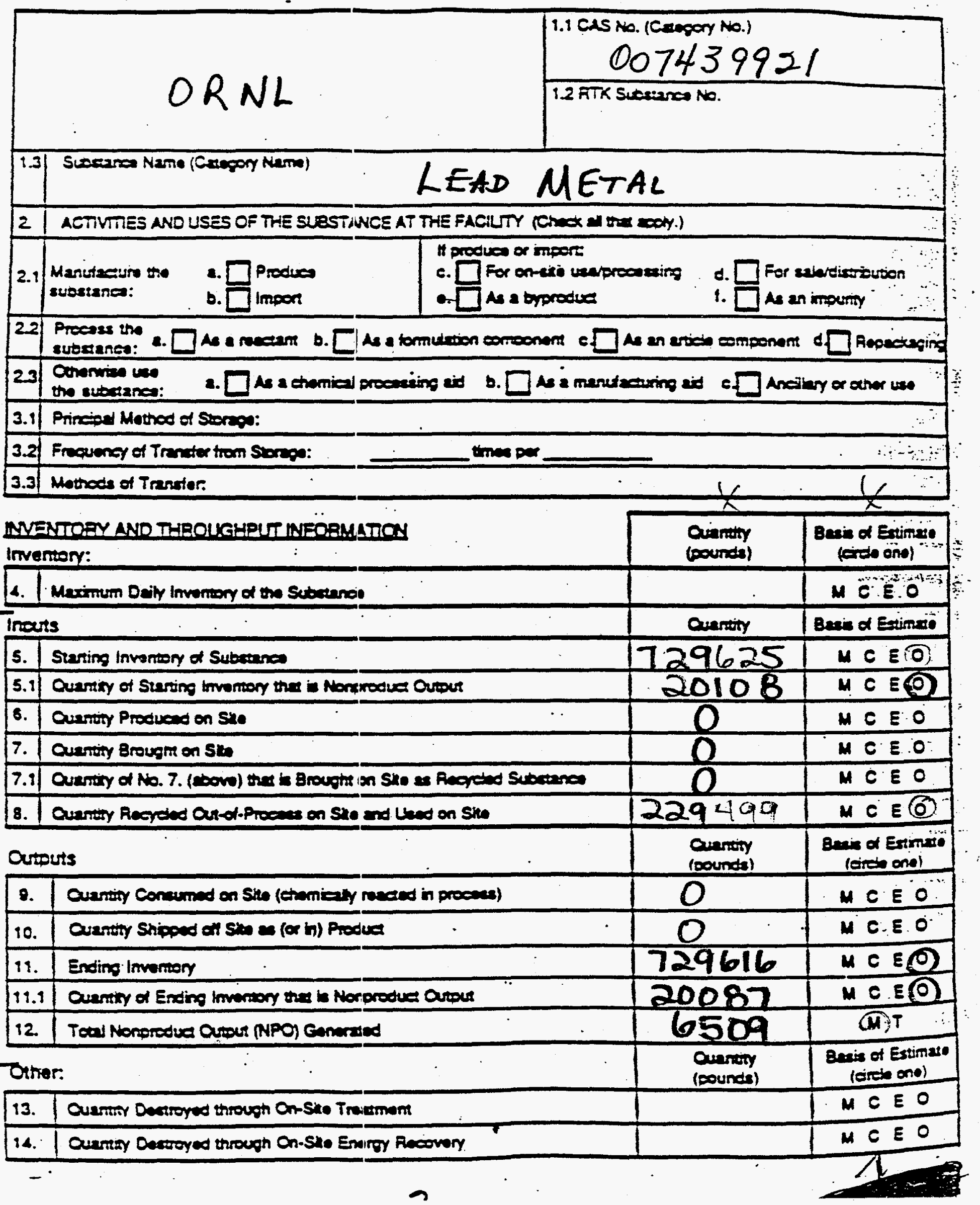




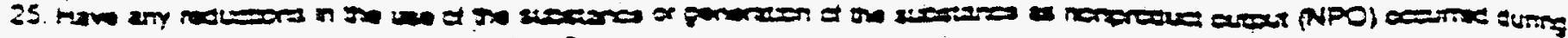
1995 sus is secorrenunes of couramora?

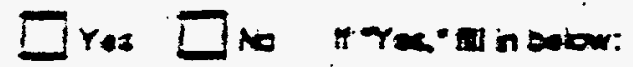

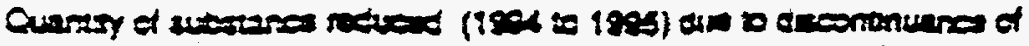

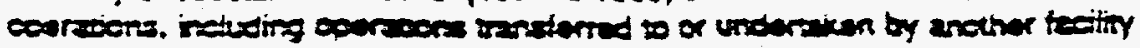

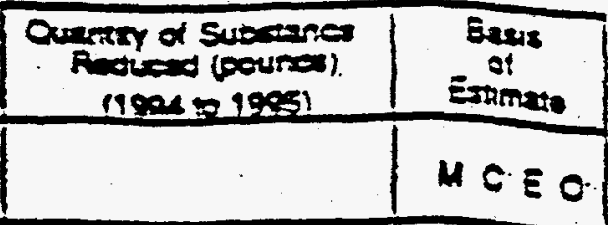

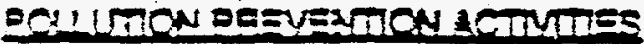

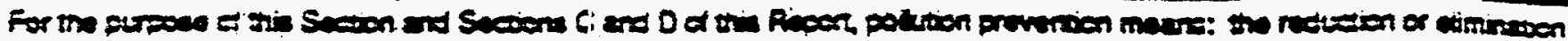

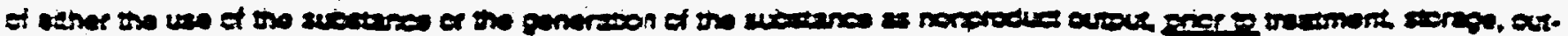

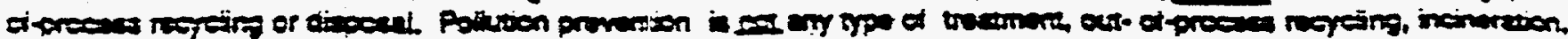

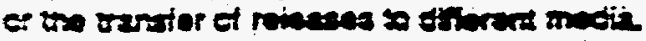

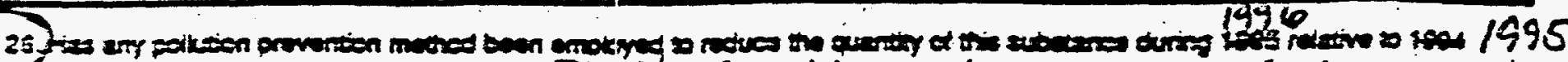

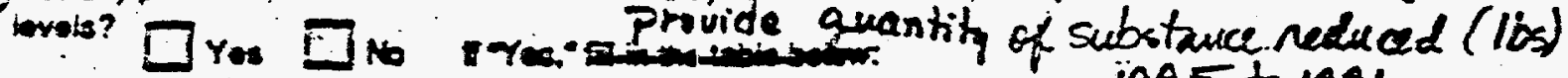
1995 to 1996

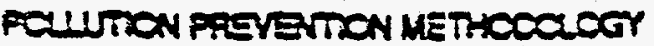

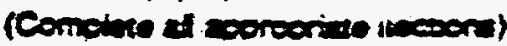

\section{Cromity at Subaren \\ Enis}

Budiod (oordet)

nems o 1900$)$

of

Eming

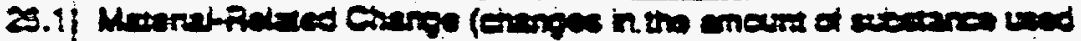

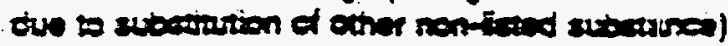

I. $\quad$ M E E o

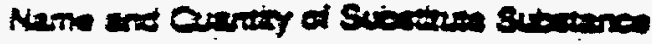

cestrases

STasting

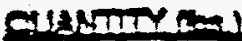

a)

b)

c)

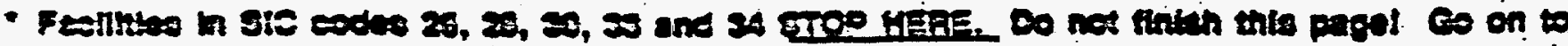

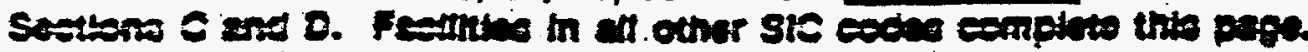

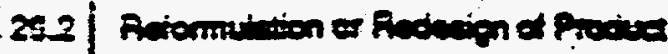

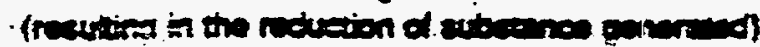

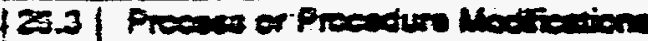

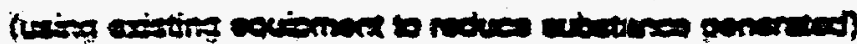

\begin{tabular}{|c|c|}
\hline 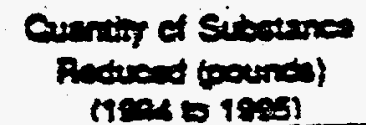 & $\begin{array}{l}\text { Banis: } \\
\text { Ex }\end{array}$ \\
\hline
\end{tabular}

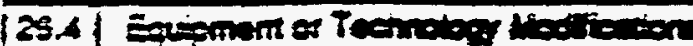

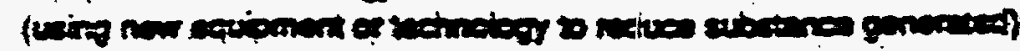

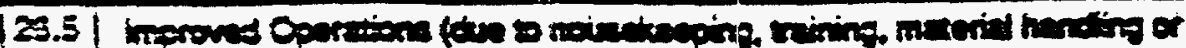

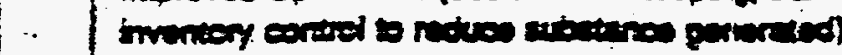

1:

$4<50$

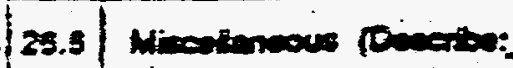

נ)

u $\div \cdot \mathbf{E}:$

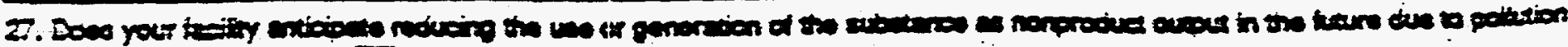

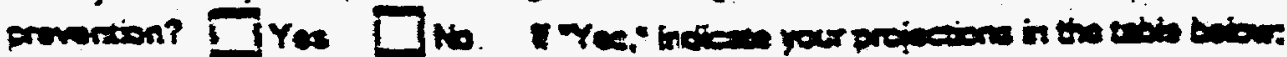

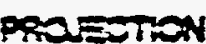

\begin{tabular}{|c|c|}
\hline \multicolumn{2}{|c|}{ reth } \\
\hline 1807 & 200 \\
\hline - & \\
\hline
\end{tabular}

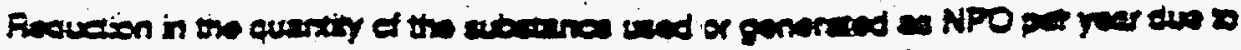

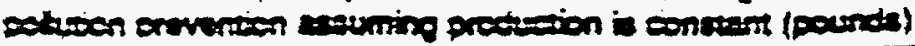




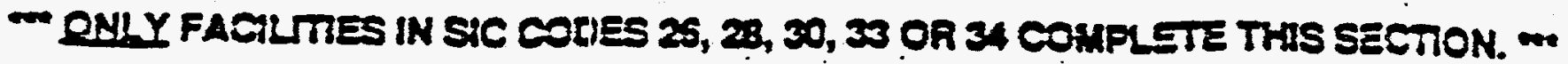

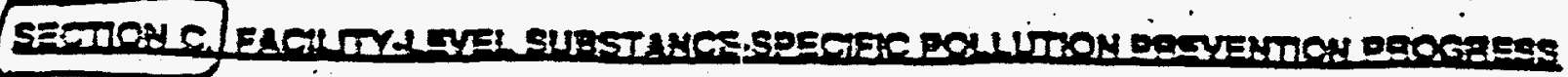

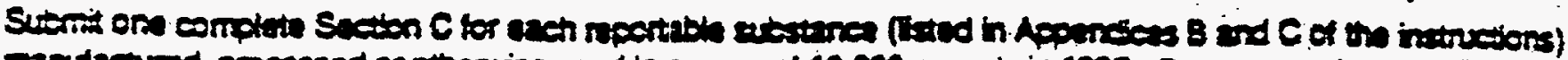

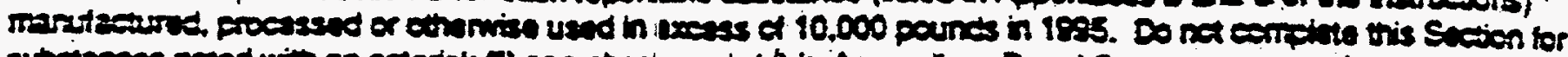

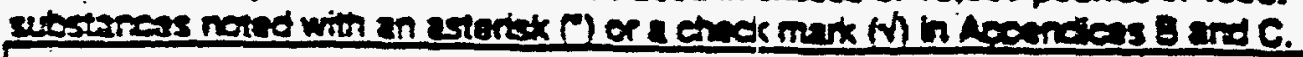

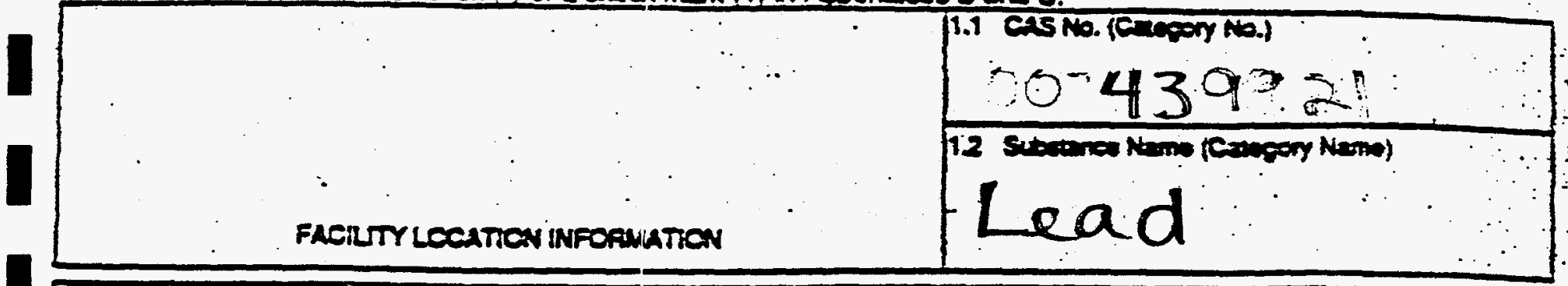

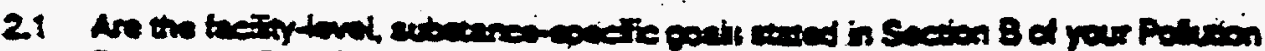

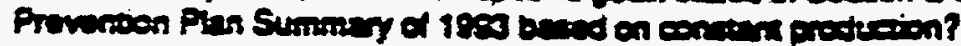

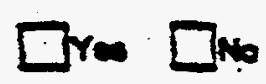

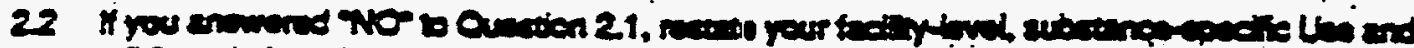

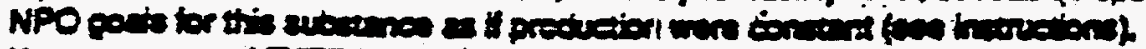

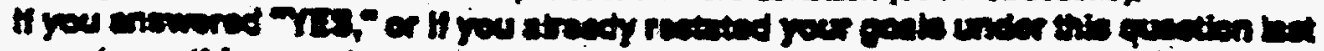

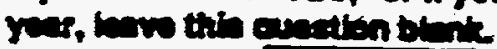

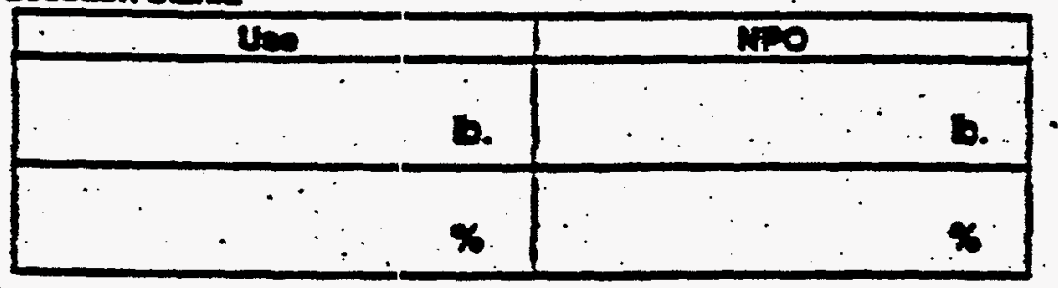

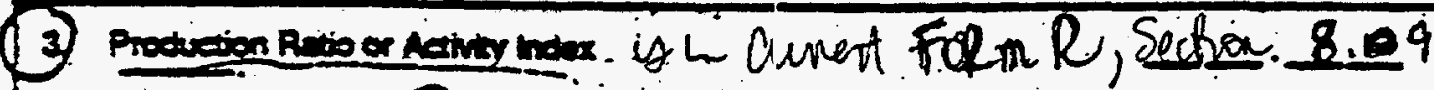
(4.) Porow Actuain $2.33 \ldots$

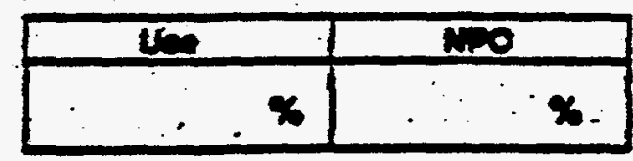

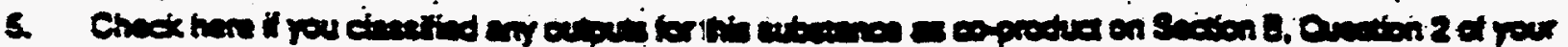

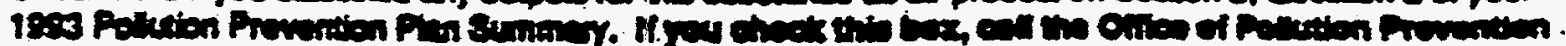

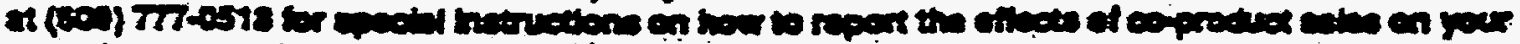

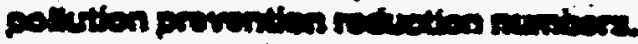

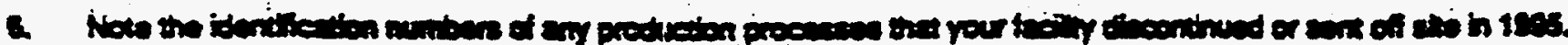

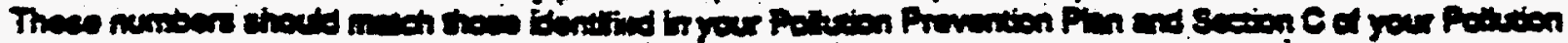

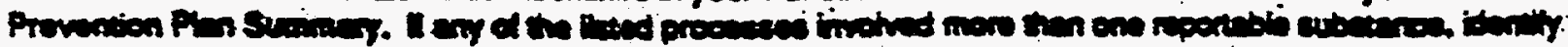

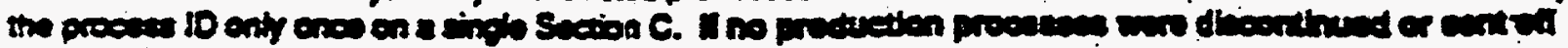

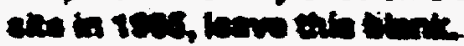

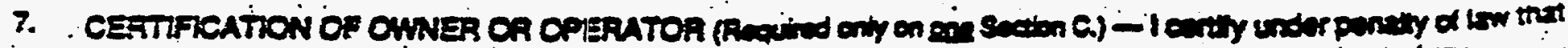

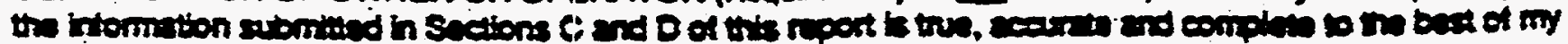
crovindos.

Simero - Dene Finento. 


\section{New Jersey Form S}

\subsection{Starting Inventory of Substance on Site:}

Only looked at the one process at OFNL. The Lead Shop takes lead items on Site to melt and pour lead bricks and other styles. Melting and pouring the lead IS the Process. The newly poured bricks and other styles are used on Site. The Lead Shop melted and poured $236000 \mathrm{lbs}$ of lead for radiological shielding needs on Site. For purposes of this report only accounted for lead that is slated to go to the Lead Shop and the lead melted in CY 97 at the Lead Shop. Did not inventory the lead that is part of a facility that is (or was) used for shielding. Did not consider the lead that was brought on Site as an article for shielding and was used for shielding. The lead that is designated to go to the Lead Shop consists of nonradiolocial lead items and surface radiologically contaminated lead itenis. To melt radiologically contaminated lead at the Lead Shop will require a modification to the existing air permit. Until the permit is modified no radiologically contaminated lead will be melted at the Lead Shop. Starting inventory consists of $267575 \mathrm{lbs}$ nonradiologically contaminated lead (per Dale Knight) $+215000 \mathrm{lbs}$ of radiologically contaminated lead (per Russ Carvin) +11050 lbs of radiologically contaminated lead (per Dale Knight $)+236000 \mathrm{lbs}$ of lead melted in Calendar Year $1997=729625 \mathrm{lbs}$ 


\subsection{Starting Inventory that is NPO}

The only amount of starting inventory' that is Nonproduct Output is the slag generated from lead melting at the Lead Shop. In CY 97 he Lead Shop melted $236000 \mathrm{lbs}$ of lead and generated $6500 \mathrm{lbs}$ of slag. Assumed that a proportional amount of slag will be generated from the lead slated for melting.

$236000 \mathrm{lbs} \mathrm{Pb} / 1 \mathrm{lb} \mathrm{Pb}=6500 \mathrm{lbs}$ slag $/ \mathrm{X}$ lbs slag

$1 \mathrm{lb} \mathrm{Pb}=2.75424 \mathrm{E}-2 \mathrm{lbs}$ slag

Total amount of lead in inventory (see 5.0) is $729625 \mathrm{lbs}$

$(729625 \mathrm{lbs} \mathrm{Pb})(2.75424 \mathrm{E}-2 \mathrm{lbs}$ slag/lb Pb) $=20096$ (this number includes the $6500 \mathrm{lbs}$ of slag generated at the Lead Shop in CY $9^{\circ}$ )

Lead to air from melting at the Lead Shop

Per Air Pollutant (AP) 42 Emission Factors for Secondary Lead Processing for Refining/Casting indicates that 0.01 pounds $/$ ton +0.0004 pounds/ton (fugitive) $=0.011$ pounds $/$ ton is the factor to be used for lead emissions. The furrace at the Lead Shop vents to one of several stacks.

Air emissions $236000 \mathrm{lb} * 1$ ton $/ 20 \mathrm{Co} \mathrm{lb} * 0.011 \mathrm{lb} /$ ton $=1.3 \mathrm{lb}$ for lead melted in CY 97

Air emissions $(729625 \mathrm{lbs})(1 \mathrm{ton} / 2000 \mathrm{lb})(0.011 \mathrm{lb} / \mathrm{ton})=4 \mathrm{lbs}$ if all lead was melted on Site in a CY

The Lead Shop is located inside a building with no patent drains to the Stormwater System. However, a portion of the lead that is slated for melting at the Lead Shop is stored outside. Assumed that $25 \%$ of the lead to White Oak Dam is attributed to runoff from lead that is destined for the Lead Shop.

Lead to Stormwater

Received WOD information (flow across WOD) from Melinda Salmons. Talked with Wes Goddard on 4-16-97 and he indicated that ORNL used 3-5 MGD supply water which is exempt from reporting any additional water: contribution to WOD would be a result of groundwater and stormwater. Made the following assumptions: Added the twelve sampling events for lead at WOD for CY ' 96 and averaged (0.0017 mg/); Because ORNL uses 3-5 MGD supply water 
calculations subtracted out 4 MGD from total flow at WOD. Due to issuance of a new NPDES Permit ORNL is no longer required $t$ is monitor for lead. Operations have not changed over the last calandar year that should affect lead concentrations in storm water. Used ' 96 lead numbers and the ' 97 measured flow at WOD. Based upon discussions with Melinda Salmons, Charlie Valentine, and Wes Goddard amount of lead in storm water is a function of storm events.

$(4 \mathrm{MGD}) *(3.7854 \mathrm{l} / \mathrm{gallon}) *(365$ days/yr $)=5526684000$ liters/yr

CY 97

$(13957.50 \mathrm{E} 61)-(55266840001)=\$ ; 430816000$ liters

$(8430816000 \mathrm{l}) *(0.0017 \mathrm{mg} / \mathrm{l}) *(1 \mathrm{~g} / 1000 \mathrm{mg})=1.46 \mathrm{E} 4 \mathrm{~g}$

$(1.46 \mathrm{E} 4 \mathrm{~g}) *(2.205 \mathrm{E}-3 \mathrm{lb} / \mathrm{g})=30.8 \% \mathrm{lbs}$

Assumed that only $25 \%$ is attributable to the Lead Shop operations

$(30.87 \mathrm{lbs})(0.25)=8 \mathrm{lbs}$

$-25 \%$ of the $8 \mathrm{lbs}$ is due to lead melted in CY 97 or $2 \mathrm{lbs}$

Total Starting Inventory that is NP()

$20096 \mathrm{lbs}+4 \mathrm{lbs}+8 \mathrm{lbs}=\mathbf{2 0 1 0 8 \mathrm { lhs }}$

\subsection{Quantity Produced on Site}

No lead was produced on Site

\subsection{Quantity brought on Site}

No lead was brought on Site for melting at the Lead Shop. Only considered the lead that is meited at the Lead Shop. Lead was brought on Site (article) and used as shielding (article) on Site.

\subsection{Quantity of No. 7 that was hrought on Site as Recycled Substance}

No lead was brought on Site for melting at the Lead Shop. 


\subsection{Quantity recycled Out-of-Process on Site and used on Site}

Our Process IS recycling or reusing lead by melting into needed configurations for radiological shielding on Site. Although our recycling is the Process, tried to fit our activities into the form provided. The amount of melted lead in CY 97 that was used on Site was:

$236000 \mathrm{lbs}$ melted $\mathrm{pb}-6500 \mathrm{lbs}$ slayg $-1 \mathrm{lb}$ to air $=229499 \mathrm{lbs}$ of $\mathbf{P b}$

\subsection{Quantity Consumed on Site}

No lead was consumed on Site

\subsection{Quantity Shipped off Site as Product}

No lead melted on Site was shipperl off Site

\subsection{Ending Inventory}

Because the $6500 \mathrm{lbs}$ of slag generated in CY 97 remains on Site the ending inventory $729625 \mathrm{lbs}$ of lead on Site (see 5.0) - I lb to air (see 5.1) - $8 \mathrm{lbs}$ to stormwater runoff (see 5.1) = $729616 \mathrm{lbs}$

\subsection{Quantity of Ending Inveniory that is NPO}

Because the $6500 \mathrm{lbs}$ of slag generated in CY 97 remains on Site the ending inventory of NPO is $20096 \mathrm{lbs}$ (see 5.1) $-1 \mathrm{lb}$ to air (sie 5.1) $-8 \mathrm{lbs}$ to stormwater runoff (see 5.1) $=\mathbf{2 0 0 8 7} \mathrm{lbs}$ 


\subsection{Total NPO Generated}

$6500 \mathrm{lbs}$ of slag was generated from melting at the Lead Shop in CY 97

$6500 \mathrm{lbs}+1 \mathrm{lb}$ to air (see 5.1$)+8 \mathrm{lbs}$ to stormwater runoff (see 5.1) $=6509 \mathrm{lbs}$

\subsection{Has any Pollution Prevention method been employed ...}

Our recycling of lead IS the Process (see 5.0). This section could not be completed because it does not consider processes that are recycling.

\subsection{Does your facility anticipate reducing NPO}

No. Melting of lead produces slag as a waste product.

\section{Section C}

\subsection{CAS No.}

007439921

\subsection{Substance Name}

Lead

\section{Production Ratio}

Based upon conversations with Dale Knight Production Ratio should be based on lead bricks and other styles produced. This is calculated in pounds by subtracting the slag generated from lead melted. ' 96101700 pounds -3321 ) pounds $=98380$ pounds and ' 97236000 pounds -6500 pounds $=229500$ pounds. Production Ratio $229500 / 98380=2.33$ 


\section{Percent Reduction}

Did not reduce slag generated between CY 96 and CY 97 because melted more lead. Our reduction was melting and pouring the lead into usable styles for shielding rather than disposing of the lead as a hazardous or mixed waste. Could consider that our percent reduction was the $236000 \mathrm{lbs}$ melted $-6500 \mathrm{lbs}$ slag $-\mathrm{llb}$ to air $=229499 \mathrm{lbs}$ of lead reused. Avoided disposal or the cost associated with finding a user for the lead and shipping costs. Do not believe that this fits well with the question or intention of this section on the form.

NOTE: ORNL's functional titles for the above mentioned individuals are as follows:

Russ Carvin - Supervisor, Solid Waste Management Operations Group

Wes Goddard - Engineer, Clean Water Act Group

Dale Knight - Supervisor of Fabrication, Plant and Equipment Group

Melinda Salmons - Data Analyist, Environmental Compliance and Documentation Group

Joe Wolfe - Group Leader, Clean Air Act Group 


\section{TRI - Phase III \\ DOE Cinemical Use Reporting Pilot and \\ Burden \& Benefit Evaluation}

Instructions: For each chemical you prepare a 1997 Form $\mathrm{R}$ for:

1) Please complete the attached N.J. form for just the Inputs, Outputs and Pollution Prevention Activities and Progress sections identified below.

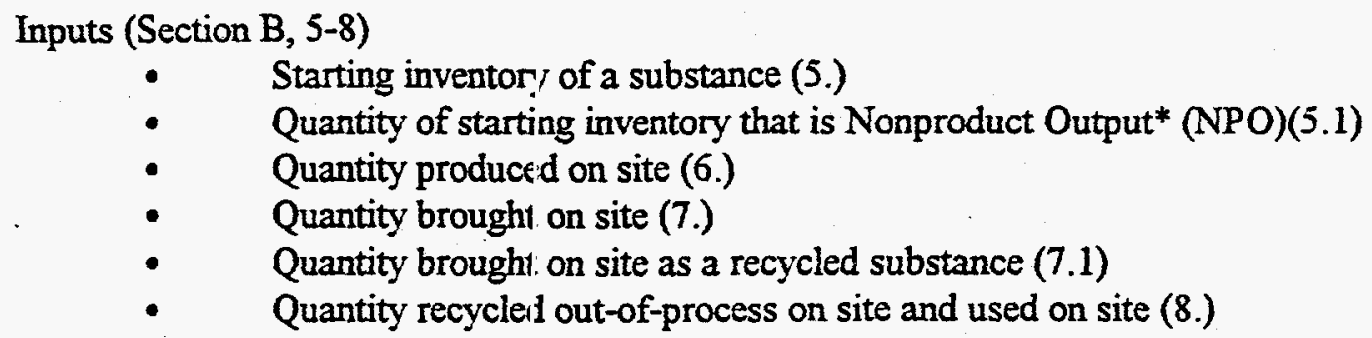

Pollution Prevention Activities (Gection B, 26.-26.6)

- Has any pollution prevention method been employed to reduce the quantity of this substance during this reporting year relative to last year's levels? If yes complete items 26.1-26.6 for years 1995 to 1996 (26.)

- Material-Related change and substitute substance (complete all appropriate sections) (26.1)

- $\quad$ Reformulation or redesign of product (26.2)

- $\quad$ Process or procedure modifications (26.3)

- Equipment or technology modifications (26.4)

- Improved operations (26.5)

- $\quad$ Miscellaneous (26.6)

Facility-Level Substance-Specilic Pollution Prevention Progress (Section C, 4.)

- $\quad$ Percent reduction (4.)

2) While completing the form, please cimmplete the burden evaluation form to indicate the number of increased labor hours for each reporting element with regard to managerial, technical and clerical aspects of TRI reporting for the first and subsequent ytars.

3) Please complete the survey on the binefits evaluation form for evaluating the usefulness of toxic chemical use reporting.

All quantities are reported in pounds.

* Nonproduct Output (NPO) is the quantity of the reported substance that was generated prior to storage, out-of-process recycling, treatment, control or disposal, and that was not intended for use as a product. This includes environmental releases and off-site transfers for energy recovery or recycling, and as (or in) waste for treatment and/or disposal.) 
Burden Evaluation Form

5.0

Requsted additional information from the Lead Shop (Dale Knight) regarding amount of lead in inventory. Inventory was conducted and information was provided - 1 hour Technical.

Requested information from Waste Managment (Russ Carvin) regarding amount of contaminated lead in inventory slated for recycle. Inventory was conducted and information was provided - 2 hours Techincal. Joe Wolfe provided information regarding the status of the existing air permit at the Lead Shop - 1 hour Technical. Ny time requesting and compiling information, completing forms, and gathering backup information for audit purposes - 2 hours Technical. Typing forms and backup documentation - 0.5 hours Clerical. Management review and committee meetings 0.5 hours Managerial.

Note

Only looked at the Lead Shop operations. Lead is used as shielding in many buildings thoughout the Laboratory. The shielding was not included in the inventory. The instructions need to be clearer. Do the 313 exemptions apply?

\section{1}

The information from Question 5.0 was used along with calculations from the 313 Report. Calculated the starting inventory that is NPO. My time compiling information, completing forms, and gathering backup information for audit purposes -0.5 hours Technical. Typing forms and backup documentation - 0.5 hours Clerical. Management review and committee meetings - 0.5 hours Managerial.

6.0

Process knowledge aquired while cornleting the 313 Report. No lead produced on site. My time compiling information, completing forms, and gathering backup information for audit purposes 0.5 hours Technical. Typing forms and backup documentation - 0.5 hours Clerical. Management review and committee meetings - 0.5 hours Managerial.

7.0

No lead was brought on site for melting at the Lead Shop. Lead brought on site was used for shielding (article). Do the 313 exempitions apply? Looked at the information gathered for 313 purposes. My time compiling information, completing forms, and gathering backup information for audit purposes -0.5 hours Technical. Typing forms and backup documentation - 0.5 hours Clerical. Management review and committee meetings - 0.5 hours Managerial. 


\section{1}

No lead was brought on site for melting; at the Lead Shop. Looked at the information gathered for 313 purposes. My time compiling irformation, completing forms, and gathering backup information for audit purposes -0.5 hours Technical. Typing forms and backup documentation 0.5 hours Clerical. Management review and committee meetings - 0.5 hours Managerial.

\section{0}

Our process is recycling or reuse. Tried to fit our operations with the questions on the forms. My time compiling information, completing forms, and gathering backup information for audit purposes -0.5 hours Technical. Typing forms and backup documentation -0.25 hours Clerical. Management review and committee meetings -0.25 hours Managerial.

\section{0}

No lead was consumed on site. My time compiling information, completing forms, and gathering backup information for audit purposes -0.25 hours Technical. Typing forms and backup documentation -0.25 hours Clerical. Management review and committee meetings - 0.25 hours Managerial.

10.0

No lead melted was shipped off site. My time compiling information, completing forms, and gathering backup information for audit purposes -0.25 hours Technical. Typing forms and backup documentation -0.25 hours Clerical. Management review and committee meetings -0.25 hours Managerial.

11.0

Calculated ending inventory from 313 information. My time compiling information, completing forms, and gathering backup information for audit purposes -0.5 hours Technical. Typing forms and backup documentation - 0.5 hours Clerical. Management review and committee meetings 0.5 hours Managerial.

\section{1}

Calculated using information from Question 5.0 and 313 information. My time compiling information, completing forms, and gathering backup information for audit purposes -0.5 hours Technical. Typing forms and backup documentation -0.5 hours Clerical. Management review and committee meetings -0.5 hours Mianagerial. 
Calculated using information from the 313 report. My time compiling information, completing forms, and gathering backup information for audit purposes -0.25 hours Technical. Typing forms and backup documentation - 0.25 hours Clerical. Management review and committee meetings 0.25 hours Managerial.

26.0

Recycling (pollution prevention) is the process. Could not answer this question because no consideration given to operations outside of manufactoring. My time compiling information, completing forms, and gathering backup information for audit purposes -0.25 hours Technical. Typing forms and backup documentation -0.25 hours Clerical. Management review and committee meetings -0.25 hours Masagerial. 


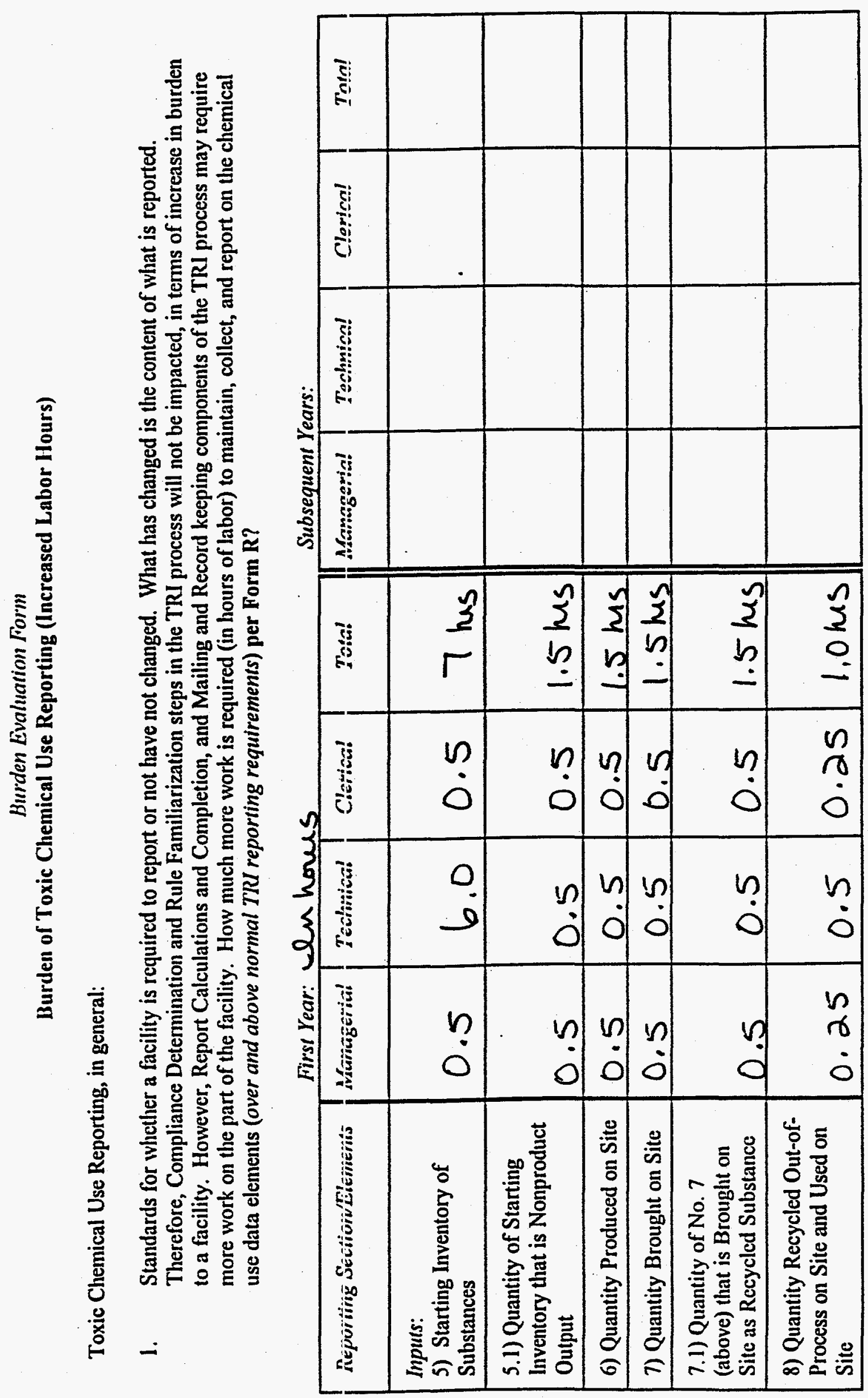


1
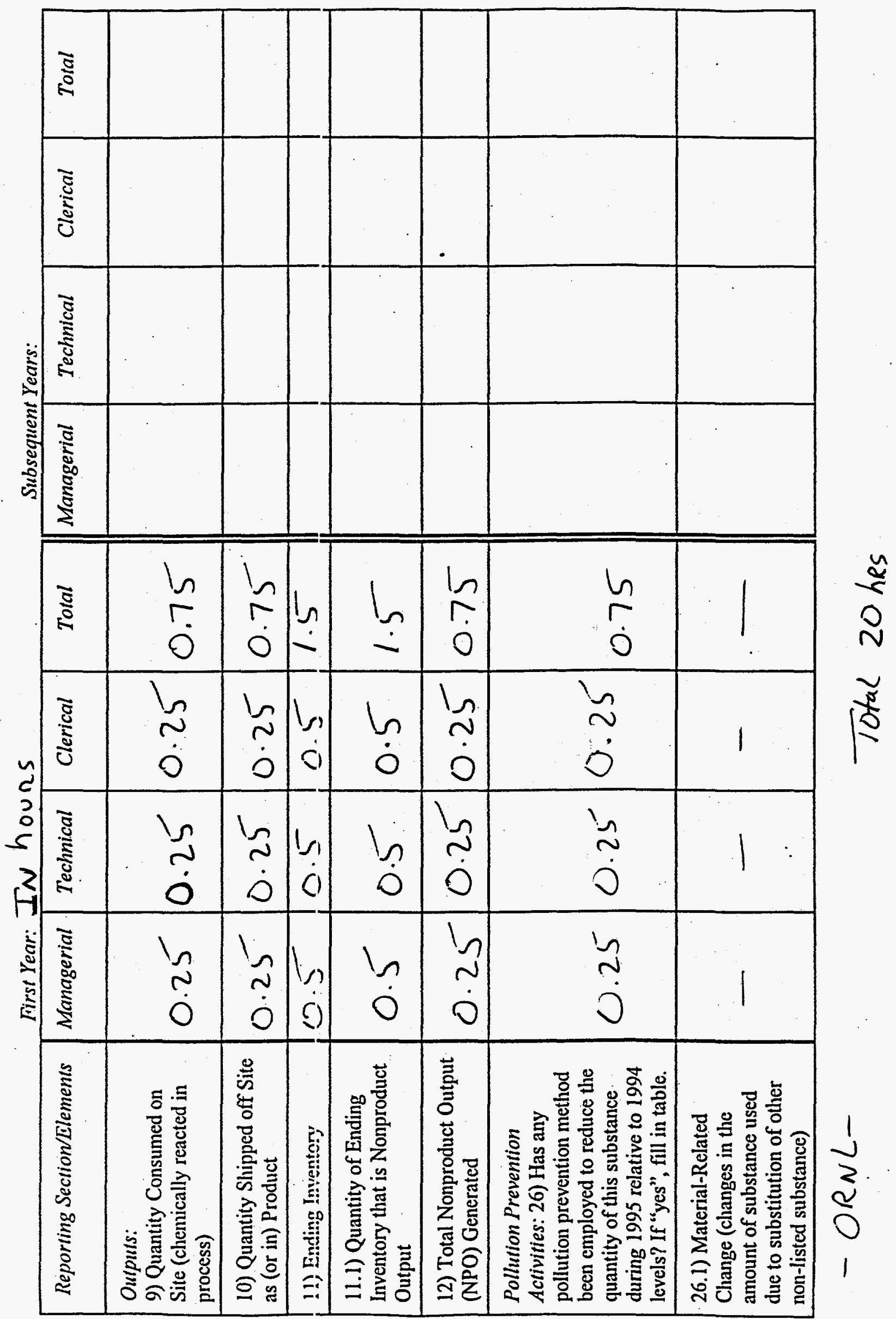
茟

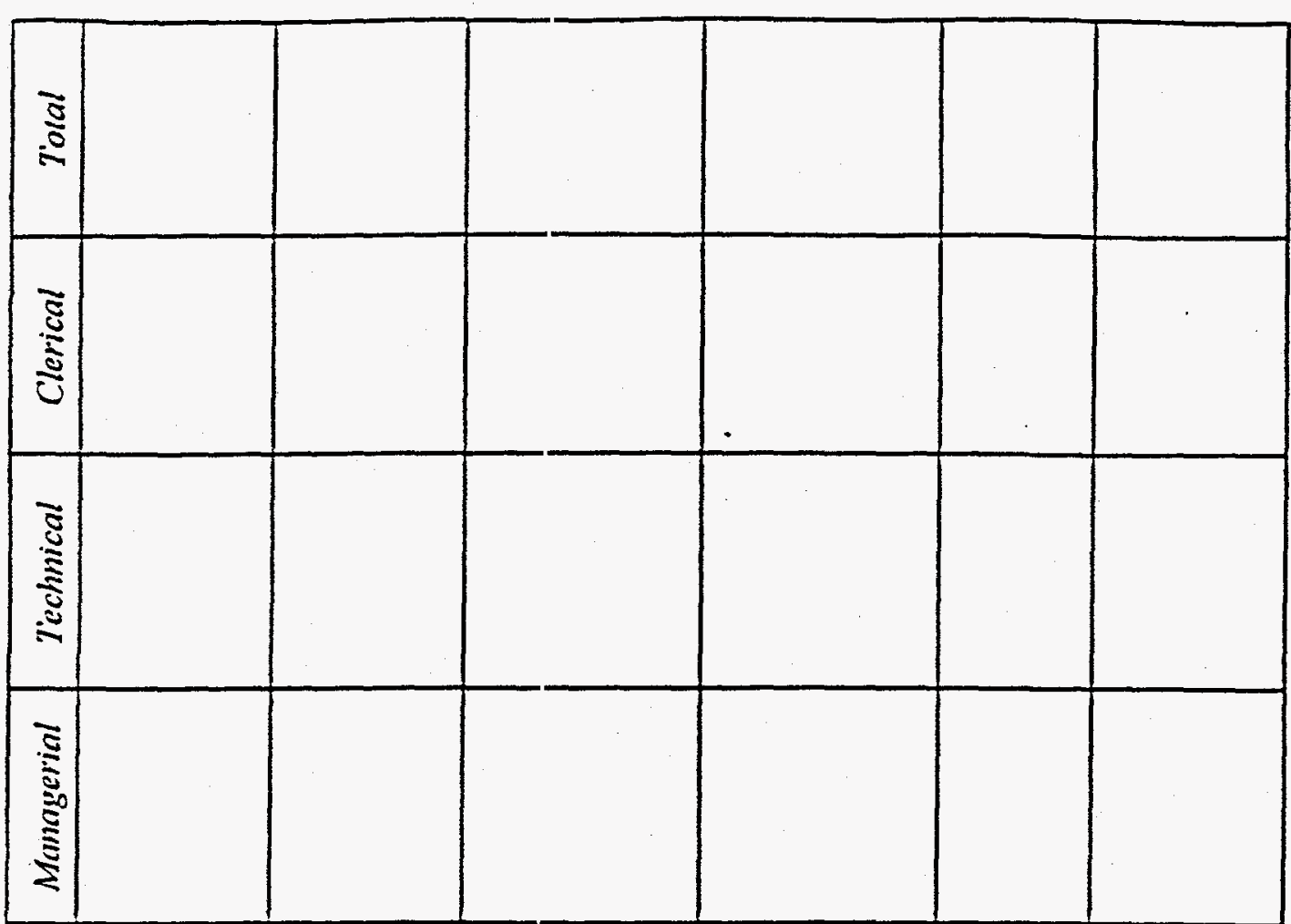

\begin{tabular}{|c|c|c|c|c|c|c|}
\hline$\stackrel{\Xi}{0}$ & & 1 & & & 1 & \\
\hline 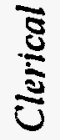 & & & 1 & 1 & & \\
\hline 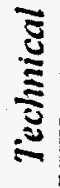 & & & & 1 & 1 & 1 \\
\hline 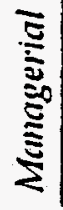 & 1 & & & & & \\
\hline 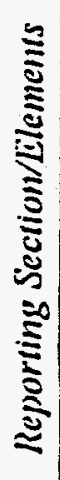 & 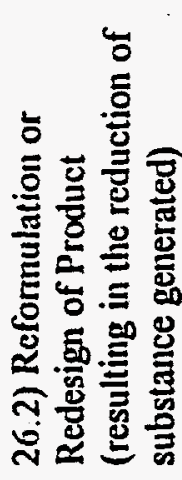 & 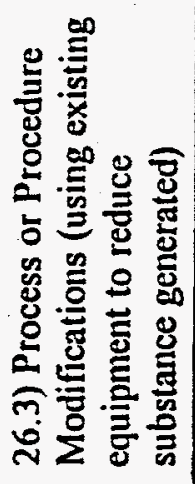 & 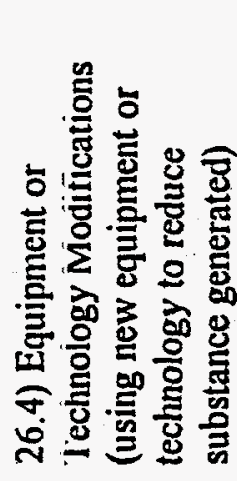 & 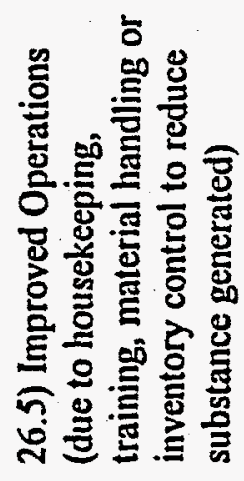 & 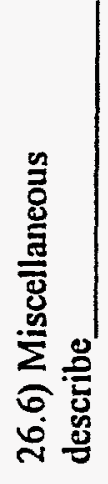 & 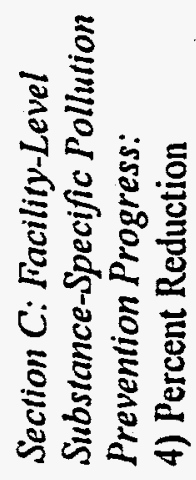 \\
\hline
\end{tabular}


DOE Chemical Use Pilot - 2-24-98

Pages

Benefits Evaluation Form

Benefits/Usefulnesis of Toxic Chemical Use Reporting

Toxic Chemical Use Reporting, in general:

1. How effective is chemical use reporting to facilities and the general public in improving their understanding of the volumes and patters of chemical use (rate on a 1-5 scale; (1) hot effective, 2-slightly effective, 3-somewhat effective, 4-moderately effective, 5- highly effective)?

Why? The firms do not provide enough infumation

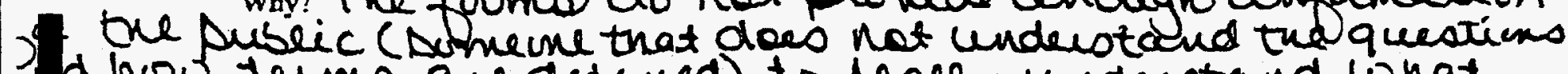
Id how terms are defined) to really understand what i the regulations versus the pus hew a Release is defined

2. How useful is chemical use reporting to state agencies for the purposes of targeting state resources (rate on a 1-5 scale; 1-nct useful, 2-slightly useful, 3-somewhat useful, 4-moderately useful, 5-highly useful)?

? From my Respective depends on the agencies Why dew tandirs of the infermatimperuded on the fums

3. Does chemical use reporting offer an improved basis for measuring progress in pollution prevention over current reporting information (rate on a 1-5 scale; 1-no, it offers no improvement, 2-yes, slightly improved, 3-yes, somewhat improved, 4-yes, moderately improved, 5-yes, highly improved)?

Do not kurus - have tried to call Why? Donecre in P2. Sur y

4. Does chemical use reporting lead to improved toxic chemical management in facilities (rate on a 1-5 scale; 1-no, (Dyes, slightly improved, 3-yes, somewhat improved, 4-yes, moderately improved, 5-yes, highly improved)?

Why? Chemical use reputing may unativats Hes to look tu alternative, less toxic. Chenuicabs to aid reputing. Based or my experiences the P2 Program Institutions. 
5. Does chemical use reporting provide a better basis for promoting technology transfer among firms (rate on a 1-5 scale; 1-no, 2-yes, silightly better, 3-yes, somewhat better, 4-yes, moderately better, 5yes, highly improved)?

Why?

6. How useful is chemical use reporting: (rate on a 1-5 scale; 1-not useful, 2-slightiy useful, 3-somewhat useful, 4-moderately useful, 5-highly useful)

$\begin{array}{lllllll}1 & 2 & 3 & 4 & 5\end{array}$

For tracking tonics in products

As a P2 "scorecard"

As a TRI "ledger check"

02

a

For improving quality of TRI database

For community level capability for looking at transportationrelated issues

For highlighting areas of potential cost savings and environmental benefit at facility

For facility public relations<smiles>[CH]CC</smiles>

For facility inventory managemint<smiles>[B]C=[18O]</smiles><smiles>[CH]C</smiles> 
DOE Chemical Use Pilot - 2-2498

Page 7

Toxic Chemical Use Reporting, by data element:

7. Which dat z element categories are subject to potential misunderstanding about a facility: (rate on a 1-5 scale; 1-no potential, 2-little potential, 3-some potential, 4-moderate potential, 5-high potential)

Inputs

Outputs

Pollution Prevention Activities

Facility-Level Substance-Specific

Pollution Prevention Progress

Which specific data elements are the most subject to misunderstanding within each category? The endive furn, was difficult to Compete - had to make it fit fo our situation.

Why? fo manufacturing. El the chenueal usage was the questions were difficult or impost ted to answer.

Which specific data elements are the least subject to misunderstanding within each category?

Why? 
8. Please rate the usefulness of reporing the following data elements of chemical use (on a 1-5 scale; 1 not useful, 2-slightly useful, 3-somewhat useful, 4-moderately useful, 5-highly useful), to the public, the facility, and state regulators.

Input Options

Public

Facility

State Regulators

Staring inventory of substance (5.)

Quantity of starting inventory

that is NPO (5.1)

Quantity produced on site (6.)

Quantity brought on site (7.)

Quantity brought on site as

recycled substance (7.1)

Quantity recycled out-of-process

on site and used on site (8.)

Input Options as a whole

\section{Output Options}

Quantity consumed on site (9.)

Quantity shipped off site as

(or in) product (10.)

Ending inventory (1l.)

Quantity of ending inventory

that is NPO (11.1)

Total NPO generated (12.)

Output Options as a whole

\section{Pollution Prevention Activities}

Has any pollution prevention method been employed to reduce the quantity of this substance during 1995 relative to 1994 levels? If "yes", fill in table.

(26.)

Material-Related change (changes in the amount of substance used due io substitution of otber non-listed sub-stance) (26.1)

Reformulation or redesign of produce (resulting in the reduction of substance generated) (26.2)

Process or procedure modification: (using existing equipment to reduce substance getrerated) (26.3) 


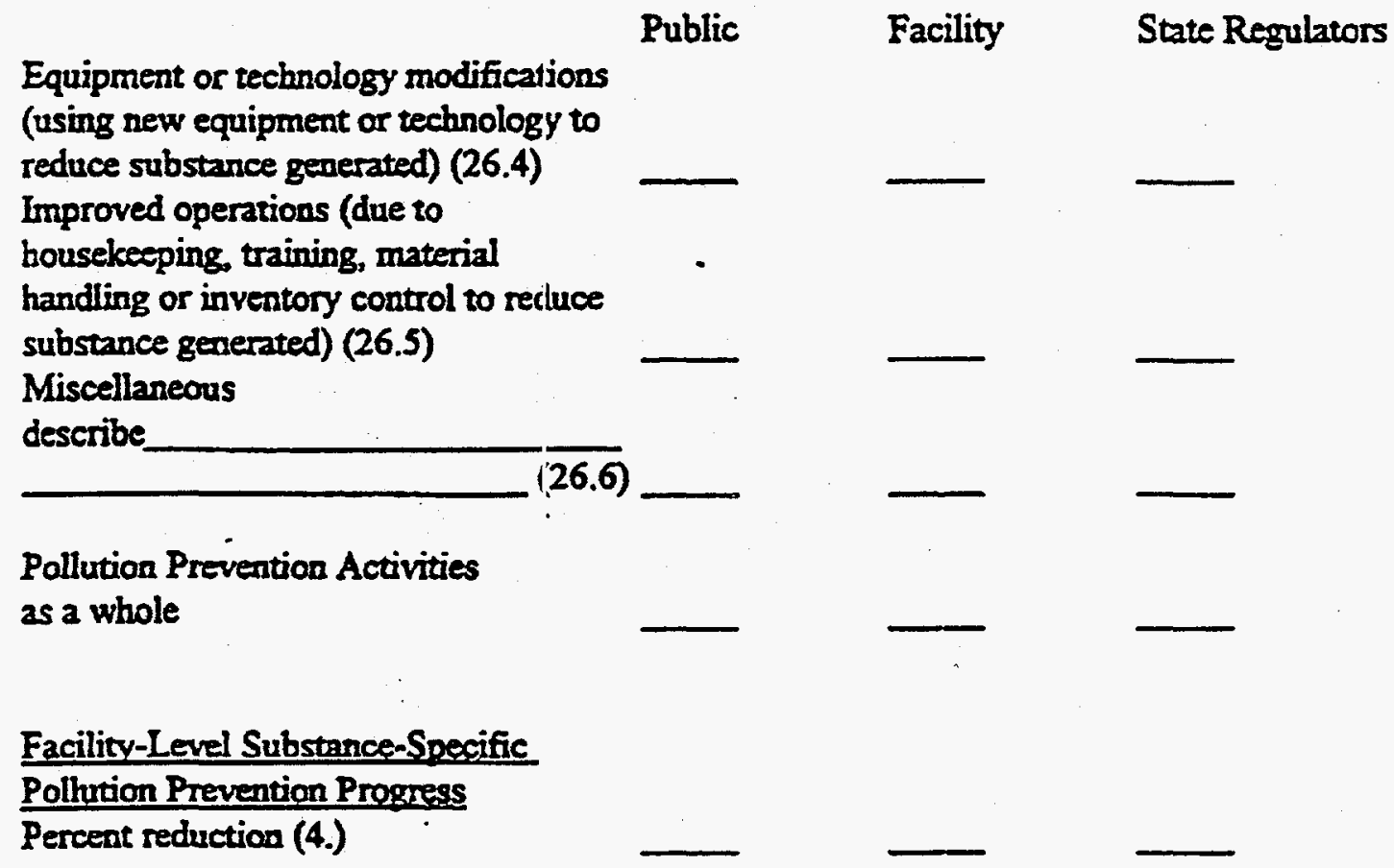

Name of person(s) completing the forms

Date completed 


\section{INTENTIONALLY BLANK}




$$
\begin{aligned}
& Y-12 P(A N T \\
& \text { LEA })
\end{aligned}
$$

Massachusetts Department of Environmental Protection

Page 1 of 5

\section{TURA REFOORT - COVER SHEET \\ Toxics Use Relluction Act - Form S Cover Sheet}

\section{Section 1: General Information}

1.1 ATTACH MAILING LABEL with facility name

ATTACH CORRECTED MAILING LABEL or enteT address \& DEP Facility Identification Number

facility, name \& address

1.2 Are you making a trade secret claim for any of the information sut mitted in this COVER SHEET and/or Form S(s)?

1.3 If YES, attach a statement substantiating the claim. Is this copy: _ _ _ Sanitized __ Unsanitized

1.4 This report is being filed for reporting year:

1997

\section{Section 2: Certification Statement}

2.0 This CERTIFICATION STATEMENT should be signed after all the forms have been completed.

I hereby certify that I have reviewed this and all attache 1 documents and that, to the best of my knowledge and belief, the submitted information is true and complete and that the amounts and values in these documents are accurate based on measurements and/or reasonable estimates using data available to the preparers of these documents. I am aware that there are significant penalties for willful or intentional submission of false or incomplete information.

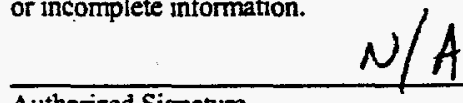

Authorized Signature

Print Name

Position/Title

Date

\section{Section 3: Chemicals Previously Reported That Are Not Reportable This Year}

3.0 OPTIONAL QUESTION. In this section, you may provide infonnation on any chemical reported last year that is not subject to reporting this year. If you substituted a non-listed chemical for a TURA chemical, you may identify the substitution, as well.

The codes to explain why the chemical is not reportable are: [1] Chemi al Below Threshold But $>0$ [2] No Chemical Usage in Reporting Year [3] Chemical Substitution [4] Chemical Eliminated (No Substitution) [5] Decline in Business [6] Other (Explain below in the additional comments section). Enter all the codes that apply.

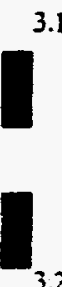

\section{CAS \# of Chemical Not Reportable (if applicable)}

Chemical Name

Explanation of Why the Chemical Is Not Reportable. (Enter Cods):

\section{CAS \# of Chemical Substituted for TURA Chemical}

\section{Chemical Name}

3.2

$$
\text { CAS \# of Chemical Not Reportable (if applicable) }
$$

Chemical Name

Explanation of Why the Chemical Is Not Reportable. (Enter Cods): $L$ 
$1-12$ PLANT ACILITY NAME

TOWN or TURA ID\#

$\frac{1997}{\text { Reporting Year }}$ Page 3 of 5

M S COVER SHEET (Continuation Page, for use, if necessary)

\section{Section 4: Facility-Wide Listing of Production Units}

\section{action \\ 7: N/A $:$}

\section{PRODUCTION PROCESS STEP INFORMATION FOIR THIS PRODUCTION UNIT}

Enter the production process code(s) to identify the process step(s) that involves a TUR-reportable chemical(s) as an input, output or throughput. (See the reporting guidance da:ument for the list of production process codes and instructions on when a given code needs to be listed.)

$1 .+1$

5. $5.1+11$
2.

6.
3.

7.
4.

8. L + 1 1

List below, the TURA-reportable chemicals associated with the production unit. If a chemical is associated with ALL the process steps identified above, check the All block. If the chemical is associated with some but not all of the process steps, put the relevant code(s) (from above) next to the cheinical.

Chemical(s)

\begin{tabular}{l}
\hline Chemical Name \\
\hline CAS\# \\
\hline Chemical Name \\
\hline CAS\# \\
\hline Chernical Name \\
\hline CAS\# \\
\hline Chemical Name \\
\hline CAS\# \\
\hline Chemical Name \\
\hline CAS\# \\
\hline CAS\#
\end{tabular}

Production Process(es)

ALL
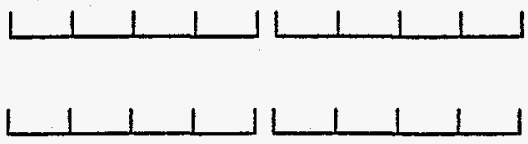

ALLL

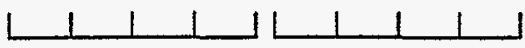

ALL

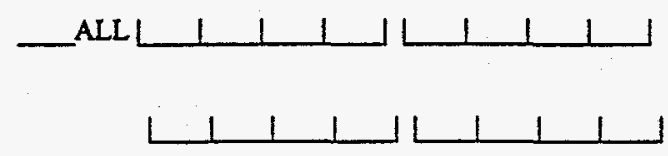

ALL

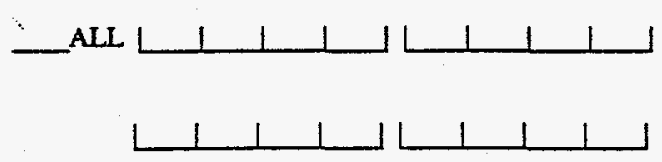

ALL

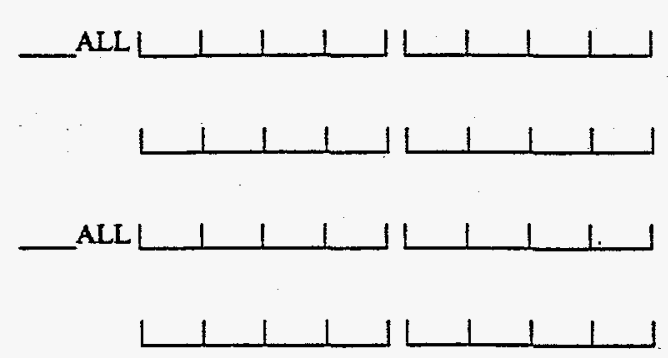




\begin{tabular}{|l|l|}
\hline & \\
\hline Facility Name: $Y-12$ PLANT & Facility D\# \\
\hline Eemical: : $L G A D$ & Reporting Year: 1997 \\
\hline
\end{tabular}

\section{Massachusetts Department of Environmental Protection TURA REPORT - FORM S}

Tarics Use Reduction Act - Chemical Usage Facility-Wide \& by Production Units

5 tion 1: Facility-Wide Usage of Listed Chemical

$.1 \quad 007439921$

Chemical Abstract Service (CAS) Number (if applicable)
Lead

Chemical Identification (from Form R)

1.2 Facility-Wide Usage of Chemical Identified in 1.1 above. Enter lotal amount (in POUNDS) for each applicable category.

NOTE: Byproduct (item 1.2d) generally means all wastes containing the listed chernical before the waste is treated or recycled. Read the instructions carefully, however, before completing this section.

1.2a Manufactured

1.2b Processed:

2c Otherwise Used: 1.2d Generated as Byproduct:

1.2e Shipped in or as Product:
1

9

1.3 OPTIONAL QUESTION. When the amounts reported in $1.2 \mathrm{a}, 1.2 \mathrm{~b}$, and $1.2 \mathrm{c}$ are added together, the sum will - in many

cases - equal the sum of $1.2 \mathrm{~d}$ and $1.2 \mathrm{e}$. In other words, the left and right columns will often form a "materials balance." If the two columns are ot in approximate balance, you may use this block to explain why. Mark. all the reasons that apply, or indicate the number of pounds in the appropriate lock below. (i.e.: 4.000 Chemical was held in inventory).

Chemical was recycled on site. Chemical was consumed or transformed.

Chemical was held in inventory. Chermical is a compound.

$\mathbf{x}$ Other (explain):

The remaining 9 pounds (end product eg.. lead substrate) was teturned to the customer for use.

OPTIONAL QUESTION: Did anything non-routine occur at your facility during the reporting year which affected the data reported? YES _ _ $\quad \mathbf{X}$ NO If YES, you may use this space to comnient

- YES _ $-\mathbf{X}$ _ NO If YES, you may use this space to comnient

ersich

ion 2: Chemicals Used in Waste Treatment Units

Is this chemical used to treat waste or control pollution? YES_X_No

If YES, enter the quantity of chemical code for the amount used to trea! waste or control pollution:

OPTIONAL - You may enter the amount:

01 (Enter \# from the Form S Cover Sheet.)

3.1 Base Year. _ 1997

3.4 Byproduct Reduction Index:

-

3.2 Quantity of Chemical Code: $\lfloor A\rfloor$

3.5 Emissions Redıction Index

-

3.3 Toxics Use Reduction Techniques Code:

If there has been a change from one reporting year to the current year in a (1) base year, and/or (2) estimating methods (that significantly alter previously reported data) for this PRODUCTION UNIT REPORT, describe the change: 
Page 5 of 5

\begin{tabular}{|l|l|l|}
\hline Facility Name: $\quad y-12 P(A N T$ & Facility D\# \\
\hline Chemical: $\quad C E A D$ & Reporting Year: 1997 \\
\hline
\end{tabular}

Section 3: 'TURA Report on Production Unit \#: (Enter \# from the Form S Cover Sheet)

1 Base Year: —_ 3.4 Byproduct Reduction Index:

3.2 Quantity of Chemical Code: 3.5 Emission R:duction Index:

$\sqrt[4]{14}$

.3 Toxies Use Reduction Techniques Code: $L 1 / L 1 / L 1 / L 1 / L 1 / L 1 / L$

there has been a change from one reporting year to the current year in a (1) base year, and/or (2) estimating methods (that significantly alter

previously reported data) for this PRODUCrION UNIT REPORT, describe the change:

TURA Report on Production Unit \#:

(Enter \# from the Form S Cover Sheet.)

.1 Base Year:

3.4 Byproduct Reduction Index:

.2 Quantity of Chemical Code:

3.5 Emission Reduction Index:

$N / 4$

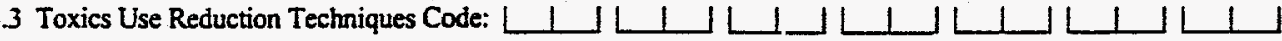

If there has been a change from one reporting year to the current yiar in a (1) base year, and/or (2) estimating methods (that significantly alter previously reported data) for this PRODUCTION UNIT REPORT, describe the change:

TURA Report on Production Unit \#: (Enter \# from the Form $S$ Cover Sheet)

1 Base Year.

3.4 Byproduc: Reduction Index:

2 Quantity of Chemical Code:

3.5.Emission lReduction Index:

N)A

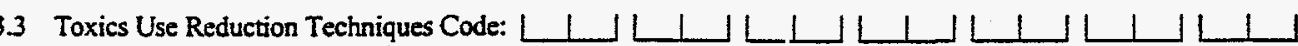

If there has been a change from one reporting year to the curren: year in a (1) base year, and/or (2) estimating methods (that significantly alter previously reported data) for this PRODUCTION UNIT REPORT, describe the change:

\section{TURA Report on Production Unit \#:} (Enter \# from the Form S Cover Sheet.)

T.I Base Year:

12 Quantity of Chemical Code:
3.4 Byproduc: Reduction Index:

3.5 Emission leduction Index:
$N / A$

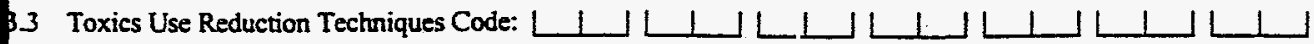

If there has been a change from one reporting year to the current year in a (1) base year, and/or (2) estimating methods (that significantly alter $m$ oreviously reported data) for this PRODUCTION UNIT REPORT, describe the change: 


\section{Toxic Use Reduction Act (TURA) - Form $S$ (Massachusetts) \\ COVER SHEET}

\section{Section 1: General Information}

1.1 Mailing Label

$1.3 \times$ _ Sanitized Unsanitized
1.2 Making Trade Secret YES _ NO x

1.4 This report is for reporting year 1997

\section{Section 2: Certification Statement}

NA (not applicable)

Section 3: Chemicals Previously Reported.......

NA

\section{Section 4: Facility-Wide Listing of Production Units}

\section{Production Unit\#: 01}

\section{Describe the Process:}

Building 9201-1 is a complete machine shop facility used to perform large and small machining operations such as cutting, welding, drilling, forming of special components and individual items; and the assembly, testing, and packaging of the completed product. This building is divided into several shop areas such as Saw Shop, Weld Shop, Tool Fabrication Shop, Precision Shop and other general machine shops. Some of these operations are conducted in enclosed shops and open work areas. Microsol 165 solution (coolant) is circulated through a clean-up system and returned to the machine coolant system for re-use. The machine chips, and/or turnings are removed from the coolant and disposed of through an appropriate metal waste bin. Operations performed in each of these shops are very similar, except that the Tool Fabrication Shop handles smaller components, thusi requiring smaller equipment/tooling.

For the purpose of this report, we focus our attention on the Tool Fabrication Shop, whereby a ten pound lead $(\mathrm{Pb})$ plate was utilized. The process involved submerging the $\mathrm{Pb}$ plate in the coolant and drilling holes in it, thus negligible $\mathrm{Pb}$ air emissions with approximately one pound of chips as waste. The remaining nine pounds was returned to the requester to use as a counter weight in equipment. In summary and according to the Form $S$ guidelines, this process is best described as "the removal of mass from substrate". 


\section{Describe the Product:}

The product is the modified $\mathrm{Pb}$ substrate e.g., ( $\mathrm{Pb}$ plate with specified holes drilled in it).

Four digit SIC Code : 3499

Describe the Unit of Product:

Pounds and/or number of lead substrate request for modifications

Production Process Step Information for this Production Unit:

$1.0 \quad$ BB05

Chemical

Lead Metal
Production Process

$\mathbf{x}$ ALL
CAS\#

007439921 


\section{TURA REPORT - FORM S}

Section 1: Facility-Wide Usage of Listed Chemical

1.1 CAS\#: 007439921

Chemical Identification (from Form R): Lead

1.2a. $0 \#$ 1.2b. $0 \#$ 1.2c. $10 \#$ 1.2d. $1 \#$ 1.2e. $9 \#$

1.3 Optional: The sum of $1.2 \mathrm{a}, 1.2 \mathrm{~b}$, and $1.2 \mathrm{c}$ added together should equal the sum $1.2 \mathrm{~d}, \& 1.2 \mathrm{e}$ Why? The remaining $9 \mathrm{lbs}$ (end product) was returned to the customer for use as a counter weight in equipment. Also refer to st:ction 4 "Describe the Process" for additional information.

1.4 Optional: No, for non-routine ciccurrence that may have affected the data reported.

Section 2: Chemicals Used in Waste Treatment Units

2.1 Is chemical used to treat waste or control pollution? No

Section 3: TURA Report on Production Unit\# 01

3.1 Base Year: $1997 \quad 3.2$ Qty' Of Chemical Code: $\boldsymbol{A}$.

3.4 Byproduct Reduction Index: $\quad$ \#\# $\quad 3.5$ Emissions Reduction Index: $\quad$ \#\#

\subsection{Toxic Use Reduction Techniques Code: $\boldsymbol{N A}$}

Not able to use the above (3.3) due to difference in release/activities in 1996 vs 1997 for lead. Information (detail) is given in the summary on the New Jersey form in section 4.0, Percent Reduction.

rae 
FE: ELSE \& FOLUTIOH FEEYEATION FE:OกT FOก ISSE

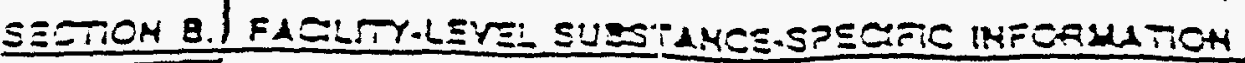

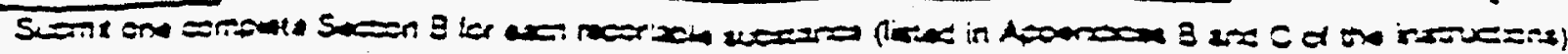

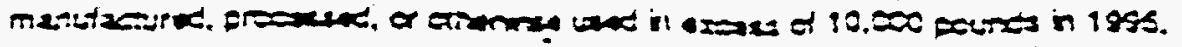

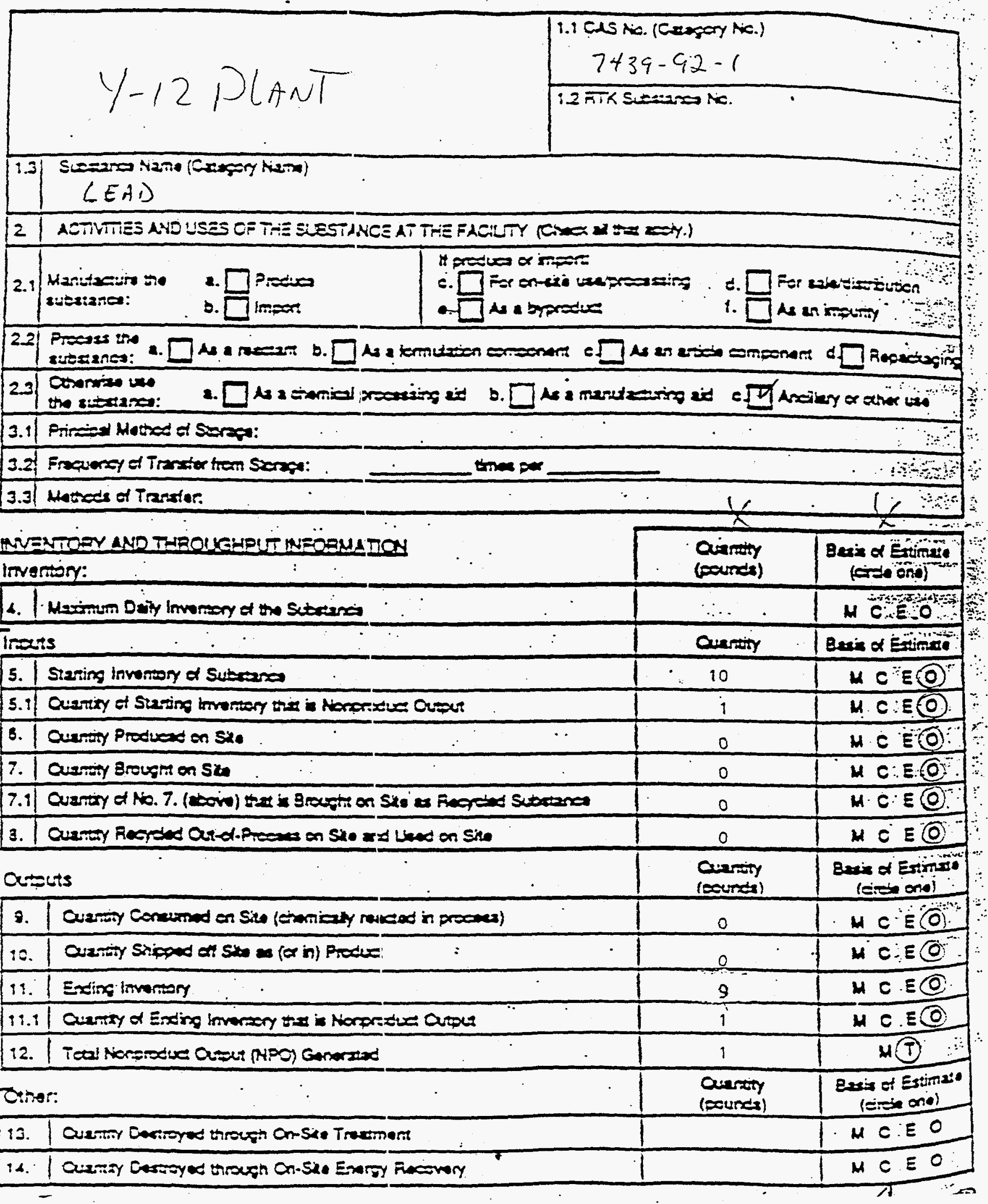


25 нim or

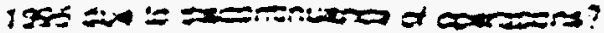

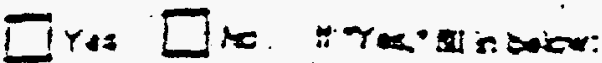

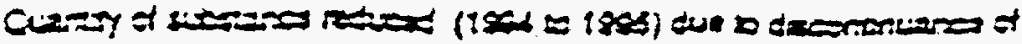

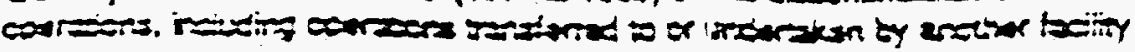

\begin{tabular}{|c|c|}
\hline 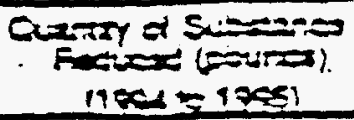 & 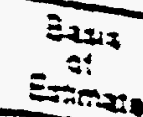 \\
\hline & \\
\hline
\end{tabular}

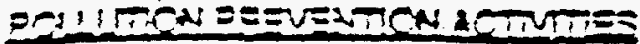

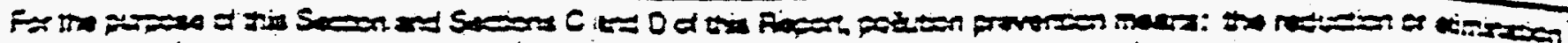

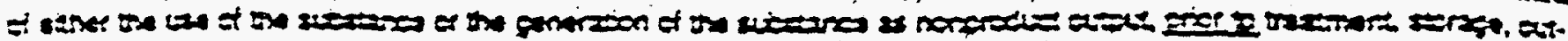

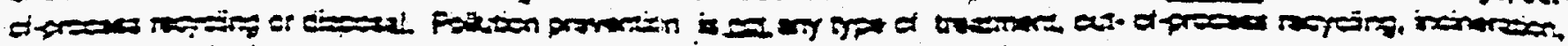

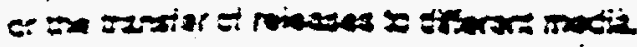

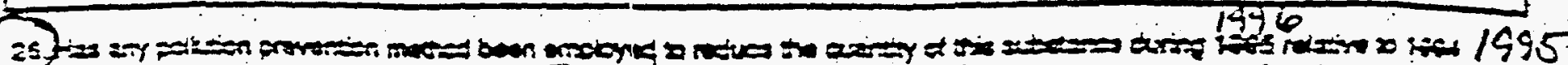

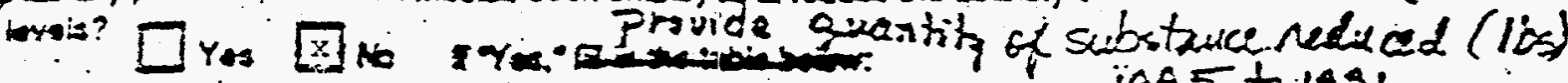

1995 to 1995

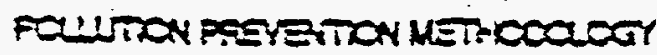

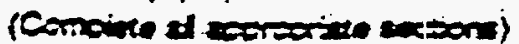

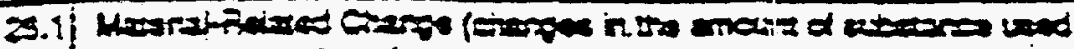

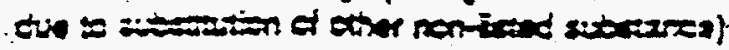

\begin{tabular}{|c|c|}
\hline 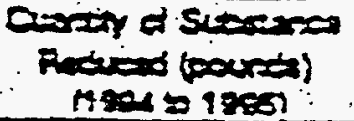 & $\begin{array}{l}\text { Busi: } \\
\text { et }\end{array}$ \\
\hline
\end{tabular}

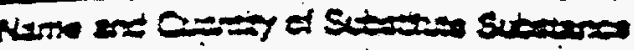

$$
\text { c1: } 2: 2=0
$$
)
b).
c)

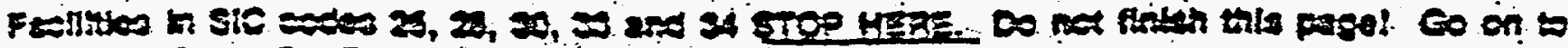

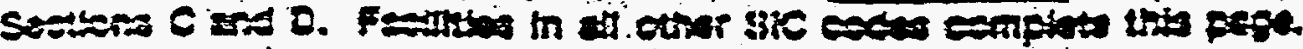

.

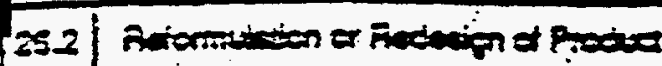

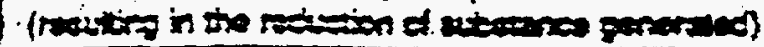

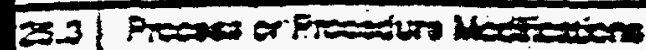

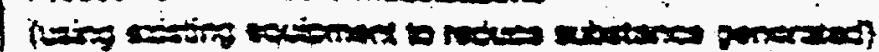

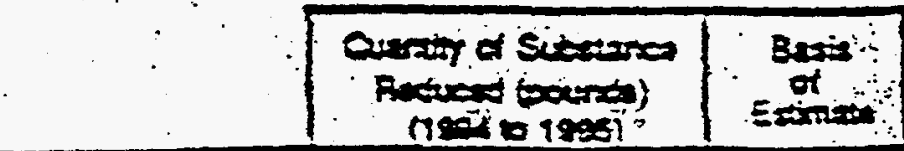

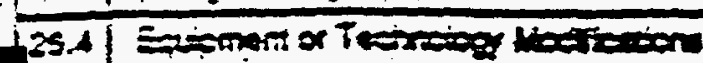

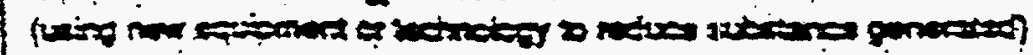

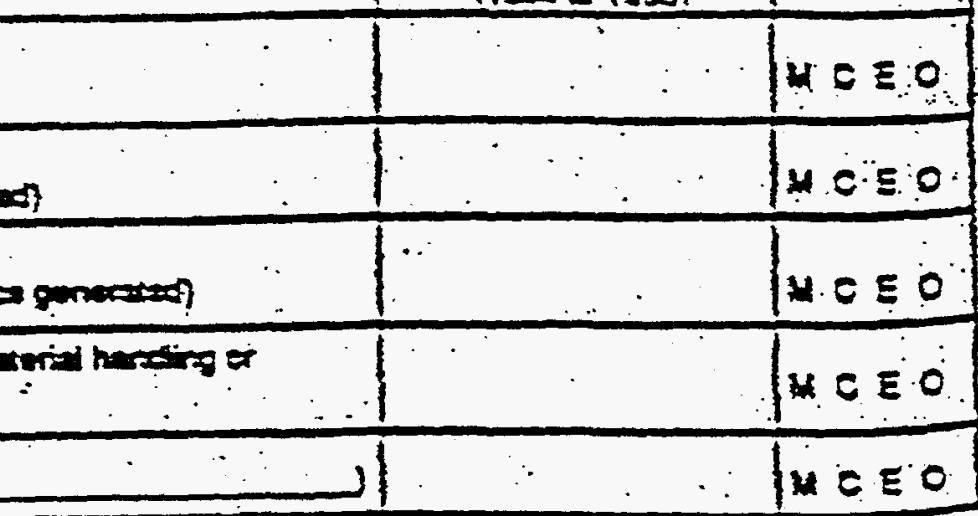

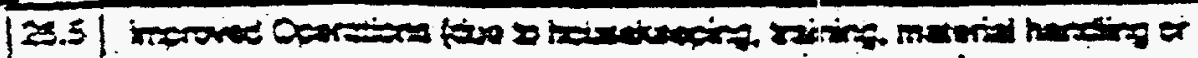

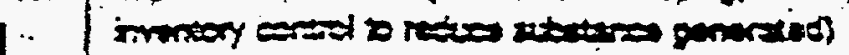

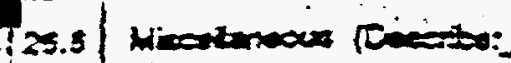

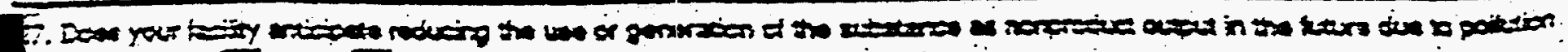

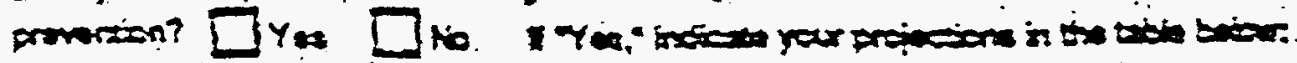

PAO $=$ TRAY

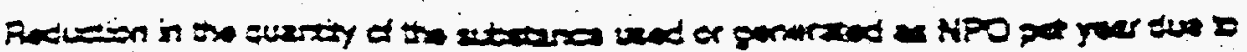

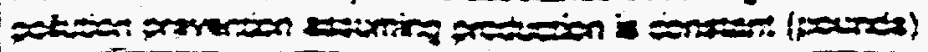

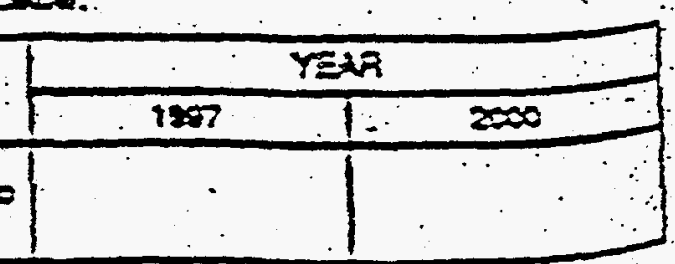




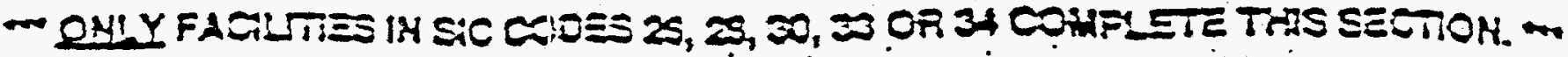

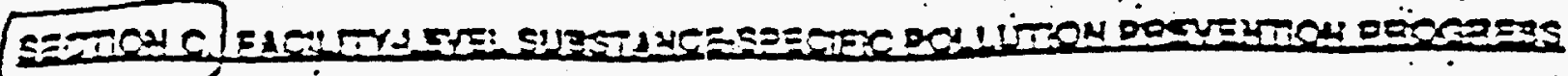

S.

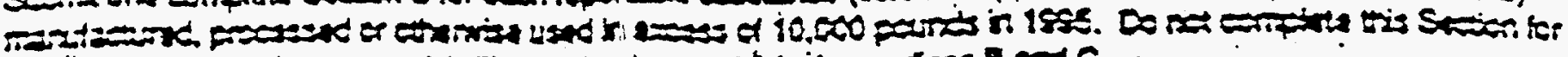

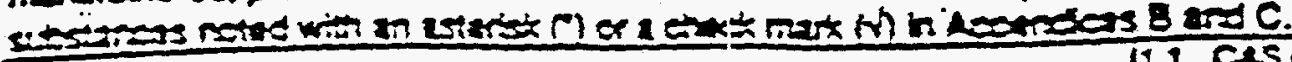

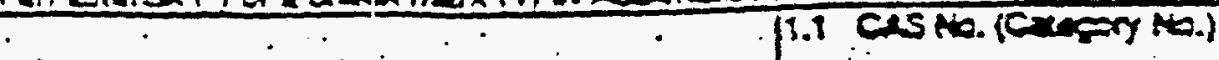

$$
\begin{aligned}
& y-12 P \operatorname{LANT} .
\end{aligned}
$$

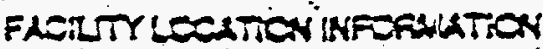

$7439-92-1$

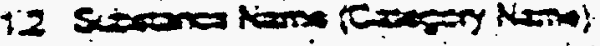

Lead

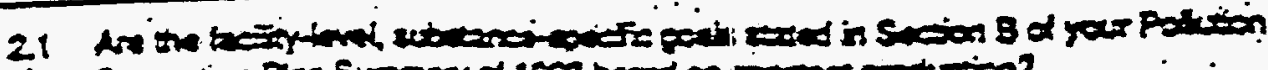

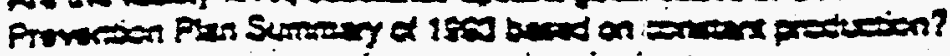

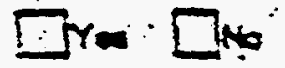

22 If

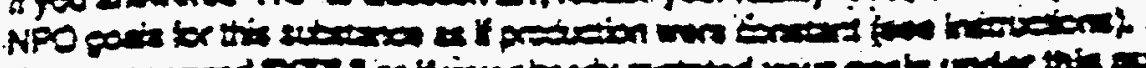

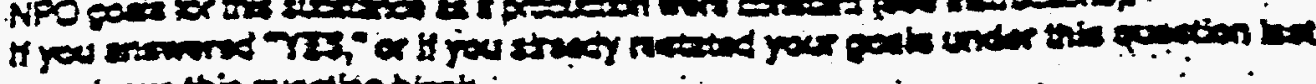

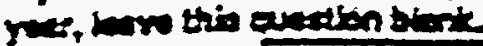

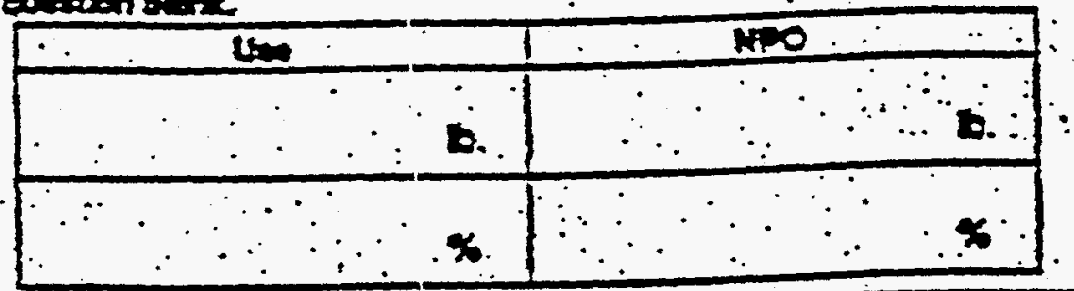

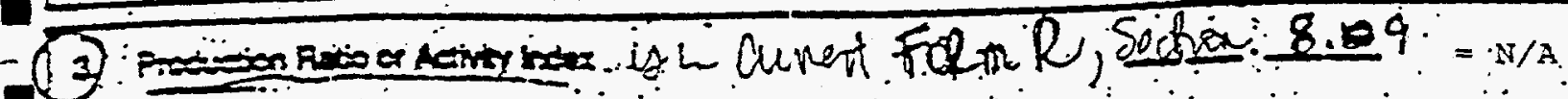

(4) Fron Rotion $=N / A ?$

$\cdots$

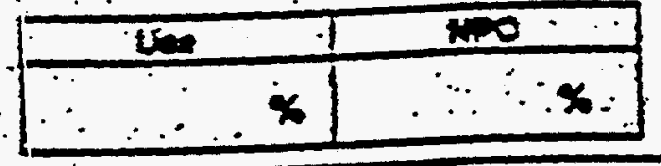

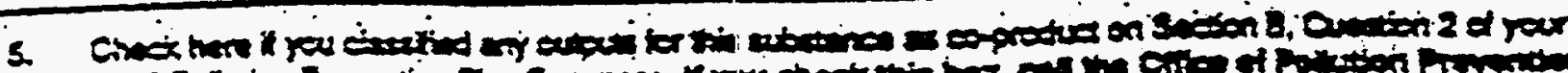

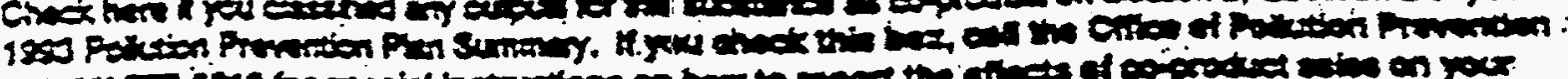

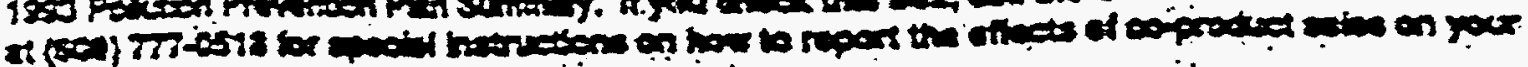

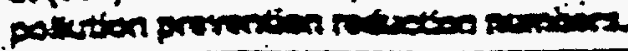

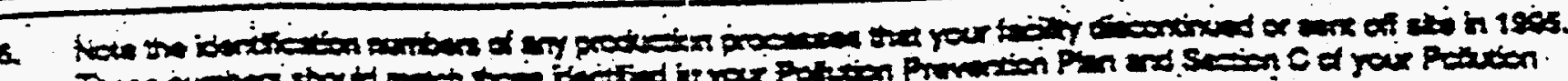

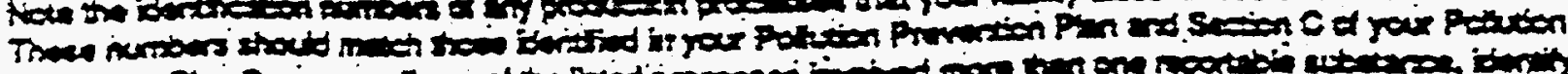

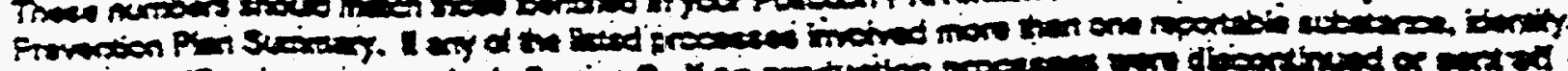

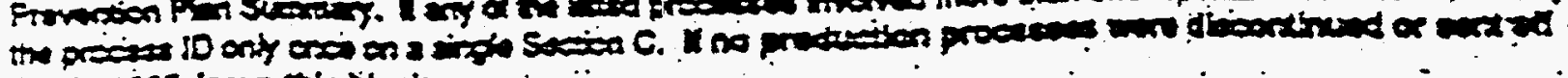

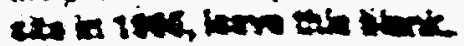

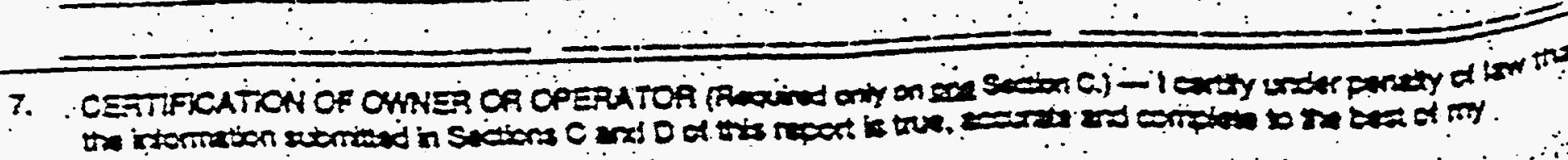
kowiedo.

Sigare ate Pros tio. 
New Jersey - Form $S$

\subsection{Starting Inventory of Substance on Site}

\section{Background/Inventory}

Based on the material selected and plint-wide inquiries, one process was identified and selected for this report. Building 9201-1 is a complete machine shop facility used to perform large and small machining operations such as cutting, welding, drilling, forming of special components and individual items; and the assembly, testing, and packaging of the completed product. This building is divided into several shop areas such as Saw Shop, Weld Shop, Tool Fabrication Shop, Precision Shop and other general machine shops. Some of these operations are conducted in enclosed shops and open work areas. Microsol 165 solution (coolant) is circulated through a clean-up system and returned to the machine coolant system for re-use. The machine chips, and/or turnings are removed from the coolant and disposed of through an appropriate metal waste bin. Operations performed in each of these shops are very similar, except that the Tool Fabrication Shop handles smaller components, thus requiring smaller equipment/tooling.

For the purpose of this report, we focus our attention on the Tool Fabrication Shop, whereby a ten pound lead $(\mathrm{Pb})$ plate was utilized in $\mathrm{CY}$ 1997. The process involved submerging the $\mathrm{Pb}$ plate in the coolant and drilling holes in it, thus negligible $\mathrm{Pb}$ air emissions with approximately one pound of chips as waste. The renlaining nine pounds was returned to the requester to use as a counter weight in equipment. In suramary and according to the Form $S$ guidelines, this process is best described as "the removal of mass from substrate", and starting inventory $=\sim 10$ lbs.

\subsection{Starting Inventory that is NPO}

The quantity of starting inventory that is Nonproduct Output is the chips/turnings generated from the drilling of holes in the $\mathrm{Pb}$ substrate. It was determined that this amount $=\sim \mathbf{l} \mathbf{~ b}$ in CY 1997.

$\mathrm{Pb}$ to air from drilling process was determined to be negligible due to the fact the process was conducted under the coolant.

The Tool Fabrication Shop is located inside a building 9201-1 with no patent drains to the Storm Water System. Therefore in summary, starting inventory that is NPO $=\sim 1 \mathbf{l b}$.

\subsection{Quantity Produced on Site}

No $\mathrm{Pb}$ was produced on site 


\subsection{Quantity Brought on Site}

$\mathrm{No} \mathrm{Pb}$ was brought on site for processing in 9201-1. As stated above only used the $\mathrm{Pb}$ indicated in number 5.0. Procurement of $\mathrm{Pb}$ was brought on site (article) i.e. $\mathrm{Pb}$ bricks and used for shielding.

\subsection{Quantity of No. 7.0 that was brought on Site as Recycled Substance}

No $\mathrm{Pb}$ was brought on site as recycleid substance for processing at 9201-1 in CY 1997.

\subsection{Quantity Recycled Out-of-Process on Site and Used on Site}

The $1 \mathrm{lb}$ of $\mathrm{Pb}$ chips which resulted form drilling process was recycled in-process i.e. extracted from the coolant and disposed in a metal waste bin. Therefore, no $\mathrm{Pb}$ was recycled out-ofprocess and used on site at 9201-1 in CY 1997.

\subsection{Quantity Consumed on Site (chemically reacted in process)}

$\mathrm{No} \mathrm{Pb}$ was consumed on site in $\mathrm{CY} 1997$, i.e. its molecular structure was altered.

\subsection{Quantity Shipped off Site as (or in) Product}

No $\mathrm{Pb}$ product was shipped off site as a result from 9201-1 processing in CY 1997.

\subsection{Ending Inventory}

Due to the $1 \mathrm{lbs}$ of chips/tuming generated in CY 1997 remained on Site in waste, the ending inventory $=9 \mathrm{lbs}$.

\subsection{Quantity of Ending Inventory that is NPO}

As stated earlier (5.1), the ending inventory that is $\mathrm{NPO}=1 \mathrm{lb}$.

\subsection{Total NPO Generated}

As stated in (11.1), the total NPO generated in CY 1997 at $9201-1$ is $=1 \mathrm{lb}$. 


\subsection{Has any Pollution Prevention method been employed to reduce the quantity....}

In CY 1997, at 9201-1 no pollution prevention was employed i.e. to reduce or eliminate of either the use of $\mathrm{Pb}$ or the generation of NPO, prior to treatment, storage, out-of-process recycling or disposal. Note: Pollution Prevention is not any type of treatment, out-of-process recycling, incineration, or the transfer to another media.

27.0 Does your facility anticipate reducing the use or generation of the substance as NPO...

No, only small quantities of NPO is generated and handled accordingly, i.e. funding is not a priority.

\section{Section C}

\subsection{CAS No.: 007439921}

1.2 Substance Name: Lead

\subsection{Production Ratio}

Unable to complete this section due to the no $\mathrm{Pb}$ activity was conducted in CY 1996 at 9201-1, therefore production ratio $=$ NA (not applicable)

\subsection{Percent Reduction}

Unable to complete this section due to the $\mathrm{Pb}$ activity conducted in CY 1996 differs from activity of $\mathrm{Pb}$ conducted in CY 1997. In other words in CY $1996 \mathrm{~Pb}$ activity was conducted in building 9766 (Model Shop) whereby $15 \mathrm{lbs}$ of: $\mathrm{Pb}$ was used in fabricating ingots with an estimated release to air of less than $1 \mathrm{lbs}$. Negligible amount of NPO was generated thus not appropriate to compare and/or calculate percent reduction with respect to activities conducted in 9201-1. In summary percent reduction $=$ NA. 
NJ Form S (continued)

\section{Section B: Inputs}

5. Starting Inventory $=10 \#$ for $(9201-1) \ldots$ Note: $8 \#$ from fly ash ETTP in CY96 $+10 \#$ fly ash from ETTP in CY 97.

5.1 Starting inventory Nonproduct Output $=1 \#$ (turnings from 9201-1)

6.0 Qty Produced on site $=0 \#$

7.0 Qty Brought on site $=0 \#$

$7.1 \& 8.0$ Qty brought as recycle... $=1 \#$

\section{Outputs:}

9.0 Qty consumed on site chemically $=0 \#$

10. Qty shipped off-site as product $=0 \#$

11. Ending Inventory $=9 \#$

11.1 Qty of ending inventory that is $\mathrm{NPO}=1 \#$

12. Total NPO generated $=1 \#$.

Basis of estimates $=O$; for question $12=T$

Note: The information above represents the events/process for 9201-1 during CY 97 only. Concerns with recipients comparing this information to CY 97 Form $R$ submittals.

rae (Y-12 Plant) 


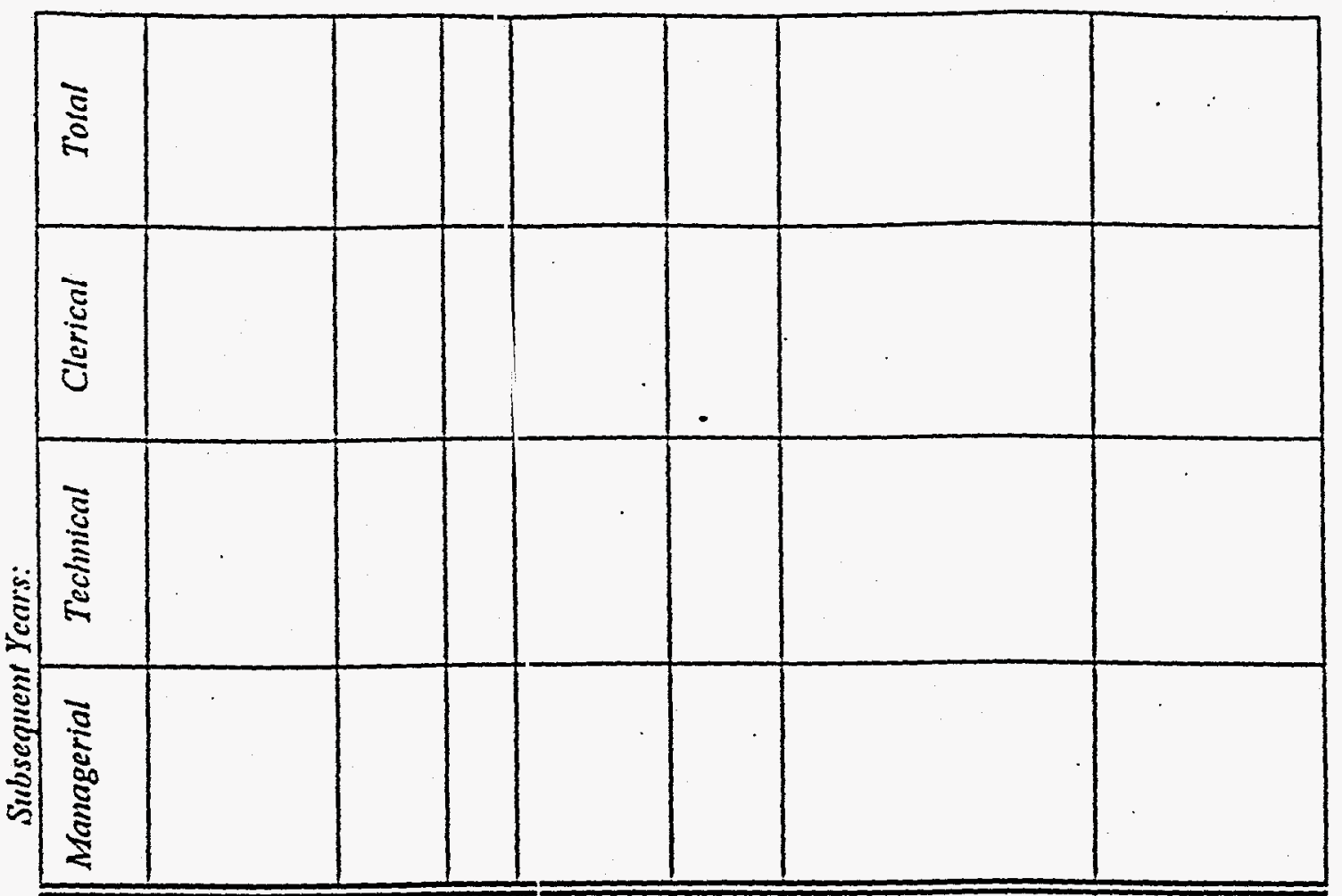

ปั.

\begin{tabular}{|c|c|c|c|c|c|c|c|}
\hline$\frac{9}{0}$ & जी & $\begin{array}{l}\overrightarrow{5} \\
0\end{array}$ & $\begin{array}{l}\overrightarrow{5} \\
0\end{array}$ & $\stackrel{0}{0}$ & $\stackrel{0}{0}$ & $\overrightarrow{0}$ & in \\
\hline$\frac{\bar{E}}{\bar{E}}$ & $\stackrel{7}{\circ}$ & $\stackrel{7}{\dddot{0}}$ & $\begin{array}{l}7 \\
0\end{array}$ & ت̈ & $\exists$ & $\stackrel{7}{0}$ & $\stackrel{7}{0}$ \\
\hline 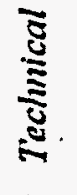 & $\stackrel{2}{\stackrel{2}{0}}$ & $\stackrel{5}{0}$ & $\begin{array}{c}0 \\
0 \\
0\end{array}$ & ? & ? & $\stackrel{0}{0}$ & 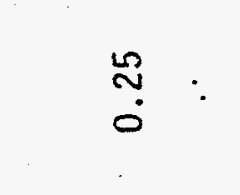 \\
\hline 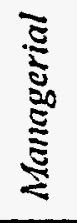 & $\begin{array}{l}8 \\
0\end{array}$ & $\begin{array}{l}8 \\
\circ \\
\circ\end{array}$ & $\begin{array}{l}8 \\
0 \\
0\end{array}$ & $\begin{array}{l}\stackrel{0}{\circ} \\
\dot{0}\end{array}$ & $\begin{array}{l}\circ \\
\circ \\
0\end{array}$ & $\begin{array}{l}8 \\
0\end{array}$ & $\begin{array}{l}9 \\
0 \\
0\end{array}$ \\
\hline 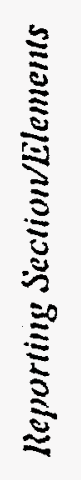 & 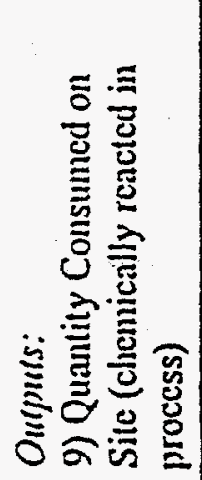 & 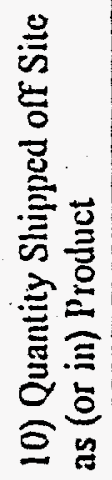 & 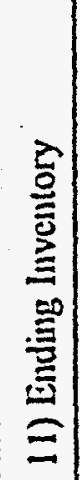 & 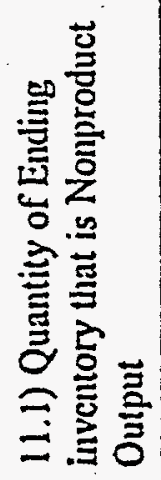 & 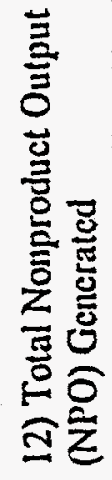 & 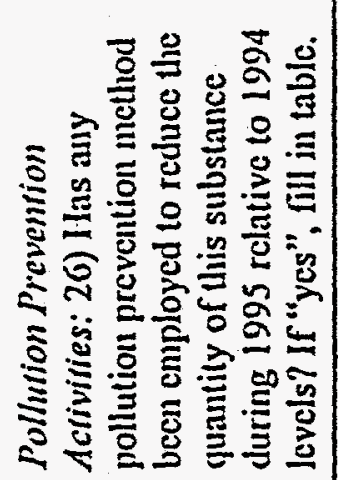 & 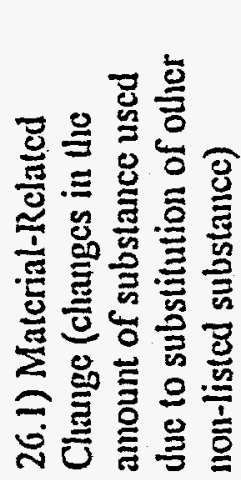 \\
\hline
\end{tabular}




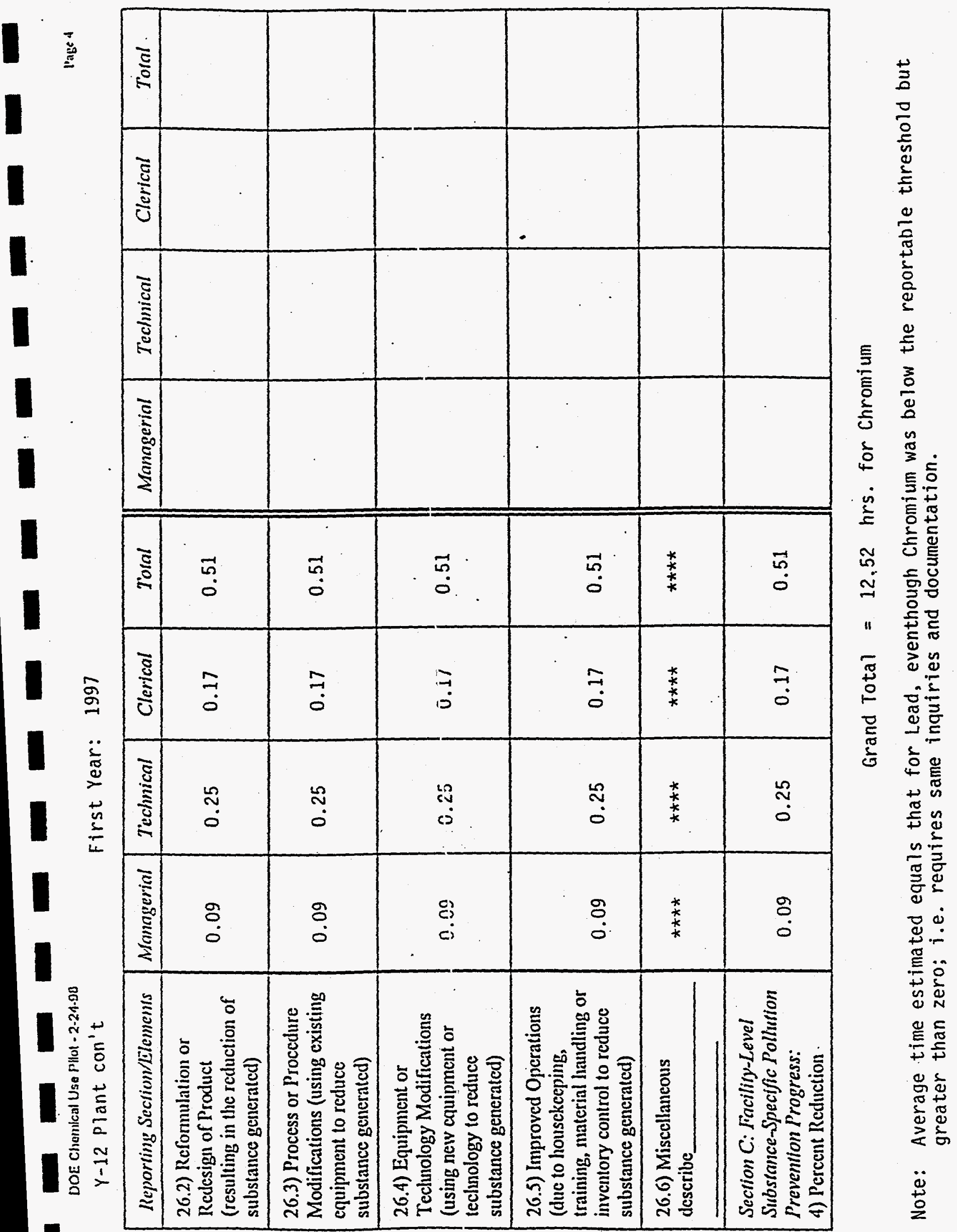


Benefits Evaluation Form

Benefits/Csefulness of Toxic Chemical Use Reporting

Toxic Chemical Use Reporting, in general: U.S. DOE Y-12 Plant

1. How effective is chemical use reporting to facilities and the general public in improving their understanding of the rolumes and patterns of chemical use (rate on a scale; 1-not effective, (3)lightly effective, 3-somewhat effective, 4-moderately effective, 5-highly effective)?

Why?

As a result of the current reporting requirements so stated under EPCRA section 313, most facilities are utilizing the release data to identify process, storage, and handling modifications to minimize chemical losses and to save money. Chemical use reporting may be somewhat effective in forcing facilities to undierstand their volumes and patterns of chemical uses, however for those facilities with active and aggressive Pollution Prevention (P2) programs, chemical use reporting will be ineffective and yet another burden on the facility. P2 focuses on a particular process as opposed to a particular material utilized aggregated across the plant/reservation. A more effective method of improving their understanding by both the public and facilities would be to restrict applicable permits i.e., discharge and disposal of chemicals via establishing the Environmental Media (e.g. air, water, soil), Quality objectives and standards that protects human health and the environment. In conclusion, I'm not convinced that the public has an understanding on the existing section 313 reports and to append additional data only increases the level of uncertainty, misunderstanding and overwhelms EPA's databases.

Note: It is now August 1998, and the 1997 TRI data was submitted to EPA in June 1998. To date, the information is not available via computer, and once made available will it be correct???......any takers........ what's 'wrong with this picture!!!

2. How useful is chemical use rejorting to state agencies for the purposes of targeting state resources (rate on a 1-5 scale, (1) not useful, 2-slightly useful, 3-somewhat useful, 4moderately useful, 5-highly useful)?

Why?

Section 313 reports are utilized to assist government agencies and others in research efforts, and the development of regulations, guidelines, and standards. Chemical use data if used properly, may allow state agençies to ienderstand where to focus their resources in encouraging $P 2$ initiatives. However, state agencies distribution of resources are based on the EPA program grants (Federally supported), i.e. more dollars more state resources. Also, most state resources funded by these grants are administrative and are necessary to support EPA's paper log jans and not real environmental quality improvements. 
3. Does chemical use reporting offer an improved basis for measuring progress in pollution prevention over current reporting information (rate on a 1-5 scale. (1) no, it offers no improvement, 2-yes, slightly improved, 3-yes, somewhat improved, 4-yes, moderately improved, 5-yes, highly improved)?

Why?

No, section 313 reporting process is an aggregate of all the activities surrounding the use of selected material in oppose to $P 2$ whereby it focus on a particular process i.e. source reduction and recycling activities. The methodology, e.g. Pollution Prevention Opportunity Assessments $(P P O A)$ is utilized to identify $P 2$ options for a specific process. Since section 313 reporting involves air emissions, etc., a systematic problem occurs i.e., these projects do not have the "return on investment" associated with waste storage/treatment/disposal, as do other $P 2$ projects. In some cases these projests are not funded. In conclusion, the section 313 reporting coupled with chemical use data will not be significant tool in identifying P2 projects, it will simply overwinelm the system with tata.

4. Does chemical use reporting lead to improved toxic chemical management in facilities ( rate on 1-5 scale; (1)no, 2-yes, slightly improved, 3-yes, somewhat improved, 4-yes, moderately improved, 5-yes, highly improved)?

Why?

As mentioned earlier chemical use clata already exist and reporting it is one thing, effective management of toxic chemicals is another, e.g. spill containment would not be significantly improved. Focusing on reporting ia order to promote or improve toxic chemical management is similar to trying to inspect end quality to a product...it doses not work.... quality should be built in at the on-set.

5. Does chemical use reporting provide a better basis for promoting technology transfer among firms (rate on a 1-5 scale (1) no, 2-yes, slightly better, 3-yes, somewhat better, 4yes, moderately better, 5-yes, highly improved)?

Why?

No, within an industrial group the chemical use reports would be useful to competitors and chemical suppliers to target nęw marketing strategies; thus not promoting technology transfer. Are we skewing the purpose, scope of EPCRA section 313 reporting to satisfy special interest groups? 
5. Does chemical use reporting provide a better basis for promoting technology transfer among firms (rate on a 1-5 scale; 1-no, 2-yes, slightly better, 3-yes, somewhat better, 4-yes, moderately better, 5yes, highly improved)?

Why?

6. How useful is chemical use reporting:

(rate on a 1-5 scale; 1-not useful, 2-slightly useful, 3-somewhat useful, 4-moderately useful, 5-highly useful)

$1234: 5$

For tracking toxics in products

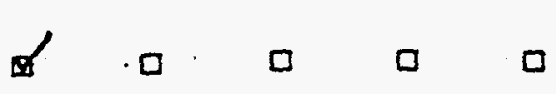

As a P2 "scorecard"

As a TRI "ledger check"

For improving quality of TRI database

For community level capability for looking at transportationrelated issues

For highlighting areas of potential cost savings and environmental benefit at facility

For facility public relations

For facility inventory managemen: 
Toxic Chemical Use Reporting, by ciata element:

7. Which data element categories are subject to potential misunderstanding about a facility: (rate on a 1-5 scale; 1-no porential, 2-little potential, 3-some potential, 4-moderate potential, 5-high potential)

$1^{\bullet} \quad 2^{*} \quad 3^{\cdot} \quad 4^{*} 5$

Inputs

Outputs

Pollution Prevention Activities

Facility-Level Substance-Specific

Pollution Prevention Progress

a

$\square \square \square$

7

Which specific data elements ars the most subject to misunderstanding within each category?

$$
\text { "Inputs" }
$$

Why?

Using a standardized form does not allow for additional information i.e., to explain the meaning of the data elements. Example given are starting inventory and NPO data.

Which specific data elements are the least subject to misunderstanding within each category?

"Poliution Prevention"

Why?

Pollution Prevention is part of and/or similar to the same information requested on the form $R$ reports. Source reduction and recycling activities seems to be more attractive in the public's opiaion 
8. Please rate the usefuiness cf reporting the following data elements of chemical use (on a $1-5$ scale; 1 not useful, 2-slightly useful, 3-somewhat useful, 4-moderately useful, 5-highly useful), to the public, the facility, and state regulators.

Inout Options

Starting inventory of substance (5.)

Quantity of starting inventory

that is NPO (5.1)

Quantity produced on site (6)

Quantity brought on site (7.)

Quantity brought on site as

recycled subistance (7.1)

Quantity recycled out-of-process

on site and used on site (8.)

Public

Facility

State Regulators

Input Options as a whole
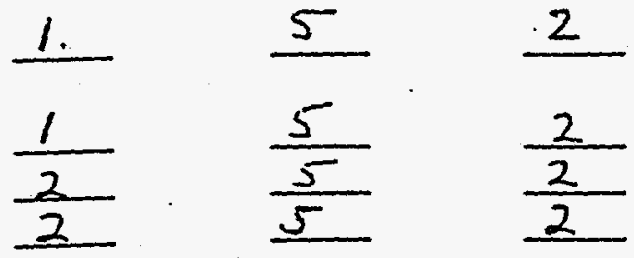

\section{Output Options}

Quantity consumed on site (9.)

Quantity shipped off site as

(or in) product (10.)

Ending inventory (11.)

Quantity of ending inventory

that is NPO (11.1)

Total NPO generated (12.)

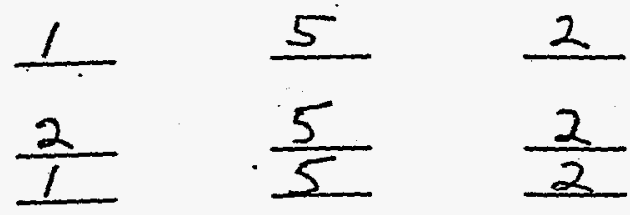

Output Options as a whole
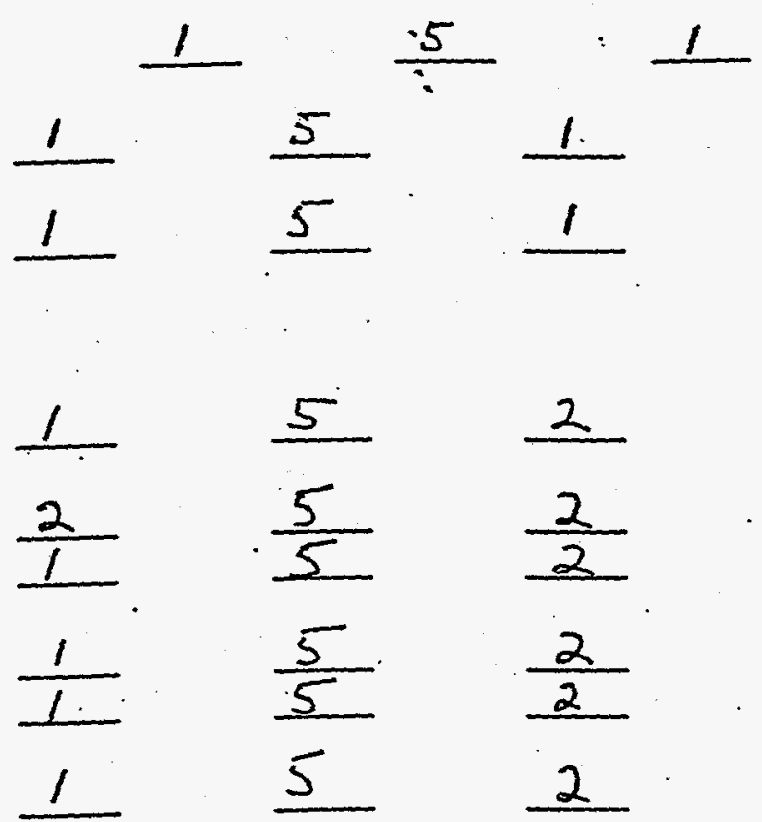

\section{Pollution Prevention Activities}

Has any pollution prevention method been employed to reduce the quartity of this substance during (1995)relative to 1994 levels? If "yes", fill in table. (26.)
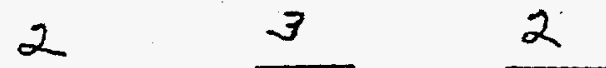

Material-Related change (changes in the amount of substance used due to substitution of other non-listed sutistance) (26.1)
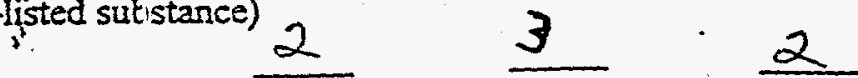

Reformulation or redesign of product (resulting in the reduction of substince generated) (26.2)

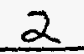

3

Process or procedure modifications (using existing equipment to reduce substance generated) (26.3) 
Equipment or technology modifications

Public

Facility

State Regulators

(using new equipment or technology to reduce substance generated) (26.4)
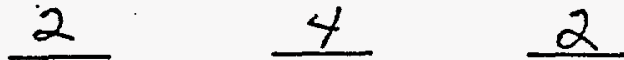

Improved operations (due to

housekeping, training, material

handling or inventory control to reduce

substance generated) (26.5)

2

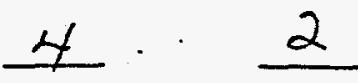

Miscellaneous

describe
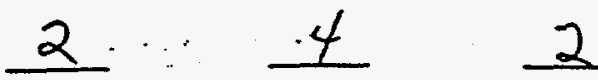

Pollution Prevention Activitie:; as a whole
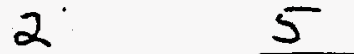

2

Facility-Level Substance-Specific Pollution Prevention Progress

Percent reduction (4.)
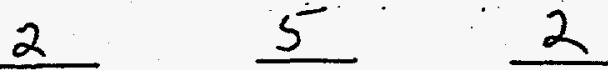

Ton Evans

Name of person(s) completing the forns

\section{$7 / 22 / 98$ \\ Date completed}




\section{INTENTIONALLY BLANK}


SETTION 9. FACLTYLLEVEL SUESTHNCE.SPECATC INFOAMATION

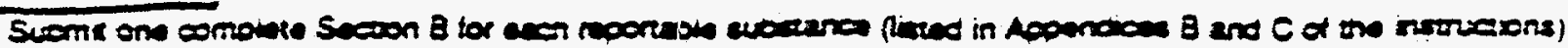

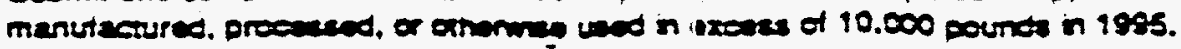

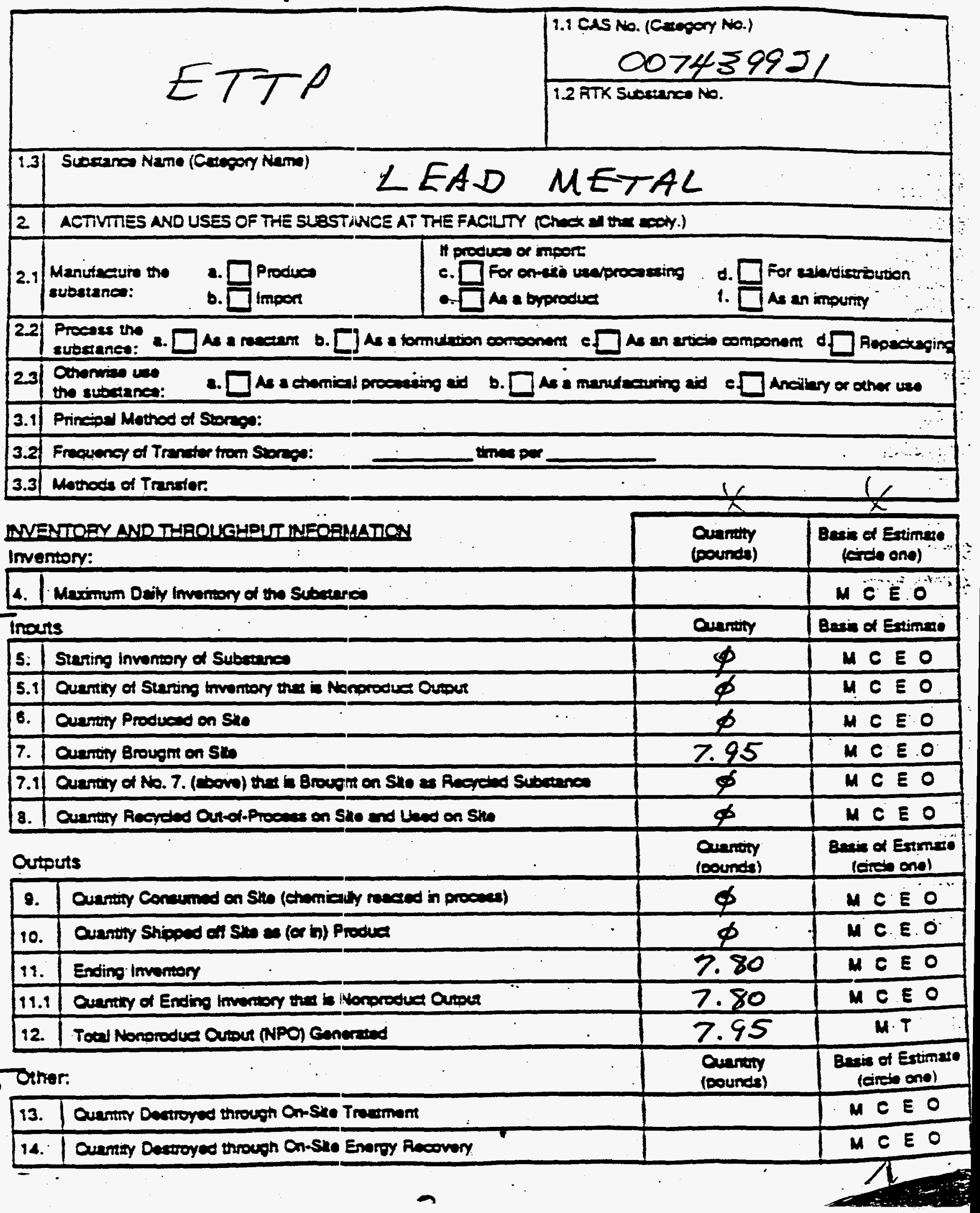




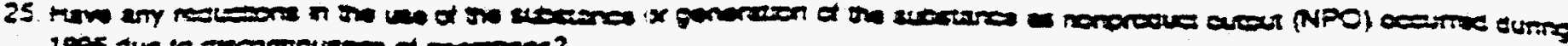

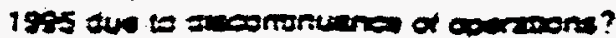

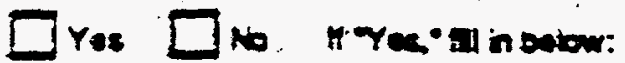

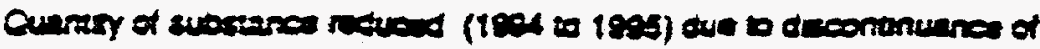

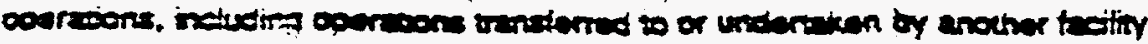

\begin{tabular}{|c|c|}
\hline 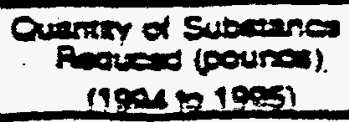 & $\begin{array}{l}\text { Eave } \\
\text { Et of } \\
\text { Enmote }\end{array}$ \\
\hline & \\
\hline
\end{tabular}

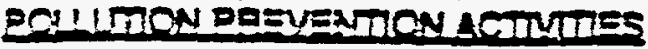

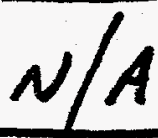

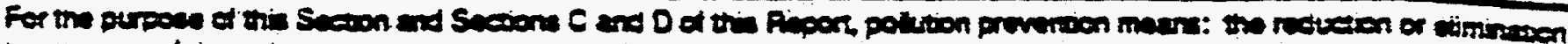

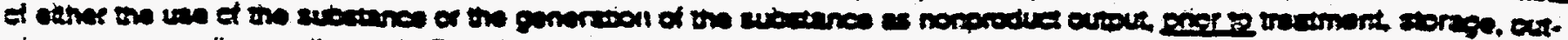

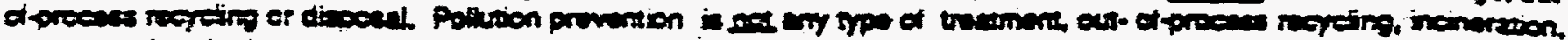

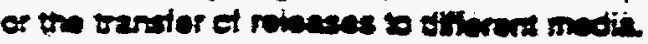

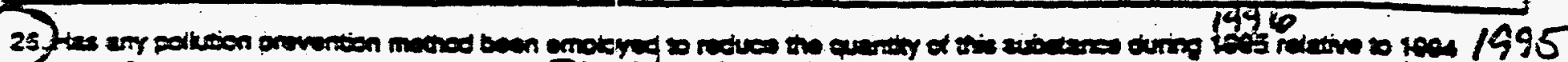
levels?

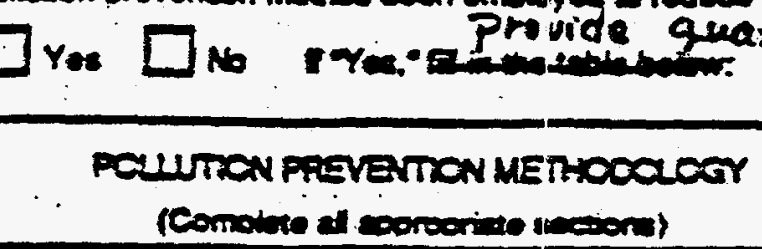

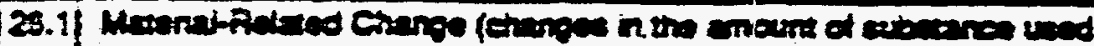

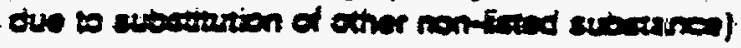

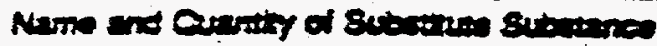

$$
\text { castratas }
$$

)

b) $\frac{\cdots}{\cdots}$

b) $\frac{\cdots}{\cdots}$

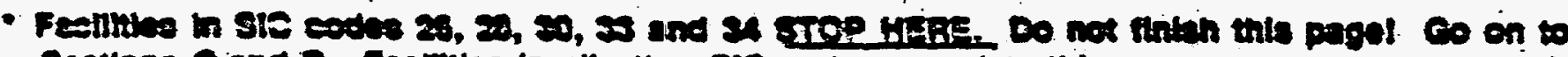

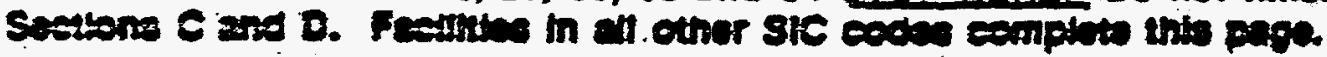
i995 to 1996

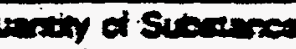

Pocheos (pourste) Anes o 18:3)

Qnis

of Exiniso

$M \in E$ -

\section{: .}

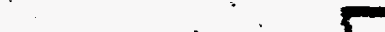

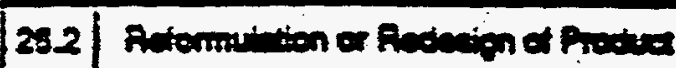

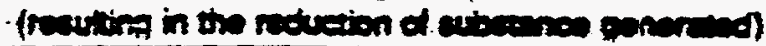

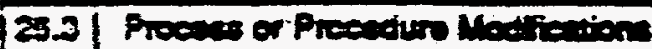

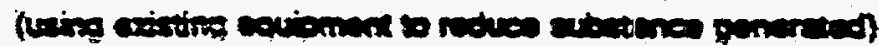

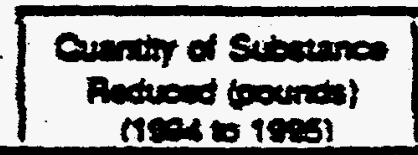

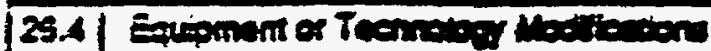

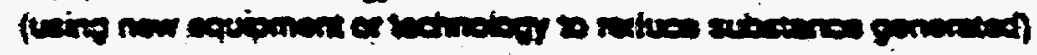

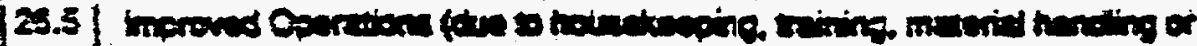

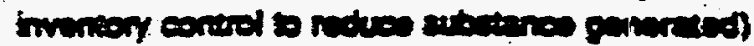

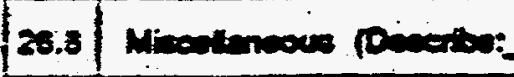

.

Bnat.

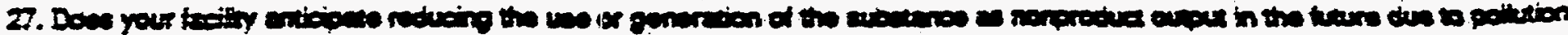

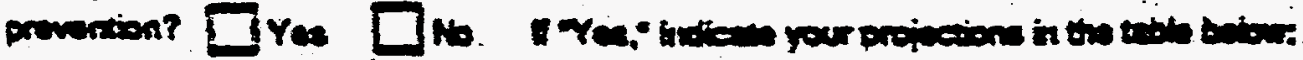

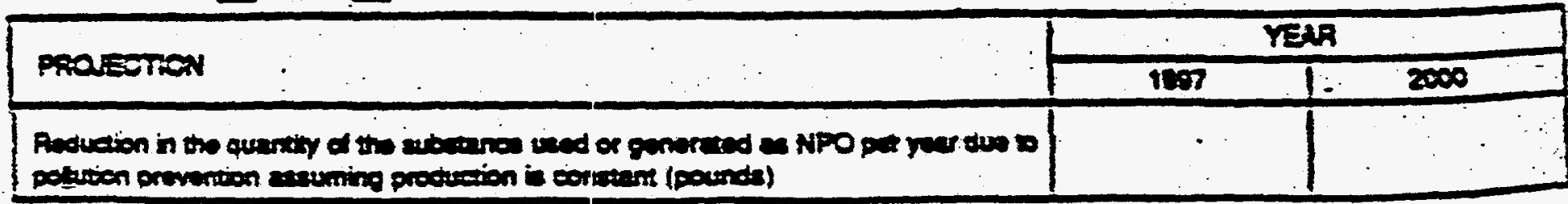




\section{New Jersey Form S \\ ETTP LEAD METAL}

5.0 Starting Inventory of Substance on Site: For purposes of the production unit covered by this report, the starting inventory is assumed to be ZERO; i.e., lead in offsite waste incinerated during the year is assumed to have beten received during the same year. The Form $R$ further addresses activities involving lead that are unrelated to the reportable lead in offsite waste.

\subsection{Starting Inventory that is NPO: Zero}

6. Quantity Produced on Site: Zero

7. Quantity Brought on Site: $7.95 \mathrm{lbs}$ of lead metal that was in waste treated at the incinerator was from offsite.

7.1 Quantity Brought on Site as Ricycled Substance: Zero

8. Quantity Recycled Out-of-Process on Site and Used on Site: Zero

9. Quantity Consumed on Site: Zero

10. Quantity Shipped off Site as (or in) Product: Zero

11. Ending Inventory: $7.80 \mathrm{lbs}$ in ash and sludge ( $0.10 \mathrm{lbs}$ lost to air, and 0.05 lost to water)

\subsection{Quantity of Ending Inventory that is Nonproduct Output: $7.80 \mathrm{lbs}$}

12. Total Nonproduct Output Generated: All $7.95 \mathrm{lbs}$ considered to be nonproduct output, although there are problems applying the nonproduct definition [generated prior to treatment] to this situation. The lead metal in waste has passed through the incinerator, and the mass balance (attached) illustrates the process.

NOTE: The remaining sections of the New Jersey reporting form are Not Applicable to waste incineration and other waste treatmert activities, according to the introduction to Item $\# 26$. 


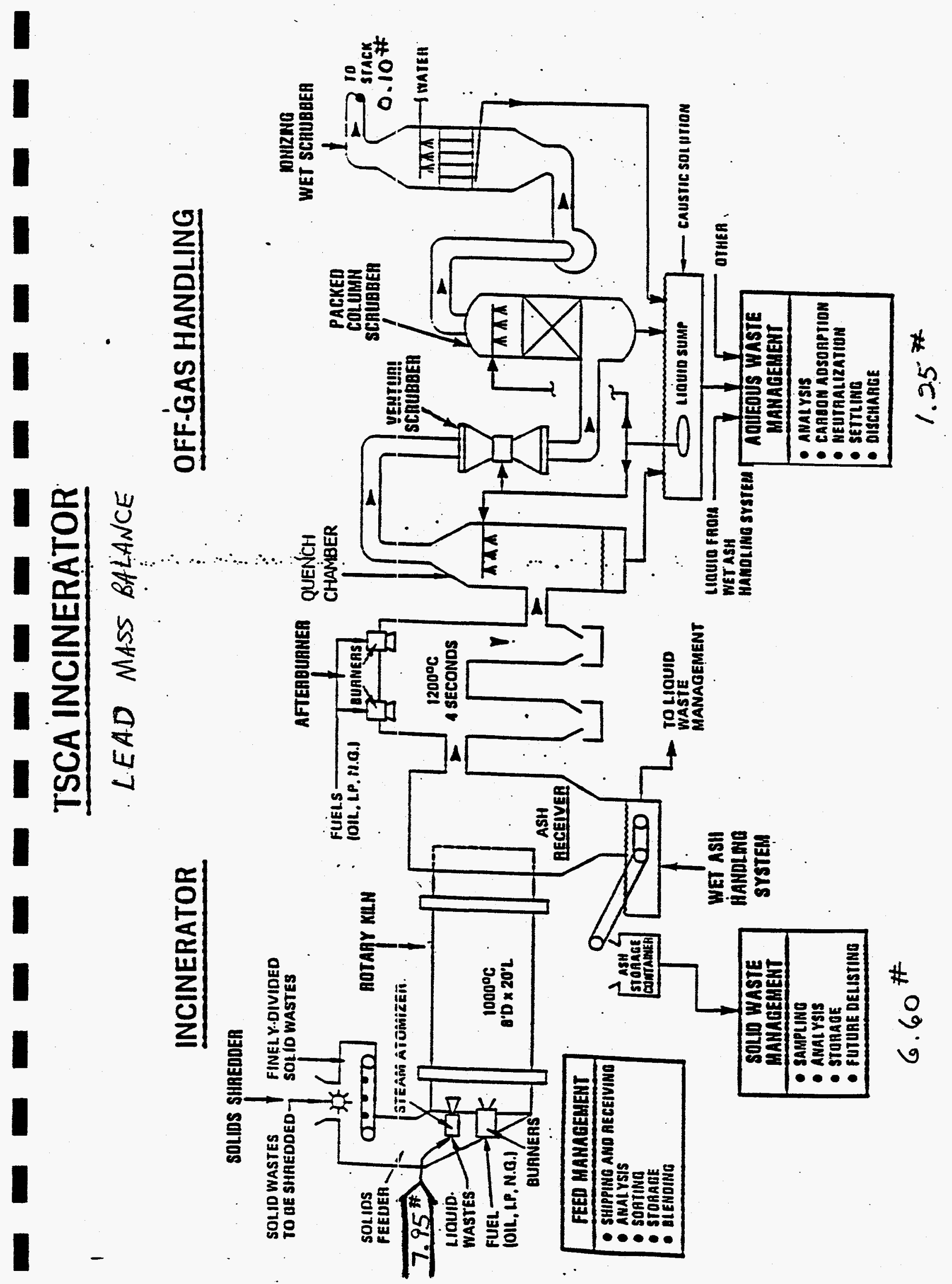


INTENTIONALLY BLANK

1 


\section{APPENDIX B}

\section{Data Package for Chromium}

B-1 
Section 1: Facility-Wide Usage of Listed Chemical

1.1 007440473

Chemical Abstract Service (CAS) Nunber (if applicable)

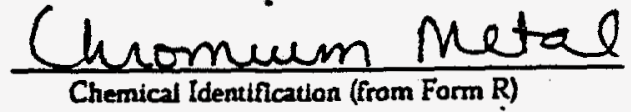

Chemical Identification (from Form $R$ )

1.2 Facility-Wide Usage of Chemical Identified in 1.1 above. Enter total amount (in POUNDS) for each applicable category. NOTE: Byproduct (item 1.2d) generally means all wastes containing the listed chemical before the waste is treated or recycied. Read the instructions carefully, however, before completing this section.

1.2a Manufactured:

1.2b Processed:

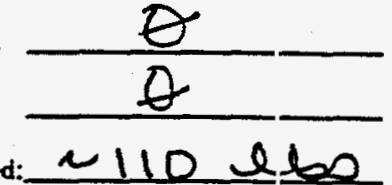

1.2c Otherwise Used: 2110 \& 1.2d Generated as Byproduct:

1.2e Shipped in or as Product:

1.3 OPTIONAL QUESTION. When the amounts reported in 1.2a. 1.2b. and $1.2 \mathrm{c}$ are added together, the sum will -- in many cases -- equal the sum of $1.2 \mathrm{~d}$ and 1.2e. In other words, the left and tight columns will often form a "materiais balance." the two columns are not in approximale balance. you may use this block to explain why. Mark all the reasons that apply, or indicate the number of pounds in the :ippropriate block below. (1.e: 4,000 Chemical was held in inventory).

Chernical was recycled on site. 109 l 10 Chemical was consumed or transformed.

Chemical was held in inventory. Chemical is a compound.

Other (explain):

\section{Welded to a ruetal}

I.4 DPTIONAL QUESTION: Did anything ncn-routine occur at your facility during the reporting year which affected the data reported? YES NO If YES, you may' use this space to comment:

\section{Section 2: Chemicals Used in Waste Treatment Units}

2.1 Is this chemical used to treat waste or control pollution? YES_X No

If YES, enter the quantity of chemical code for the amount used to treat waste or control pollution:

OPTIONAL .- You may enter the amount:

Section 3: TURA Report on Production (Init\#: (Enter * from the Form S Cover Sheet.)
3.1 Base Year:
$\longrightarrow$
3.2 Quantity of Chemical Code: $|A|$
3.4 Byproduct Reduction Index:
3.5 Emissions Reduction Index:

3.3 Toxics Use Reduction Techniques Code:
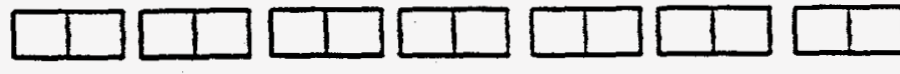

If there has been a change from one reporinis year to the current year in a (1) base year. andor (2) estimating methods (that significanty alter previously reported data) far this PRODUCTION UNIT REPORT. describe the change: 


\section{Section 4}

\section{Production Unit}

$\# 01$

\section{Process Description:}

Only identified one process as ORIL. Welding at ORNL is conducted by Plant and Equipment Division and MK Ferguson. Maintenance (ie repairing a broken pipe), construction, and fabrication captures the welding activities at ORNL. The welding rods contain $-17 \%-22 \%$ chromium. ORNL otherwise used $\sim 110$ pounds $(-500 \mathrm{lbs}$ of rods $\mathrm{X} 0.22=110 \mathrm{lbs})$ of chromium. For purposes of this report only accounted for chromium used for welding activities in CY97.

\section{Product Description:}

Welded metal by Plant and Equipment Division and MK Ferguson. Maintenance (ie repairing a broken pipe), construction, and fabrication captures the welding activities at ORNL.

\section{Unit of Product:}

Pounds of chromium used via a welding rod in a calender year

Production Process Step Information:

Welding CC-09

\section{Chemical:}

Chromium Metal

CAS No. 007440473 


\section{TURA Report - Form S}

\subsection{CAS No.}

007440473

\section{Chemical Identification}

Chromium

\section{$1.2 \mathrm{a}$}

0

\section{$1.2 \mathrm{~b}$}

0

$1.2 \mathrm{c}$

Only identified one process as ORNL. Welding at ORNL is conducted by Plant and Equipment Division and MK Ferguson. Maintenance (ie repairing a broken pipe), construction, and fabrication captures the welding activities at ORNL. The welding rods contain $\sim 17 \%-22 \%$ chromium. ORNL otherwise used -110 pounds ( $\sim 500 \mathrm{lbs}$ of rods X $0.22=110 \mathrm{lbs})$ of chromium. For purposes of this report only accounted for chromium used for welding activities in CY97.

\section{$1.2 \mathrm{~d}$}

Chromium to air from welding activities

HAP emission factors for Welding Operations indicates that (electrode type $=\mathrm{E} 316$ ) $5.22 \mathrm{E}-1 \mathrm{lb}$ $\mathrm{Cr} / 1000 \mathrm{lb}$ electrode.

$(5.22 \mathrm{E}-\mathrm{ll} \mathrm{lb} \mathrm{Cr} / 1000 \mathrm{lb}$ electrode $)(5100 \mathrm{lb}$ electrode $)=0.261 \mathrm{lbs}$ or $\sim 1 \mathrm{lb}$

\subsection{Optional Question}

$109 \mathrm{lbs}$ of chromium was welded to the metal.

\subsection{Did anything non-routine occur...}

No 
2.1 Is the chemical used to treat waste or control pollution

No

Section 3 Production Unit \#01

\subsection{Base Year}

Have never exceeded a reporting threshold for chromium.

\subsection{Quantity of Chemical Code}

A ( $0-5000 \mathrm{lbs})$ Otherwise used $\sim 110 \mathrm{lbs}$ of chromium.

\subsection{Byproduct Reduction Index}

$\mathrm{BRI}=100 * \mathrm{~A}-\mathrm{B} / \mathrm{A}$

$A=$ Byproduct quantity in the base year/\# of units of product produced in the base year

$B=$ Byproduct quantity in the repcrting year/\# of units of product produced in the reporting year

$B R I=0$ (never exceeded a threshold)

\subsection{Emission Reduction Index}

$\mathrm{ERI}=100 * \mathrm{~A}-\mathrm{B} / \mathrm{A}$

$A=$ Emission quantity in the base year/\# of units of product produced in the base year

$\mathrm{B}=$ Emission quantity in the reporting year/\# of units of product produced in the reporting year

ERI $=0$ (never exceeded a reporting threshold) 


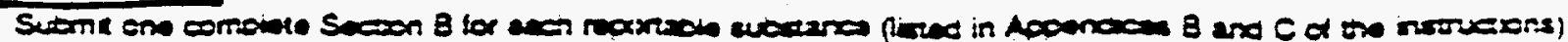

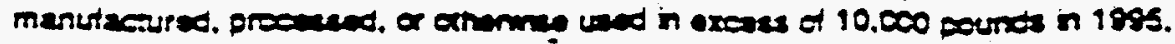

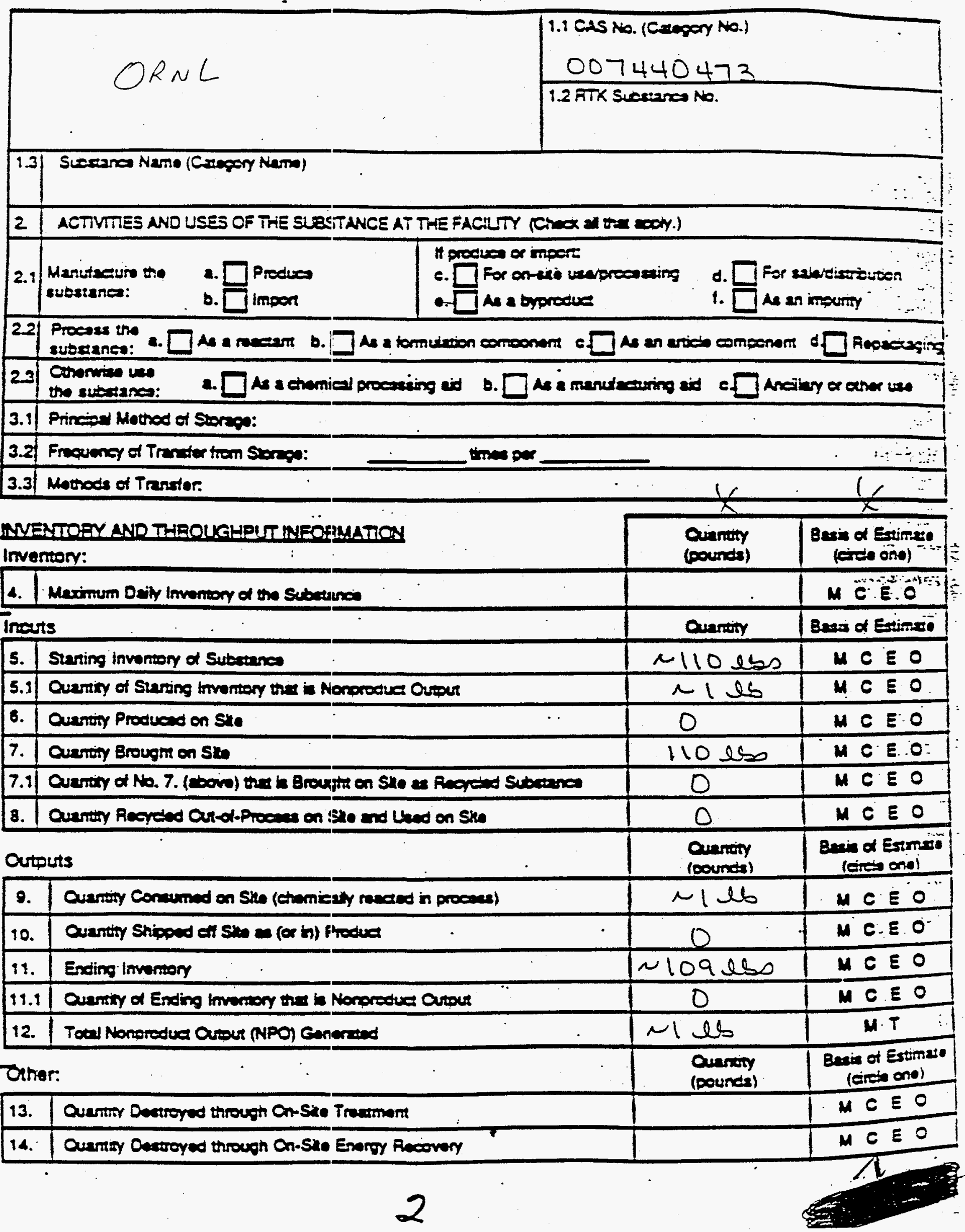




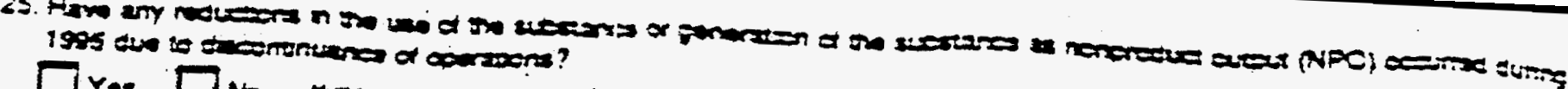

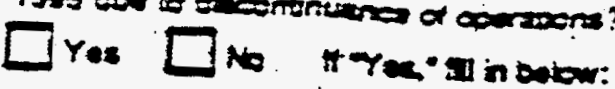

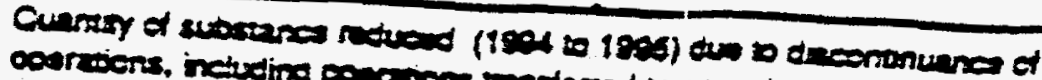

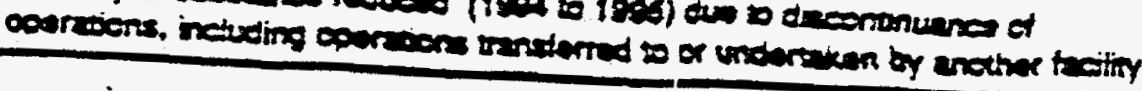

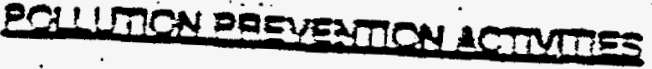

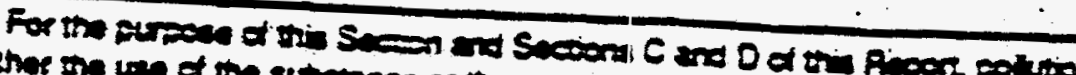

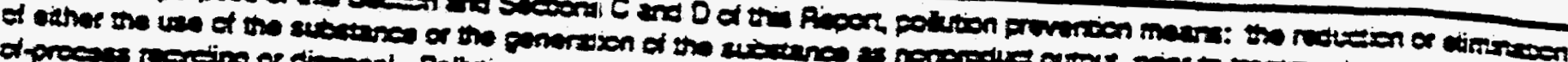

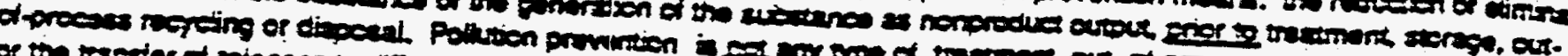

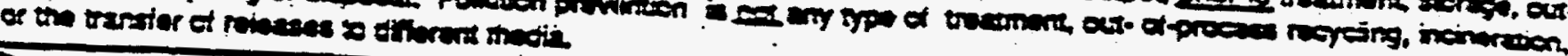

25

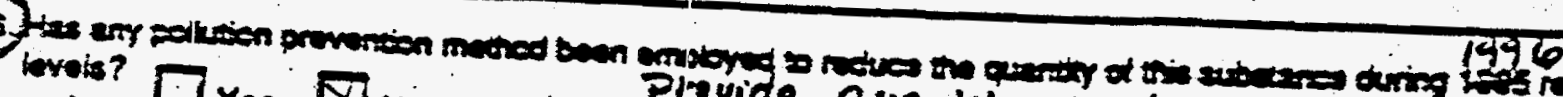

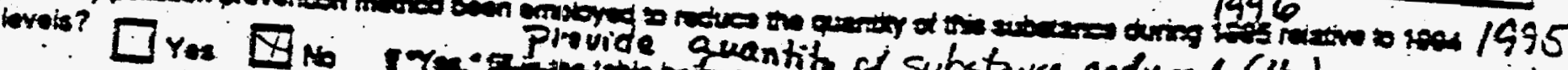

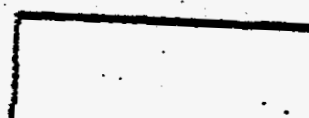

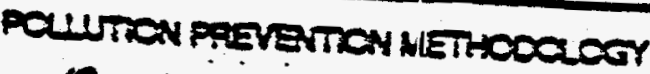

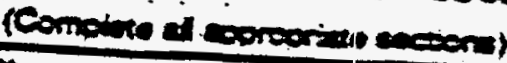

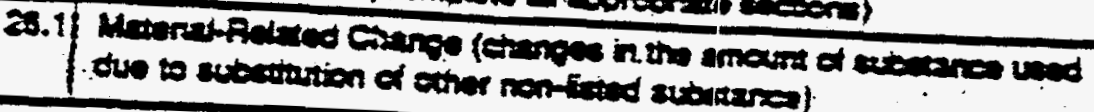

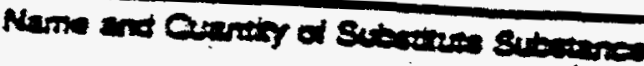
i995 to 1995

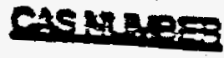
a)
Sidraxc5
).
e)

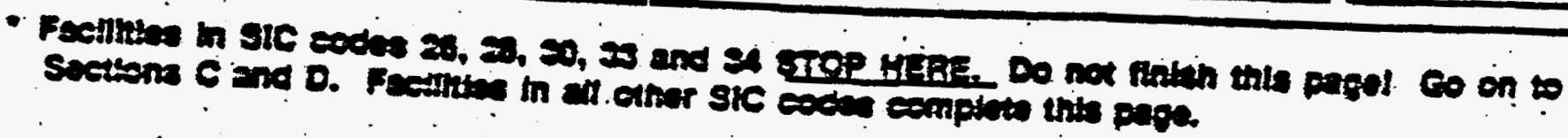

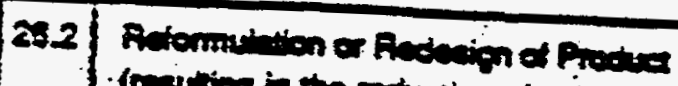

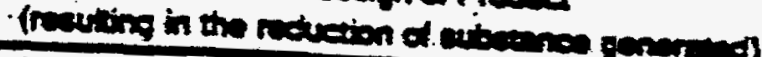

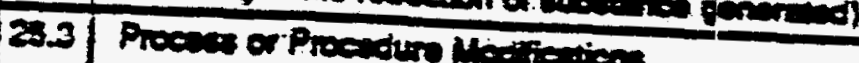

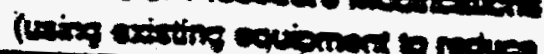

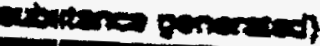

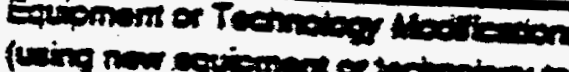

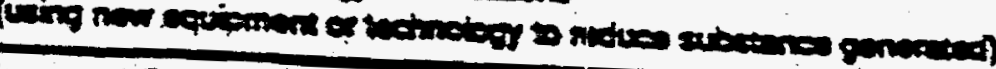

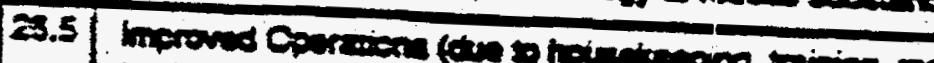

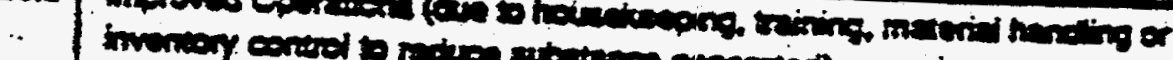

pmerted

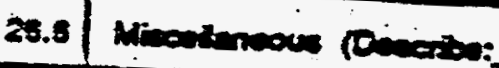

\begin{tabular}{|c|c|}
\hline 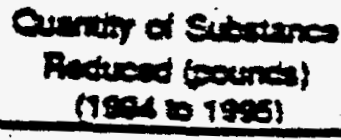 & 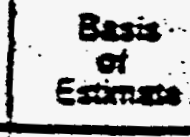 \\
\hline & $M E E 0$ \\
\hline & Mese \\
\hline & 1uc $=0$ \\
\hline & in $<\leq 0$ \\
\hline & we $=0$ \\
\hline
\end{tabular}

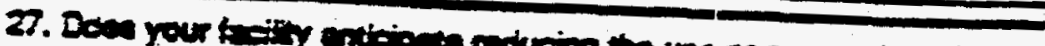

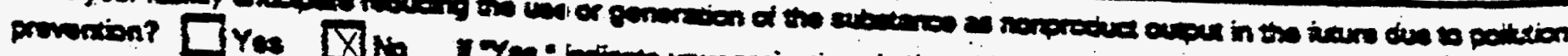

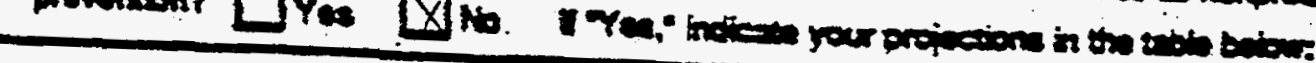

PRarenow

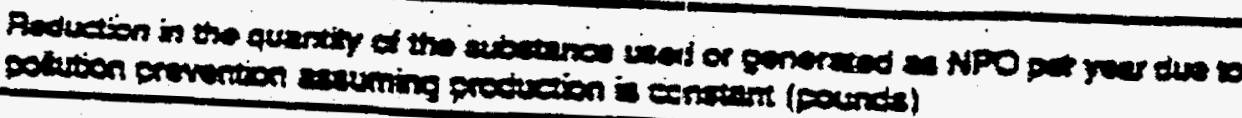

\begin{tabular}{|c|c|}
\hline \multicolumn{2}{|c|}{ YEAR } \\
\hline $18 \cdot 7$ & 2000 \\
\hline • & \\
\hline
\end{tabular}




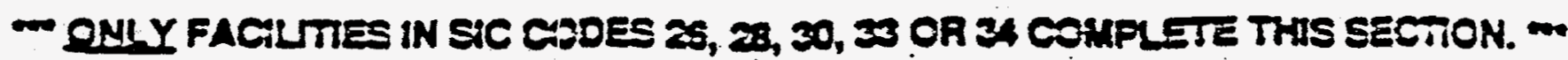

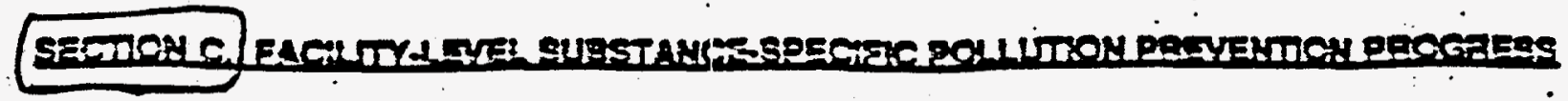

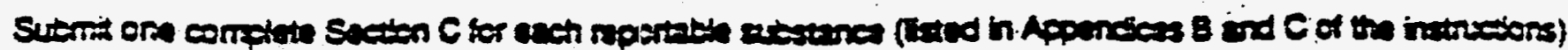

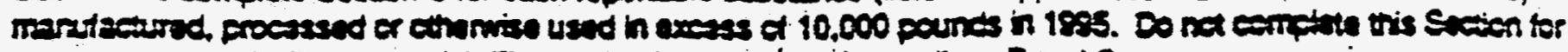

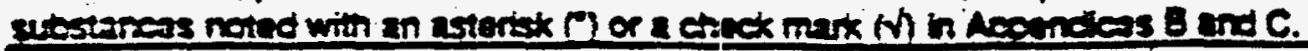

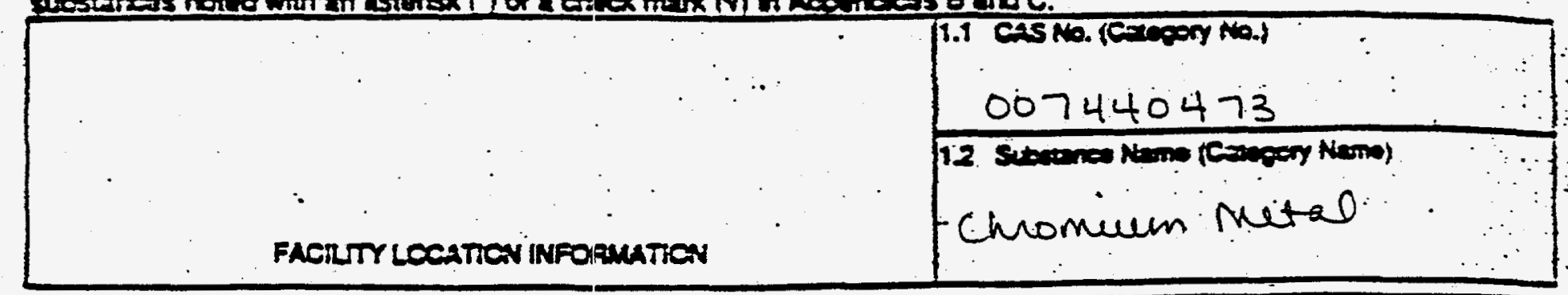

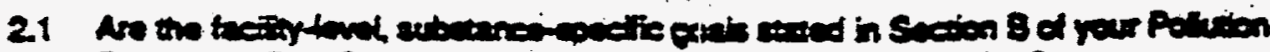

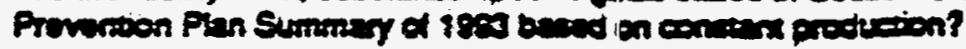

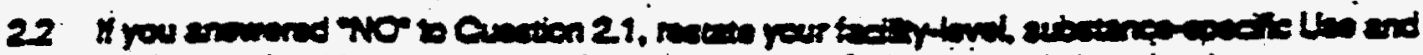

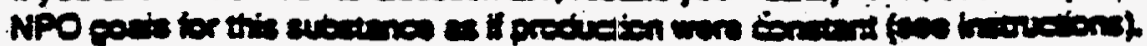

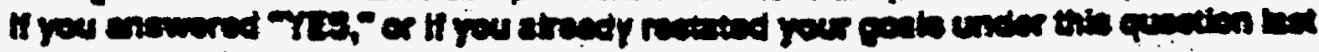

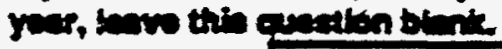

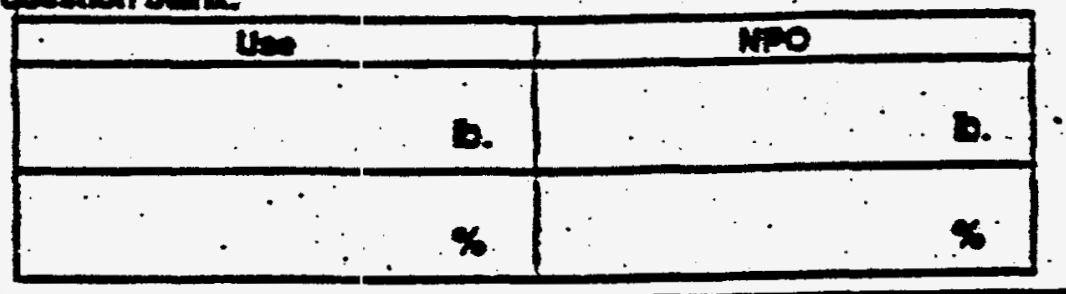

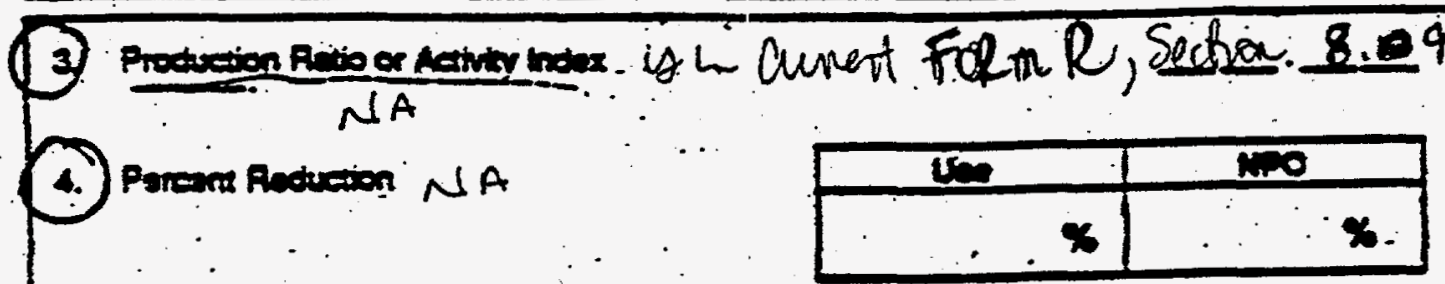

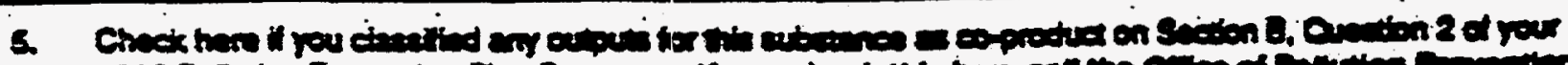

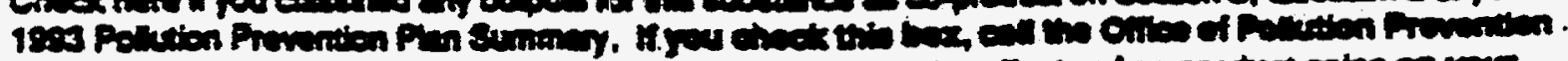

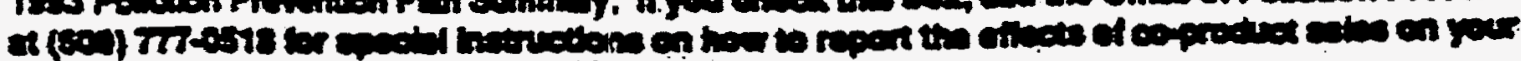

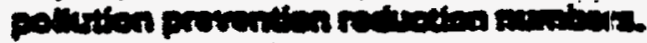

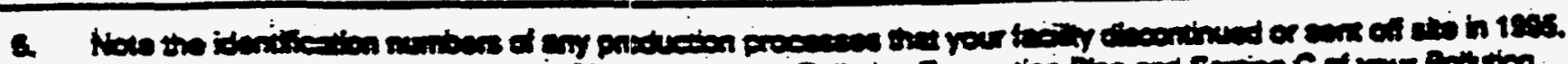

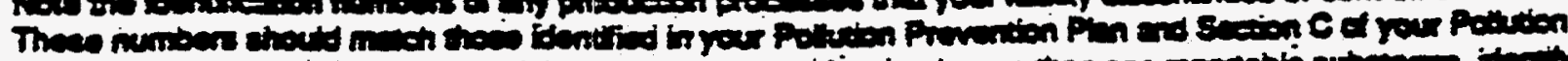

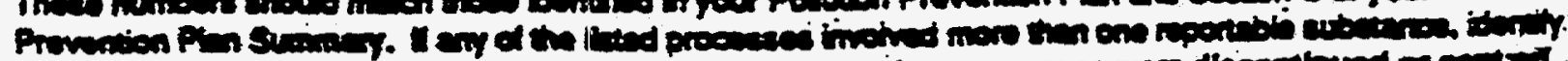

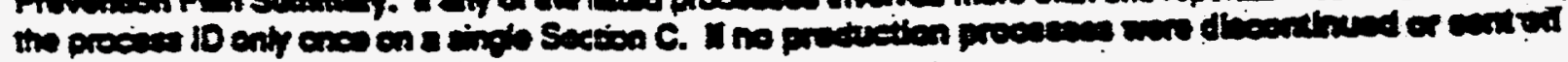

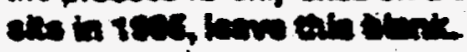

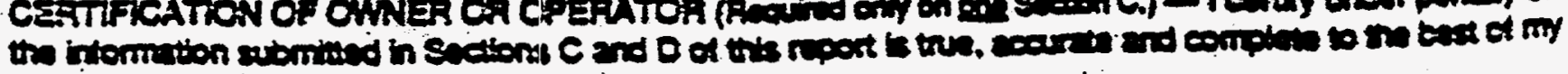
frowindos.

Simare Date. mano. 


\section{New Jersey Form S}

\subsection{Starting Inventory of Substance on Site:}

Only identified one process as ORNL. Welding at ORNL is conducted by Plant and Equipment Division and MK Ferguson. Maintenance ( ie repairing a broken pipe), construction, and fabrication captures the welding activities at ORNL. The welding rods contain $\sim 17 \%-22 \%$ chromium. ORNL otherwise used $\sim 110$ pounds $(-500 \mathrm{lbs}$ of rods $\mathrm{X} 0.22=110 \mathrm{lbs})$ of chromium. For purposes of this report only accounted for chromium used for welding activities in CY97. Did not inventory the ch:omium that is a component of stainless steel. To actually inventory all of the chromium on site (structural steel) would be an impossible task.

\subsection{Starting Inventory that is N'O}

The only amount of starting inventory that is Nonproduct Output is the chromium fumes from welding activities. HAP emission factors for Welding Operations indicates that (electrode type = E316) $5.22 \mathrm{E}-1 \mathrm{lb} \mathrm{Cr} / 1000 \mathrm{lb}$ electrode.

$(5.22 \mathrm{E}-1 \mathrm{lb} \mathrm{Cr} / 1000 \mathrm{lb}$ electrode $)(500 \mathrm{lb}$ electrode $)=0.261 \mathrm{lbs}$ or $\sim 1 \mathrm{lb}$

\section{0 . Quantity Produced on Site}

No chromium was produced on Site:

\subsection{Quantity brought on Site}

Entire amount of chromium was brought on site (110 lbs).

\subsection{Quantity of No. 7 that was brought on Site as Recycled Substance}

None. 


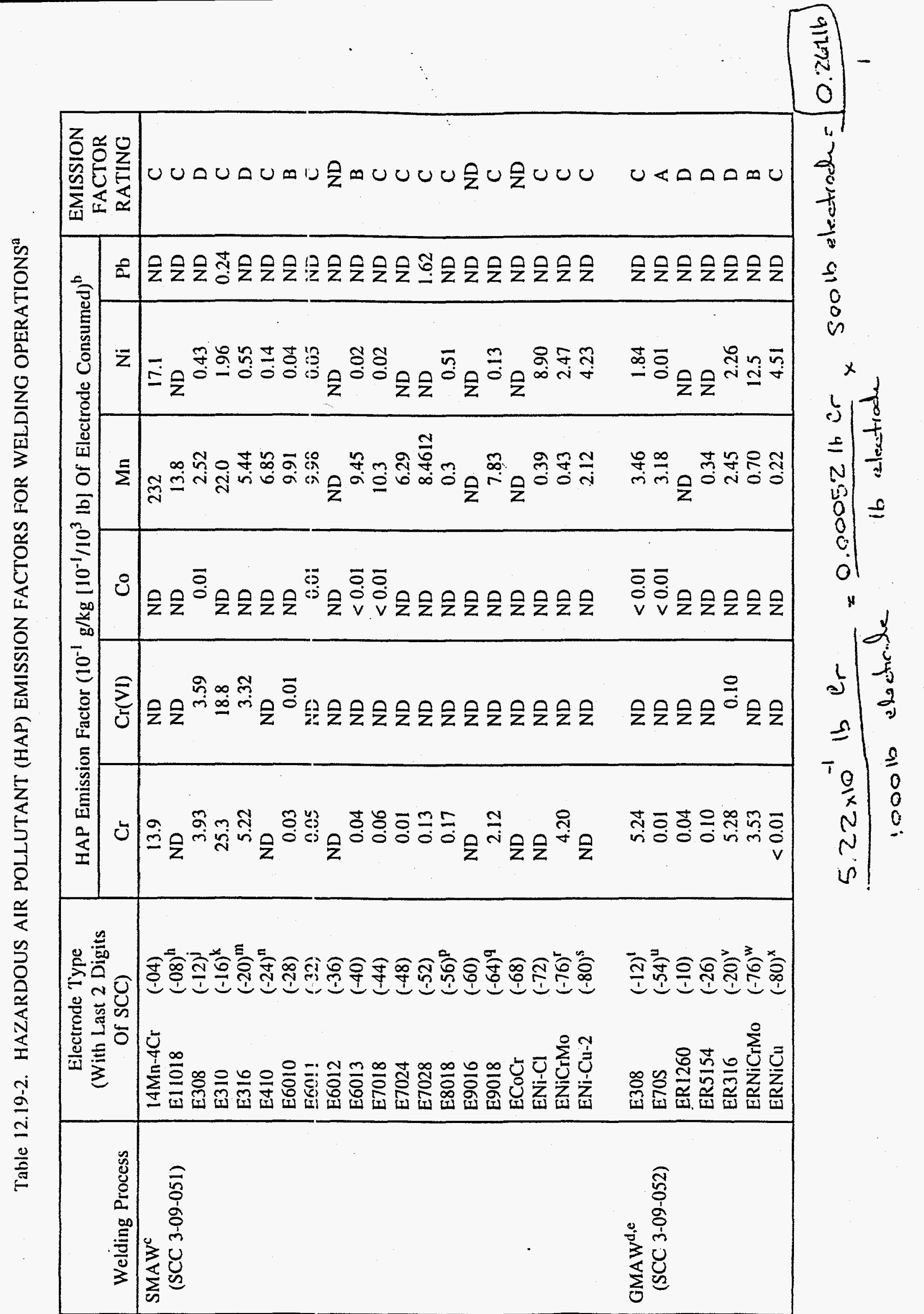


8.0 Quantity recycled Out-of-Process on Site and used on Site

None.

9.0 Quantity Consumed on Site

$\sim 1 \mathrm{lb}($ see 5.0$)$

10.0 Quantity Shipped off Site as Product

None.

11.0 Ending Inventory

Starting inventory $110 \mathrm{lbs}-1 \mathrm{lb}$ to air $=109 \mathrm{lbs}$

11.1 Quantity of Ending Inventory that is NPO

None.

12.0 Total NPO Generated

$1 \mathrm{lb}($ see 5.0$)$

26.0 Has any Pollution Prevention method been employed ...

No.

27.0 Does your facility anticipate reducing NPO

No. 


\section{Section C}

\subsection{CAS No.}

007440473

\subsection{Substance Name}

Chromium

\section{Production Ratio}

Have never reported on the substance so cannot calculate a production ratio.

\section{Percent Reduction}

Have never reported on the substance so cannot calculate a percent reduction. 


\section{INTENTIONALLY BLANK}

1 


\section{TURA REPORT - COVER SHEET}

Toxics Use Reduction Act - Form S Cover Sheet

\section{Section 1: General Information}
1.1 ATTACH MAILING LABEL with facility name address \& DEP Facility Identification Number
ATTACH CORRECTED MAILING LABEL or enter facility, name \& address

1.2 Are you making a trade secret claim for any of the information submitted in this COVER SHEET and/or Form S(s)? YES $\mathbf{X}$ _NO

1.3 If YES, attach a statement substantiating the claim. Is this cripy:

_.___anitized Unsanitized

1.4 This report is being filed for reporting year: 1997

\section{Section 2: Certification Statement}

2.0 This CERTIFICATION STATEMENT shouid be signed after all the forms have been completed.

I hereby certify that I have reviewed this and all atached documents and that, to the best of 'my knowledge and belief, the submitted information is true and complete and that the amounts and values in these documents are accurate based on measurements and/or reasonable estimates using data available to the preparers of these documents. I am aurare that there are significant penalties for willful or intentional submission of false or incomplete information.

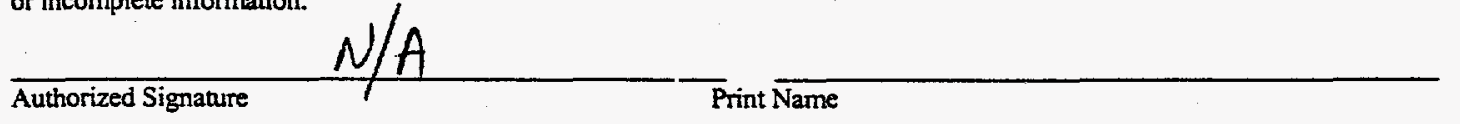

Position/Title

Date

\section{Section 3: Chemicals Previously Reported That Are ivot Reportable This Year}

3.0 OPTIONAL QUESTION. In this section, you may provide information on any chemical reported last year that is not subject to reporting this year. If you substituted a non-listed chemical for a TURA chemical, you may identify the substitution, as well.

The codes to explain why the chemical is not reportable are: [1] Chemical Below Threshold But $>0$ [2] No Chemical Usage in Reporting Year [3] Chemical Substitution [4] Chemical Eliminated (No Substitution) [5] Decline in Business [6] Other (Explain below in the additional comments section). Enter all the codes that apply.

3.1

CAS \# of Chemical Not Reportable (if applicable)

Chemical Name

Explanation of Why the Chemical Is Not Reportable. (Enter Code):

CAS \# of Chemical Substituted for TURA Chemical

Chemical Name

3.2

CAS \# of Chemical Not Reportable (if applicable)

Chemical Name

Explanation of Why the Chemical is Not Reportable. (Enter Code):

CAS \# of Chemical Substituted for TURA Chemical

Chemical Name

Additional Comments: 
$D y-120(A n)$ FACILITY NAME

\section{ORM S COVER SHEET (continued)}

\section{Section 4: Facility-Wide Listing of Production Units}

A PRODUCTION UNIT is best thought of as the combination of the process (or activities) used to produce a product or service and the product or service. In this block, please identify the PRODUCTION UNITS at the facility, tten use the production unit number to report on chemical usage in the attached Form S. If there is a substantial change in a PRODUCTION UNTT from one reporting year to the next, the PRODUCTION UNIT must be given a new, unique number.

Production

Unit \#: 01
This Production Unit (Pro:ess/Product Combination) is: The Same As Reported Last Year

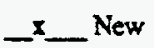

Describe the Process: Building 9201-5N has two primary operations; (1) the machining operations in which a cast, forged, or formed shape is machined, e.g., aluminum alloys, magnesium alloys, bronze...and (2) plating operations, i.e., plating various metals onto substrates. For the purpose of this report our attention is focused on operations which includes electropiating finishing and metal cleaning. Major equipmert includes tanks, and rectifiers. The current process simply involves taking a given part, zinc plate it and dipping it into a chromate solution ( $-35 \%$ sodium bichromate, and $-55 \%$ formic acid), rinse with de-ionized water and air dry. The solution and rinsate are collected in appropriate drums and is sent to waste management for treatment/disposal.

Describe the Product: Th: zinc plated and chromate conversion coating of high strength steel parts.

Enter the four-digit SIC CJde(s) that best describe(s) the product:

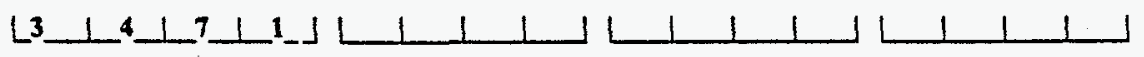

Describe the Unit of Product:_Number of plated parts.

(Please specify if the Unit of Product has been changed since the previous reporting year.)

\section{PRODUCTION PROCESS STEP INFORMATION FOR THIS PRODUCTION UNTT}

Enter the production process code(s) to identify the process step(s) that involves a TUR-reportable chemical(s) as an input, output or throughput. (See the reporting gr.idance document for the list of production process codes and instructions on when a given code needs to be listed.)

1. $\lfloor\mathbf{A} \perp A \perp 1 \perp 81$

2.

3.

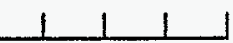

4.

5.

6. L

7.

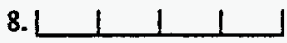

List below, the TURA-reportable chemicals asso:iated with the production unit. If a chemical is associated with ALL the process steps identified above, check the ALLbliock. If the chemical is associated with some but not all of the process steps, put the relevant code(s) (from above) next to the chemical

Chemical(s)

Production Process

Sodium Bichromate

Chemical Name

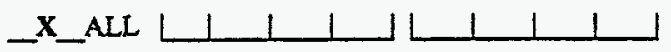

010588019

CAS\#

Carboxylic Acid

Chemical Name

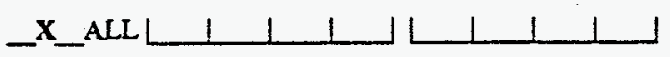

000064186

CAS\#

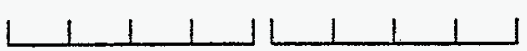

Chemical Name

ALL

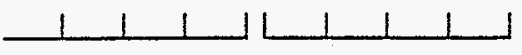

$\overline{\mathrm{CASH}}$

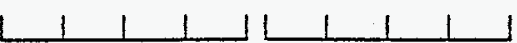


ORM S COVER SHEET (Continuation Page, for use, if necessary)

\section{Section 4: Facility-Wide Listing of Production Units}

roduction

nit \#: N/A 7

\section{PRODUCTION PROCESS STEP INFORMATIOIV FOR THIS PRODUCTION UNIT}

Enter the production process code(s) to identify the process step(s) that involves a TUR-reportable chemical(s) as an input, output or throughput. (See the reporting guidarce document for the list of production process codes and instructions on when a given code needs to be listed.)
1. $\perp 1 \perp+1$
2. L 111
3. 1111
4. $L 11111$
5.L
6.

7.L 1111

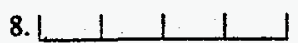

List below, the TURA-reportable chemicals associaterl with the production unit. If a chemical is associated with ALL the process steps identified above, check the All block. If the chemical is associated with some but not all of the process steps, put the relevant code(s) (from above) next to the chemical.

\section{Chemical(s)}

Chemical Name

\section{CAS\#}

Chemical Name

\section{$\overline{\text { CAS\# }}$}

Chemical Name

\section{CAS\#}

Chemical Name

\section{CAS\#}

Chemical Name

\section{$\overline{\text { CAS\# }}$}

Chemical Name

\section{Production Process(es)}

ALL

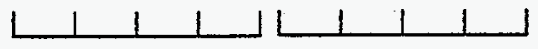

ALL L I 1 111111

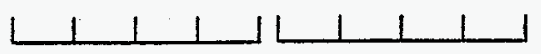

ALLL $1 \quad 1 \quad|L| 1 \mid$

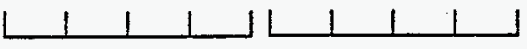

ALL L $1111 / 11111$

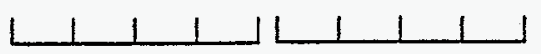

ALL L $L 111 / 1111$

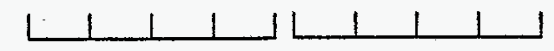

ALLL $\perp \perp 111111$

\section{CAS\#}


Page 4 of 5

\begin{tabular}{|l|l|}
\hline Facility Name: $Y-12 P(A N T$ & Facility D\# \\
\hline Chemical: ChROMIUM & Reporting Year: 1997 \\
\hline
\end{tabular}

\section{Massachusetts Department of Environmental Protection} TURA REPORT - FORM S

Toxics Use Reduction Act - Chemical Usage Facility-Wicie \& by Production Units iection 1: Facility-Wide Usage of Listed Chemical

$1.1 \quad$ No90

Chemical Abstract Service (CAS) Number (if applicable)
Chromium Compounds

Chemical Identification (from Form $R$ )

1.2 Facility-Wide Usage of Chemical Identified in 1.1 above. Enter total amount (in POUNDS) for each applicable category.

NOTE: Byproduct (item 1.2d) generally means all wastes cuntaining the listed chemical before the waste is treated or recycied. Read the instuctions carefully, however, before completing this section.

1.2a Manufactured:

0

0

30

$1.2 \mathrm{c}$ Otherwise Used:
$1.2 \mathrm{~d}$ Generated as Byproduct:

1.2e Shipped in or as Product: 0.13

1.3 OPTIONAL QUESTION. When the amounts reported in $1.2 \mathrm{a}, 1.2 \mathrm{~b}$, and $1.2 \mathrm{e}$ are added together, the sum will - in many cases - equal the sum of $1.2 \mathrm{~d}$ and 1.2e. In other words, the left and right columns will often form a "materials balance." If the two colurms are not in approximate balance, you may use this block to explain why. Mark all the reasons that apply, or indicate the number of pounds in the appropriate hlock below. (i.e.: 4,0000 Chemical was held in inventory).

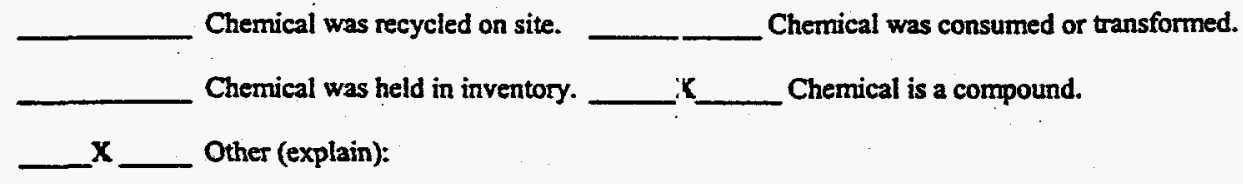

Historically to present this chemical has not exceeded the reportable threshold.

1.4 OPTIONAL QUESTION: Did anything non-routine occur at your facility during the reporting year which affected the data reported? YES _ _ _ NO If YES, you may use this space to romment:

\section{Section 2: Chemicals Used in Waste Treatment Units}

Is this chemical used to treat waste or control pollution?

- YES _ $\mathbf{X}$ _ NO

If YES, enter the quantity of chemical code for the amount used to treat waste or control pollution:

OPTIONAL - You may enter the amount:

Section 3: TURA Report on Production Unit \#: 01 (Enter \# from the Form $S$ Cover Sheet.)

3.1 Base Year: _1997

3.2 Quantity of Chemical Code: $\lfloor A\rfloor$

3.3 Toxics Use Reduction Techniques Code:

If there has been a change from one reporting year to the current year in a (1) base year, and/or (2) estimating methods (that significantly alter previously reported data) for this PRODUCTION UNIT REPORT, describe the change:
3.4 Byproduc: Reduction Index:

3.5 Emissions Reduction Index: ___ 


\begin{tabular}{|l|l|}
\hline Facility Name: $Y-12 P L A N T$ & Facility D\# \\
\hline Chemical: $C h$ ROMi um & Reporting Year: 1997 \\
\hline
\end{tabular}

Section 3: TURA Report on Production Unit \#: (Enter \# from the Form S Cover Sheet.)

3.1 Base Year: - $\quad 3.4$ Byproduct Reduction Index:

3.2 Quantity of Chemical Code: $ـ \quad 3.5$ Emission Reduction Index:

$N / K$

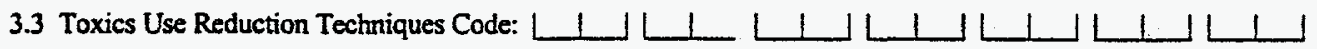

If there has been a change from one reporting year to the current year in a (1) base year, and/or (2) estimating methods (that significantly alter previously reported data) for this PRODUCTION UNIT REPORT, describe the change:

TURA Report on Production Unit \#: (Enter \# from the Form $S$ Cover Sheet) .

3.1 Base Year.

3.4 Byproduct Reduction Index:

3.2 Quantity of Chemical Code:

3.5 IEmission Reduction Index:

$N / 4$

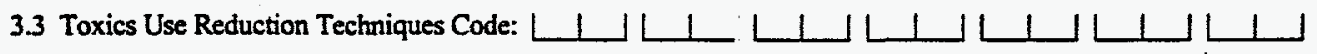

If there has been a change from one reporting year to the current year in a (1) base year, and/or (2) estimating methods (that significantly alter previously reported data) for this PRODUCTION UNIT REPORT, describe the change:

TURA Report on Production Unit \#: (Enter \# from the Form S Cover Sheet)

3.1 Base Year:

3.4 Byproducr Reduction Index:

3.2 Quantity of Chemical Code:

3.5 Emission Reduction Index:

$N / N$

3.3 Toxies Use Reduction Techniques Code: $\mid$

If there has been a change from one reporting year to the current year in a (1) base year, and/or (2) estimating methods (that significantly alter previously reported data) for this PRODUCTION UNIT REPORT, describe the change:

TURA Report on Production Unit \#: (Enter \# from the Form S Cover Sheet.)

3.1 Base Year.

3.2 Quantity of Chemical Code:

3.4 Byproduct Reduction Index:

3.5 Emission Reduction Index:<smiles>CC(C)(C)[Al]</smiles>

3.3 Toxics Use Reduction Techniques Code:

If there has been a change from one reporting year to the current year in a (1) base year, and/or (2) estimating methods (that significantly alter $m$ previously reported data) for this PRODUCTION UNIT REPOR', describe the change: 
Toxic Use Reduction Act (TURA) - Form $S$ (Massachusetts)

COVER SHEET

Section 1: General Information
1.1 Mailing Label
1.2 Making Trade Secret YES _ NO $\mathrm{x}$
1.3 _ $\mathbf{x}$ Sanitized
Unsanitized
1.4 This report is for reporting year 1997

\section{Section 2: Certification Statement}

NA (not applicable)

Section 3: Chemicals Previously Reported......

NA

\section{Section 4: Facility-Wide Listing; of Production Units}

\section{Production Unit\#: 01}

\section{Describe the Process:}

Building 9201-5N has two primary operations; (1) the machining operations in which a cast, forged, or formed shape is machined, e.g. aluminum alloys, magnesium alloys, bronze and (2) plating operations, i.e. plating various metals onto substrates. For the purpose of this report our attention is focused on operations which includes electroplating finishing and metal cleaning. Major equipment includes tanks, and rectifiers. The current process simply involves taking a given part, zinc plating and dippirg it into a chromate solution ( $-35 \%$ sodium bichromate, $\sim 55 \%$ formic acid), rinsed with de-ionized water and air dry. The solution and rinsate are collected in drums and sent to Waste Management for disposal. In summary, the process is plating of specified parts.

\section{Describe the Product:}

The product is the zinc plating and chromate conversion coating of high strength steel parts.

Four digit SIC Code : 3471 
Describe the Unit of Product:

Number of parts plated

Production Process Step Information for this Production Unit:

$1.0 \quad$ AA18

Chemical

Sodium Bichromate

Carboxylic Acid (formic)
Produrtion Process

$\times$ ALL

x ALL

\section{CAS\#}

010588019

000064186 


\section{TUFA REPORT - FORM S}

\section{Section 1: Facility-Wide Usage of Listed Chemical}

1.1 CAS\#: N090 Chemical Identification (from Form R): Chromium Compounds

1.2a. $0 \# \quad 1.2 \mathrm{~b} .0 \# \quad 1.2 \mathrm{c} .30 \# \quad 1.2 \mathrm{~d} .29 .57 \# 1.2 \mathrm{e} \quad 0.13 \#$

1.3 Optional: The sum of $1.2 \mathrm{a}, 1.2 \mathrm{~b}$, and $1.2 \mathrm{c}$ added together should equal the sum $1.2 \mathrm{~d}, \& 1.2 \mathrm{e}$ Why? The remaining estimated 0.3 \# was release to air as point source emissions. Also note "chemical is a compound", and chernical is below reporting threshold but greater than 0 .

1.4 Optional: No, for non-routine occurrence that may have affected the data reported.

Section 2: Chemicals Used in Waste Treatment Units

2.1 Is chemical used to treat waste or control pollution? No

Section 3: TURA Report on Production Unit\# 01

3.1 Base Year: $1997 \quad 3.2$ Qty. Of Chemical Code: $A$

3.4 Byproduct Reduction Index: 0; 3.5 Emissions Reduction Index: 0 \#

\subsection{Toxic Use Reduction Techniques Code: $\boldsymbol{N A}$}

Not able to use the above (3.3) due to the specified chemical/compound has been used in the past to present however in small quantities i.e. below the TRI reportable threshold, therefore this section is not applicable. 


\section{Pacie lof 3}

FE: EUSE \& FOLLUTIOH FAEYENTION FEFORT FOA ISSS

SESTON B. FACLTY.LEVE: SUSSTAYCE.SPSAFIC INFORUATOAN

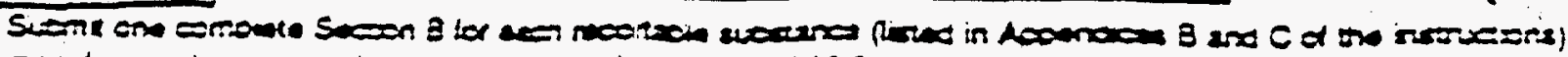

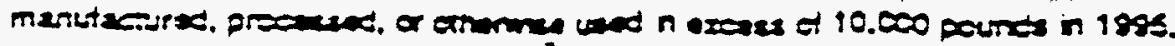

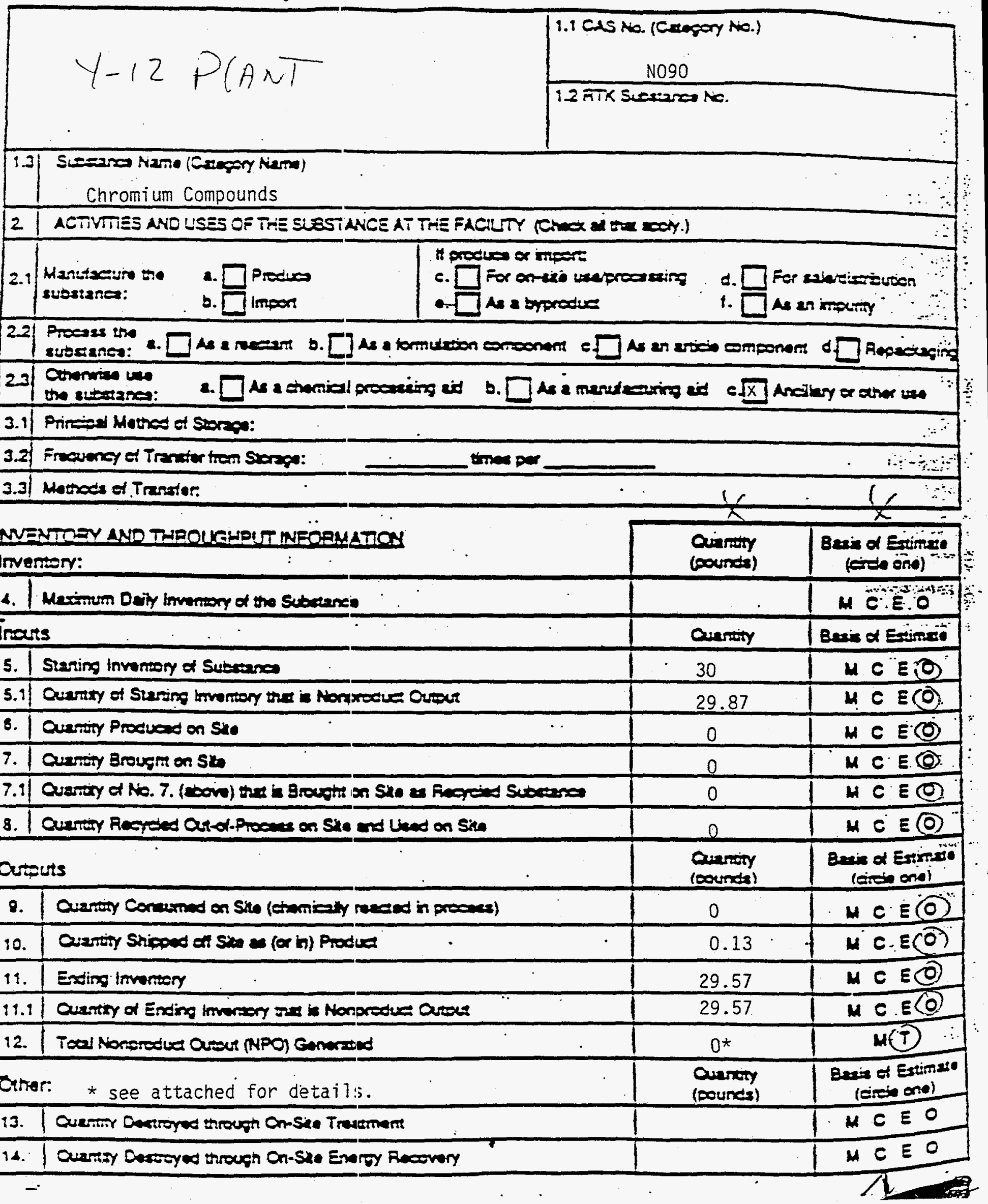




$$
2 \text { C.F } 3
$$

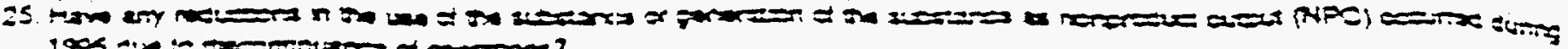

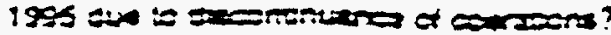

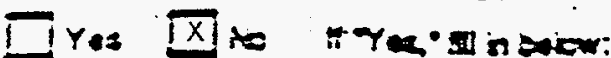

Qunfory of

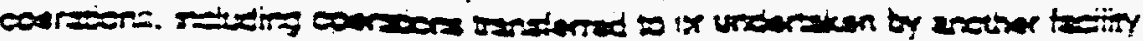

\begin{tabular}{|c|c|}
\hline 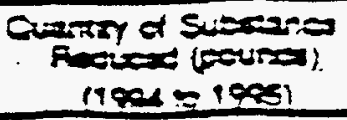 & $\begin{array}{l}\text { Exts } \\
\text { Et } \\
\text { Enineos }\end{array}$ \\
\hline & $M C$ \\
\hline
\end{tabular}

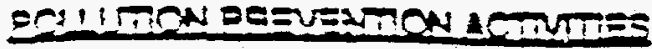

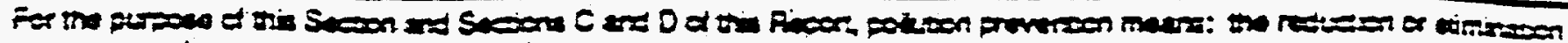

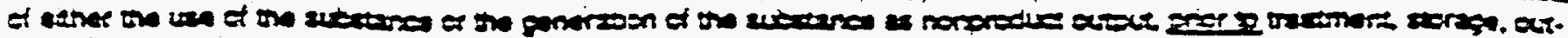

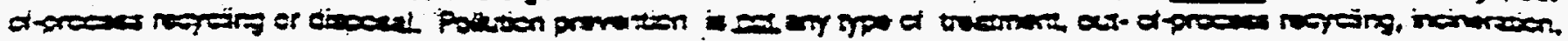

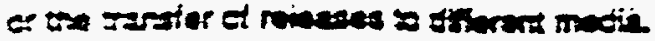

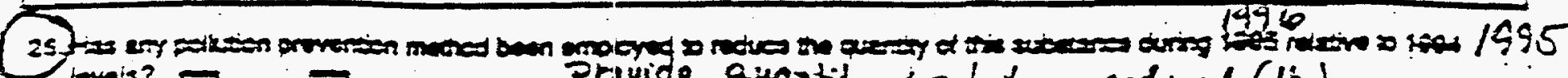

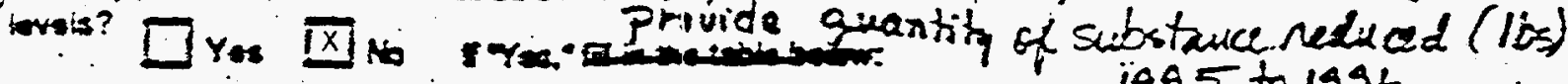
1995 to 1996

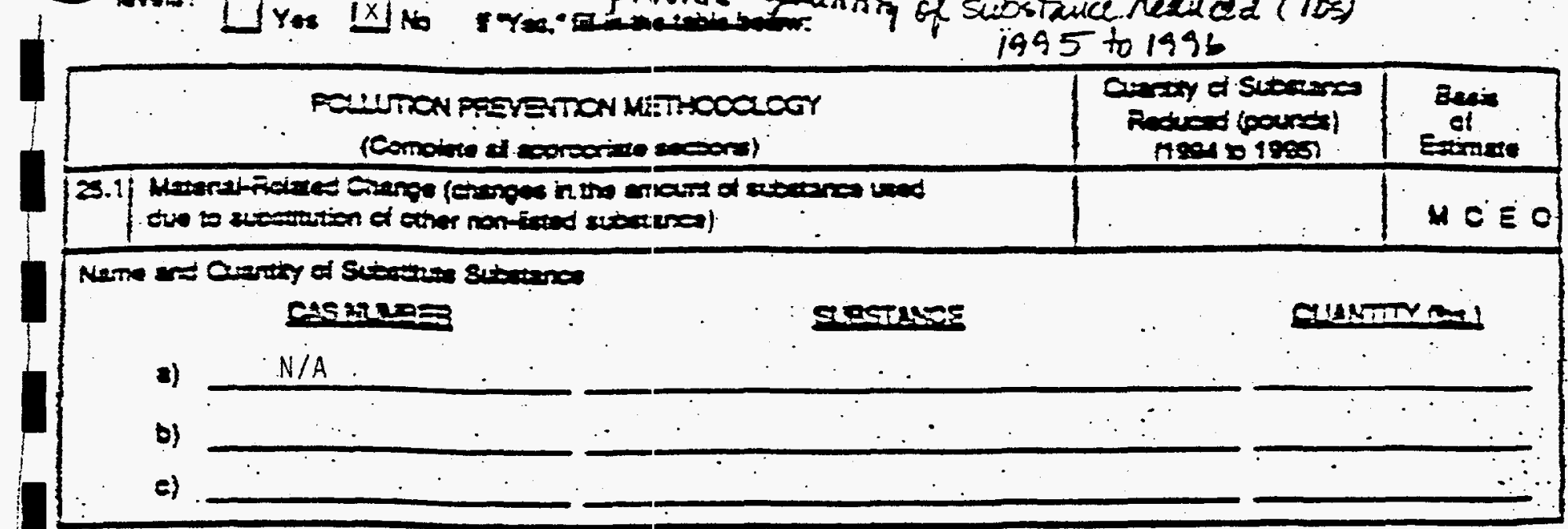

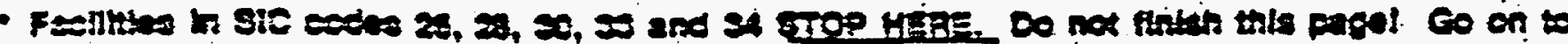

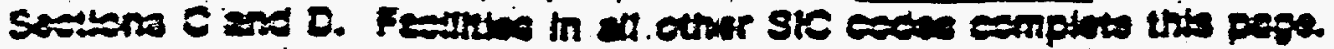

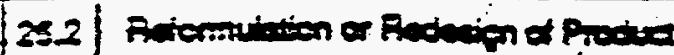

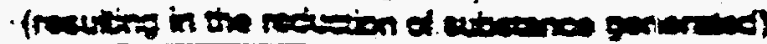

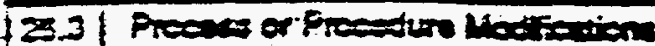

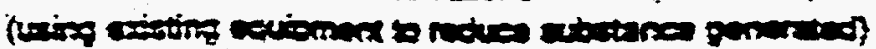

\begin{tabular}{|c|c|c|}
\hline . & 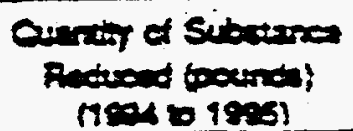 & 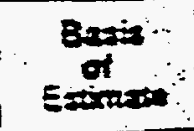 \\
\hline & & u $\mathrm{E}=0$ \\
\hline & & Me. $=0$ \\
\hline$g$ grm-at & & H. $E$ E \\
\hline Writ thexpes of & & M $\subset \leq \dot{0}$ \\
\hline & & MEEO \\
\hline
\end{tabular}

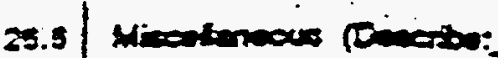

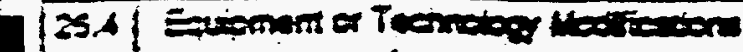

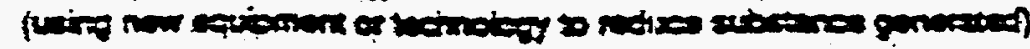

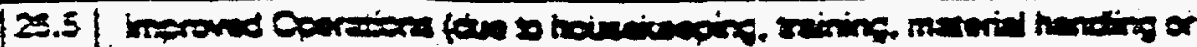

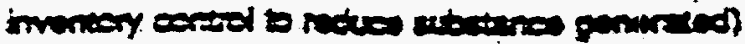

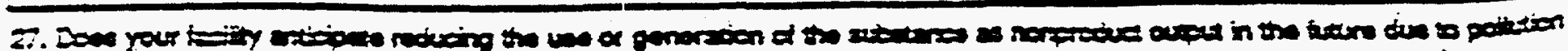

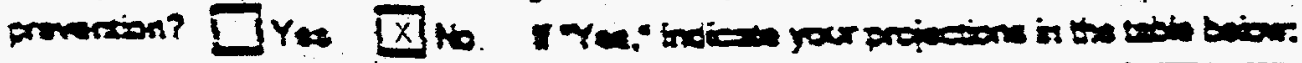

Prapinas

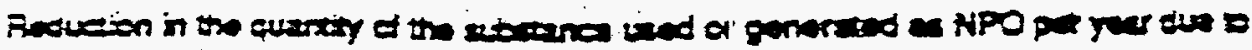

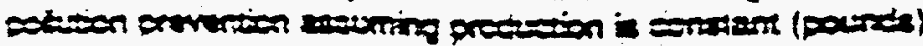




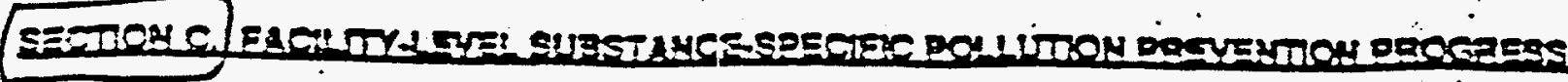

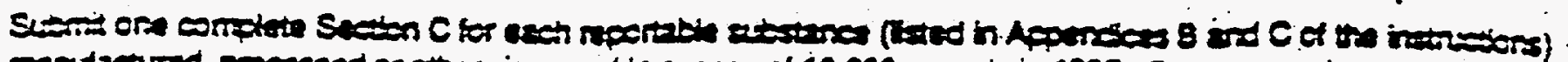

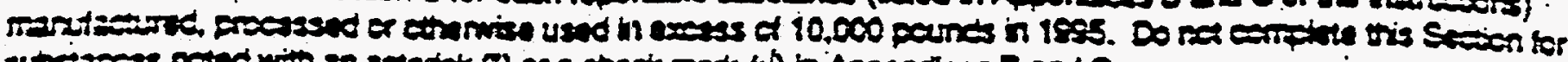

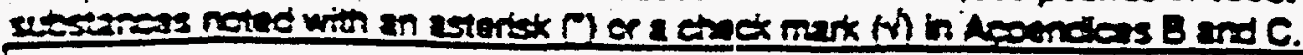
$y-12$ PlN
1.1 Ces no. (Cingory No.)
FACILTY LOCATTCN INFOAMATEN
N090

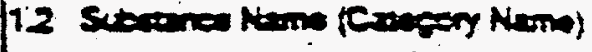
Chromium Compounds

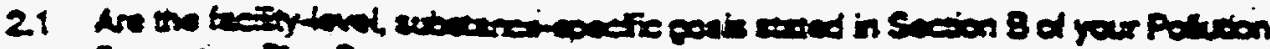

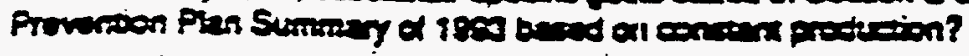

N/A

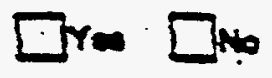

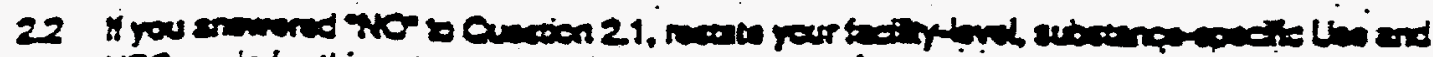

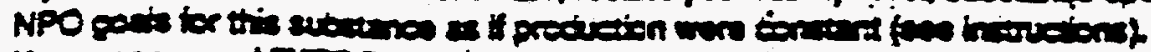

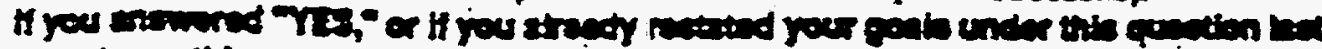

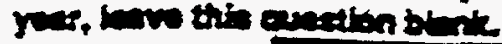

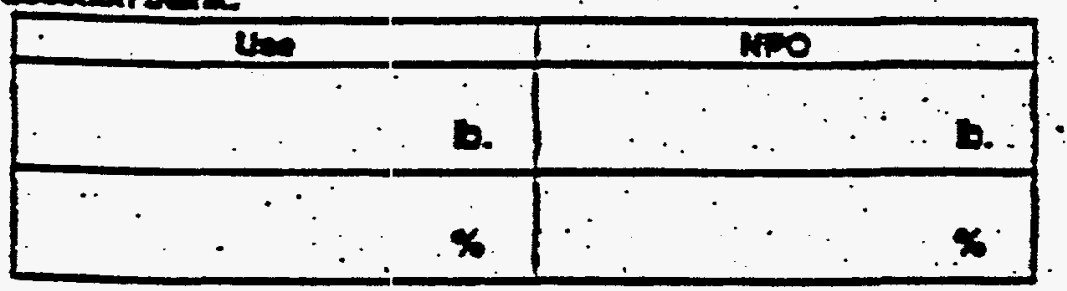

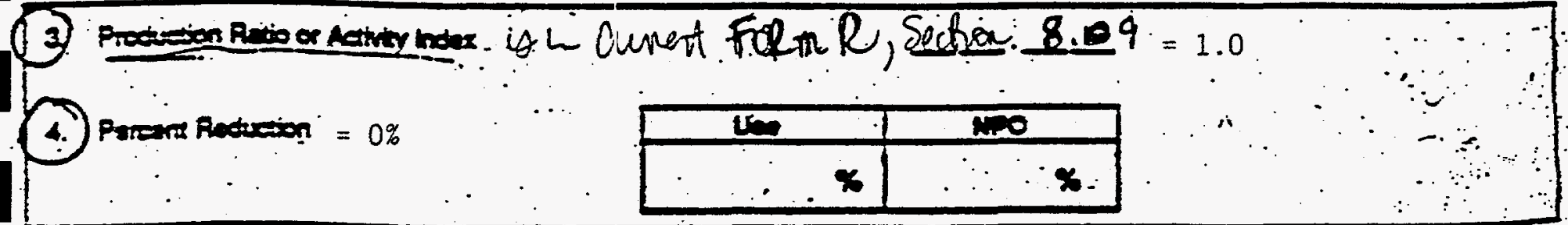

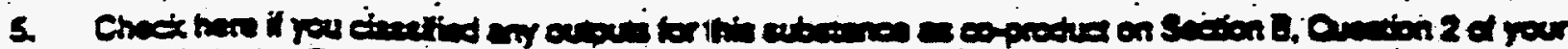

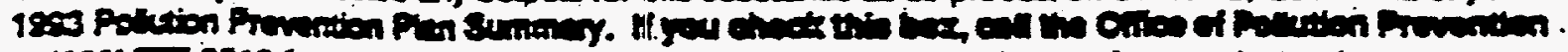

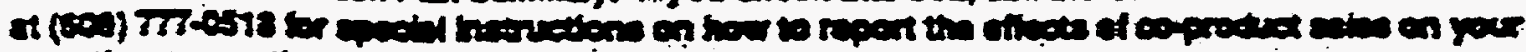

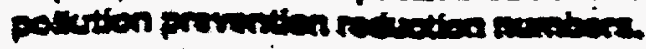

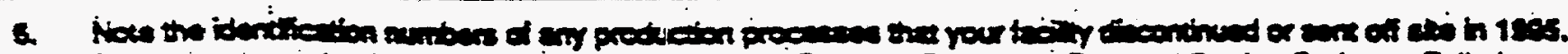

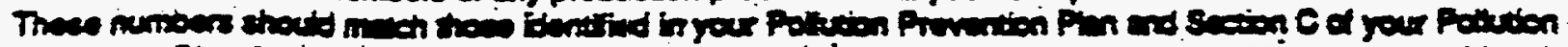

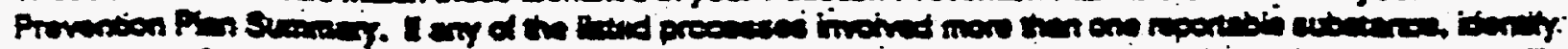

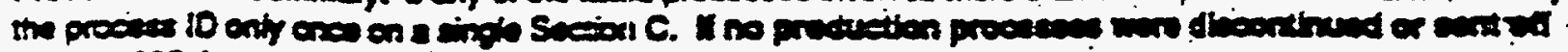

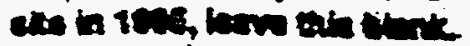

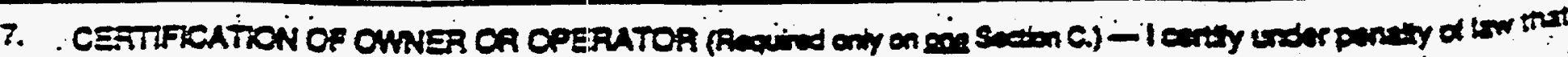

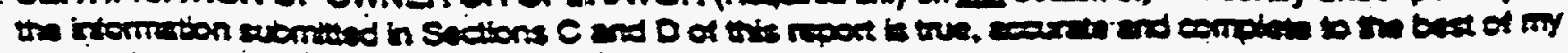
krowinedos.

sipimane Deto Pron tho. 


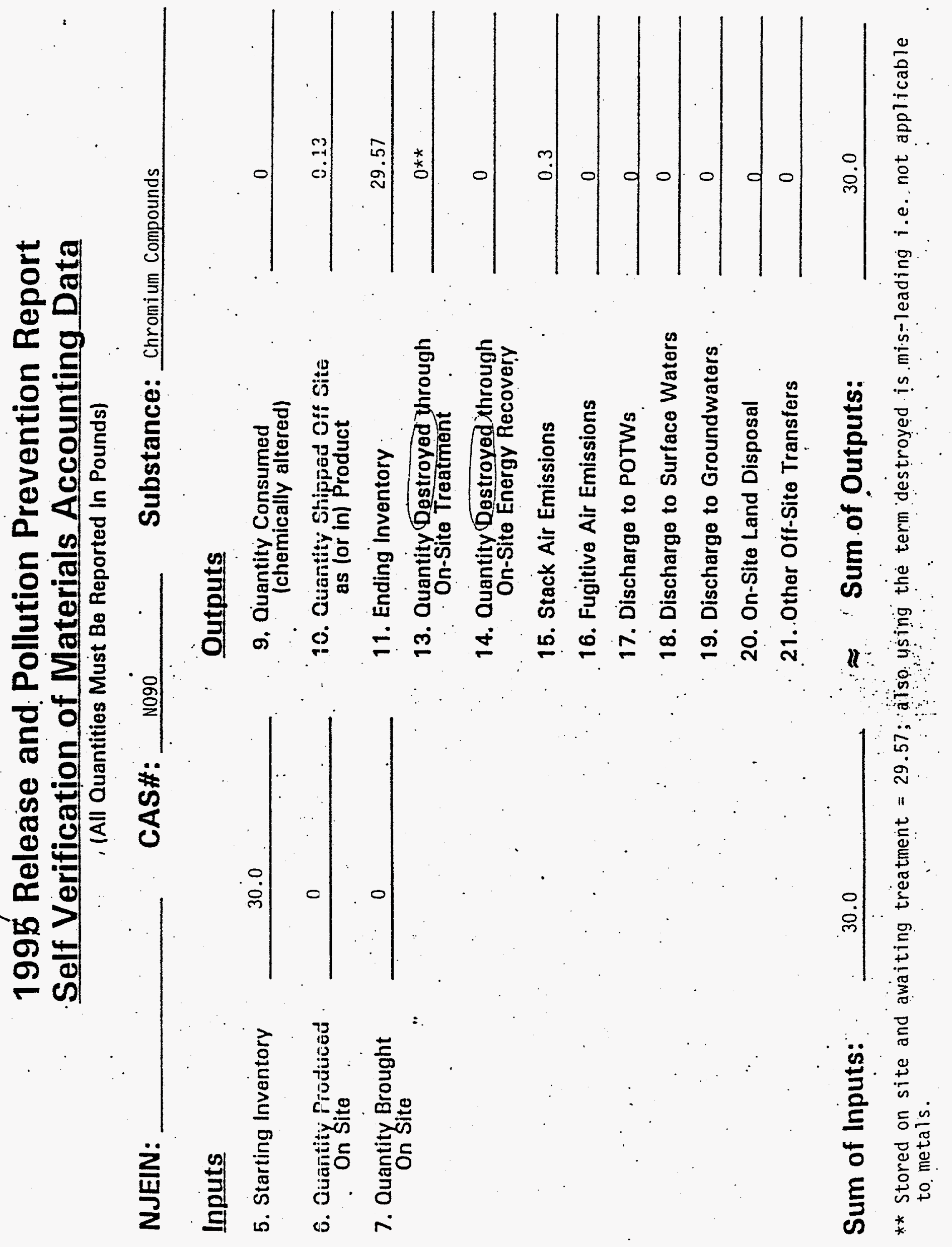




\section{New Jersey - Form $S$}

\subsection{Starting Inventory of Substance on Site}

\section{Background/Inventory}

Based on the material selected and plant-wide inquiries, one process was identified and selected for this report. Building $9201-5 \mathrm{~N}$ has two primary operations; (1) the machining operations in which a cast, forged, or formed shape is machined, e.g. aluminum alloys, magnesium alloys, bronze and (2) plating operations, i.e., plating various metals onto substrates. For the purpose of this report our attention is focused on operations which includes electroplating finishing and metal cleaning. Major equipment includes tanks, and rectifiers. The current process simply involves taking a given part, zinc plating and dipping it into a chromate solution ( $\sim 35 \%$ sodium bichromate, and $\sim 55 \%$ formic acid), rinsed with de-ionized water and air dry. The solution (macro drab) and rinsate are collected in drums and sent to waste management for treatment/disposal. In summary the istarting inventory $=30 \mathrm{lbs}$.

\subsection{Starting Inventory that is NPO}

The quantity of starting inventory that is Nonproduct Output is the spent solution and rinsate. It was determined that this amount $=\sim 29.87 \mathrm{lb}$ in CY 1997.

Cr to air from plating process was determined to $b e=\sim 0.3 \mathrm{lb}$.

The Plating Shop is located inside a building $9201-5 \mathrm{~N}$ with no patent drains to the Storm Water System or Sanitary Sewers.

\subsection{Quantity Produced on Site}

No Cr was produced on site during in CY 1997.

\subsection{Quantity Brought on Site}

No Cr was brought on site for processing in 9201-5N in CY 1997.

\subsection{Quantity of No. 7.0 that was brought on Site as Recycled Substance}

No $\mathrm{Cr}$ was brought on site as recycled substance for processing at 9201-5N in CY 1997. 


\subsection{Quantity Recycled Out-of-Process on Site and Used on Site}

No $\mathrm{Cr}$ was recycled out-of-process and used on site at $9201-5 \mathrm{~N}$ in CY 1997. The $\mathrm{Cr}$ in waste $(\sim 29.57 \mathrm{lbs})$ was sent to WETF/WTF for treatment for disposal.

\subsection{Quantity Consumed on Site (chemically reacted in process)}

No Cr was consumed on site in CY 1997 , i.e. its molecular structure altered.

\subsection{Quantity Shipped off Site as (or in) Product}

Estimated $\sim 0.13 \mathrm{lbs}$ was shipped in product.

\subsection{Ending Inventory}

Due to the $0.3 \mathrm{lbs}$ of $\mathrm{Cr}$ released to air and $0.13 \mathrm{lbs}$ shipped in product in CY 1997 the remaining $29.57 \mathrm{lbs}$ was on Site in waste, therefore ending inventory $=29.57 \mathrm{lbs}$.

\subsection{Quantity of Ending Inventory that is NPO}

Ending inventory that is NPO $=\mathbf{2 9 . 5 7} \mathbf{l b}$.

\subsection{Total NPO Generated}

As stated in (11.1), the total NPO generated in CY 1997 at $9201-5 \mathrm{~N}$ is $=29.57 \mathrm{lb}$. in waste. Using the " $T$ " method for estimating Total NPO you will derive at $=0$; however in accordance to the intructions 29.57 lbs in waste was generated as NPO.

\subsection{Has any Pollution Prevention method been employed to reduce the quantity....}

In CY 1997, at 9201-5N no pollutior prevention was employed i.e. to reduce or eliminate of either the use of Chromium compounds or the generation of NPO, prior to treatment, storage, out-of-process recycling or disposal. Note: Pollution Prevention is not any type of treatment, out-of-process recycling, incineration, or the transfer to another media. Also due the low values implementing P2 is not cost effective for current operations.

27.0 Does your facility anticipate reducing the use or generation of the substance as NPO...

No, only small quantities of NPO is generated and handled accordingly, i.e. funding is not a priority. 


\section{Section $C$}

\subsection{CAS No.: N090}

- 1.2 Substance Name: Chromium Compounds

\subsection{Production Ratio}

$\mathrm{PR}=\mathrm{CY} / \mathrm{PY}$; therefore $P R=1.0$

\subsection{Percent Reduction}

Using information for CY 96 vs CY 97, there were no percent reduction therefore $=0 \%$ 


\section{SUMMARY}

\section{Section B: Inputs}

5.0 Starting Inventory $=30 \#$ for $(92.01-5 \mathrm{~N})$

5.1 Starting inventory Nonproduct Cutput $=29.87 \#$

6.0 Qty Produced on site $=0 \#$

7.0 Qty Brought on site $=0 \#$

$7.1 \& 8.0$ Qty brought as recycle... $=$ O\#

\section{Outputs:}

9.0 Qty consumed on site chemically $=0 \#$

10. Qty shipped off-site as product $=\mathbf{0 . 1 3 \#}$

11. Ending Inventory $=29.57 \#$

11.1 Qty of ending inventory that is $\mathrm{IPO}=29.57 \#$

12. Total NPO generated $=29.57 \#$; however using " $T$ " method $=0 \#$

Note: Basis of estimates for all $=O$; for question $12=T$

rae $(\mathrm{Y}-12$ Plant $)$ 
INTENTIONALLY BLANK

I

I

I

I

I

I

I

1 


\begin{tabular}{|l|l|l|}
\hline Facility Names & $E T T P$ & Facility ID: \\
Chemicall: & Reporting Year & \\
\hline
\end{tabular}

\section{Massachusietts Department of Environmental Protection}

\section{TURA REPORT - FORM S}

Toxics Use Rèduction Act - Chemical Usage Facility-Wide \& by Production Units

Section 1: Facility-Wide Usage of Lisied Chemical

1.1 007440473

Chemical Abstract Service (CAS) Number (if applicable)

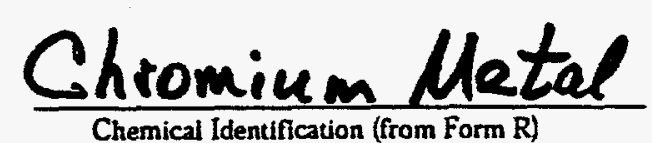

Chemical Identification (from Form R)

1.2 Facillty-Wide Usage of Chemical Identified in 1.1 above. Enter total amount (in POUNDS) for each applicable category. NOTE: Byproduct (item 1.2d) generilly means all wastes containing the listed chemical before the waste is treated or recycled. Read the instructions carefully, however, before completing this section.

1.2a Manufactured:

1.2b Processed:

1.2c Otherwise Used:

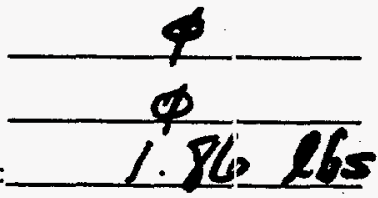

1.2d Generated as Byproduct:

1.2e Shipped in or as Product:

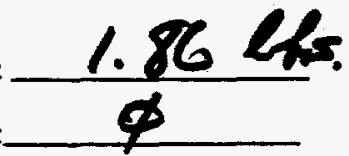

1.3 OPTIONAL QUESTION. When the amounts reported in 1.2a, 1.2b, and $1.2 \mathrm{c}$ are added together, the sum will -. in many cases -- equal the sum of $1.2 \mathrm{~d}$ and $1.2 \mathrm{e}$. In other words, the left and right columns will often form a "materials balance."

If $M A$ the two columns are not in approxintate balance. you may use this block to explain why. Mark all the reasons that apply. or indicate the number of pounds in the appropriate block below. (i.e.: 4,000 Chemical was held in inventory).

Chemical was recycled on site. Chemical was consumed or transformed.

Chemical was held In inventory. Chemical is a compound. Other (explain):

1.4 OPTIONAL QUESTION: Did anything non-routine occur at your facillty during the reporting year which affected the data reported? YES NO If YES, you rray use this space to comment:

\section{Section 2: Chemicals Used in Waste Treatment Units}

2.1 Is this chemical used to treat waste or conuol pollution? YES $\boldsymbol{X}$ No

If YES, enter the quantity of chemical codi for the amount used to treat waste or control pollution: OPTIONAL -- You may enter the amount:

Section 3: TURA Report on Production Unit\#: 01 (Enter \# from the Form S Cover Sheet.)

3.1 Base Year: $\longrightarrow$

3.2 Quantity of Chemical Code: A

3.3 Taxics Use Reduction Techniques Cude:
3.4 Byproduce Reduction Index:

3.5 Emissions Reduction Index:

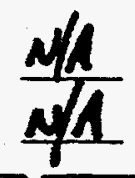

If there has been a change from one reporing year to the current year in a (1) base year. and/or (2) estimating methods (that significantly alter previously reported data) for this PRODUCTION UNIT REPORT, describe the change: 
FORM S COVER SHEET (continue-1)

\section{Section 4: Facility-Wide Listing of Prcduction Units}

A PRODUCTION UNIT is best thought o: as the combination of the process (or activities). used to produce a product or service and the product $\alpha$ service. In this block, please identify the PRODUCTION UNITS at the facility, then use the production unit number to report on chemical usage in the attached Form S. If there is a substantial change in a PRODUCTION UNIT from one reporting year to the next, the PRODUCTION UNTT must be given a new, unique number.

This Production Unit (Process/Product Combination) is: The Same As Reported Last Year New

Unit \#:

Describe the Process:

\section{Attacled}

Describe the Product: Atached

Enter the four-digit SIC Code's) that best describe(s) the product:

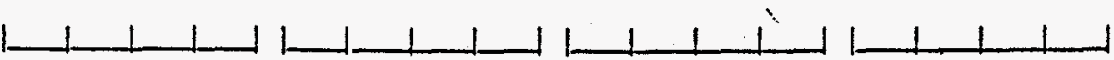

Describe the Unit of Product:__ Luclefined

(Please specify if the Unit of Froduct has been charged since the previous ceporting year.)

\section{PRODUCTION PROCESS STEP INFORMATION FOR THIS PRODUCTION UNTT}

Enter the production process code(s) to identify the process step(s) that involves a TUR-reportable chemical(s) as an input, output or throughpt:. (See the reporting guidance document for the list of production process codes and instructions on when a given code needs to be listed.)
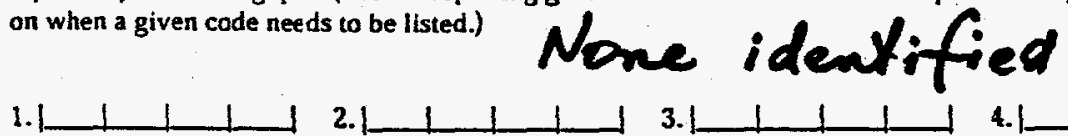

$$
\text { 2.1 }
$$

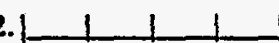

3.

4.

6. $1+111$

$7.1+111$

8. $\mid+1+1$

List below, the TURA-refortable chemicals associated with the production unit. If a chemical is associated with ALL the process steps identified atiove, check the ALLblock. If the chemical is associated with some but not all of the process steps, put the relevant code(s) (from above) next to the chemical

Chemical(s)

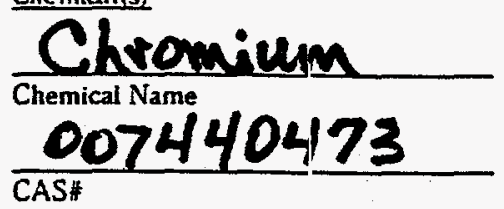

Chemical Name

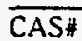

Chemical Name

\section{$\overline{\text { CAS* }}$}

Production Process

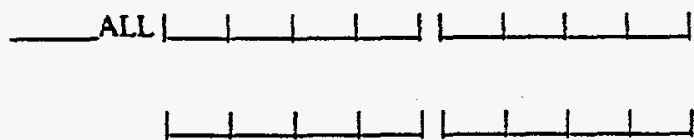

ALL

$1+1+111$

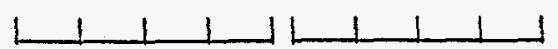

ALL

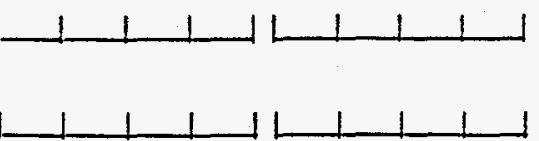

Page of 


\section{TURA Report - Form S}

ETTP - CHROMTUM

1.1 CAS No. 007440473 Chemical Identification Chromium Metal

1.2a Manufactured 0

1.2b Processed 0

1.2c Otherwise Used $1.86 \mathrm{lbs}$ was "otherwise used" according to the TRI-P2 definition, which includes chemicals in waste; this small amount of offsite waste had to be distinguished from the total amount of $111.56 \mathrm{lbs}$ of chromium in waste that was treated at the incinerator in 1997.

1.2d Generated as Byproduct $1.86 \mathrm{Ibs}$ could be considered byproduct if one applies the statement that "All process outputs from a recycling operation are counted as byproduct." (Current definitions do not accomodate the incineration process very well.)

1.2e Shipped in or as Product 0 . Chromium metal that passes through a waste treatment process cannot be considered both product and byproduct.

1.3 Optional Question Not Applicable

1.4 Optional Question Not Applicable

2.1 Is the chemical used to treat waste or control pollution?

No, the chemical is contained in the waste as a minor constituent.

3.1 Base Year: 1997; not previously reported.

3.2 Quantity of Chemical Code: A (0-5000 lbs)

3.3 Toxics Use Reduction Code: None available for waste treatment

3.4 Byproduct Reduction Index:

Not Applicable for 1997 because it is the base year; but given data from a prior year, BRI is not an appropriate calculation for metals in waste...there is no product produced.

3.5 Emission Reduction Index:

As in 3.4 above, the ERI equation assumes that there is a production activity for the chemical being reported. 
Section 4. Facility-Wide Listing of Production Units

Production Unit: 01

Process Description:

The production unit is a DOE hazardous waste incinerator at ETTP. Its primary purpose is to chemically transform hazardous liquid wastes from past DOE operations in the Oak Ridge area and at a few out-of-state locations. Small amounts of metals are contained in the waste feed, and are removed by the air pollution ccntrol equipment at an efficiency of greater than $99 \%$ for most metals. The residual metals are contained in the aqueous wastewater, and the sludge, and the ash which is containerized for landfill disposal.

\section{Product Description:}

This is a waste management process aimed at hazardous waste destruction and size reduction; in the case of parent metals contained as a minor ingredient in waste, the process can only recontainerize the metals for some other means of disposal.

Unit of Product: Undefined; assunes there to be an end product for which the chromium was otherwise used; the chromium is a very minor constituent in the waste being incinerated, and if it were not for strict RCRA permitting requirements, there would be no data available for reporting.

Production Process Step Information:

None identified. Appendix $\mathrm{H}$ does not have codes that describe this process. In fact, the reporting instructions would exempt this entire waste production unit from Form $\mathrm{S}$ reporting; a report is being attempted in this pilot project to determine the suitability of the reporting forms.

Chemical: Chromium metal

CAS No: $\quad 007440473$ 


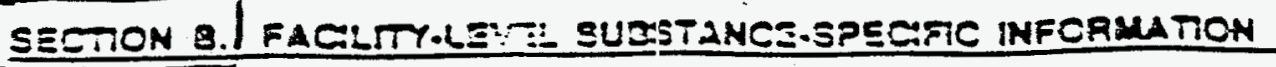

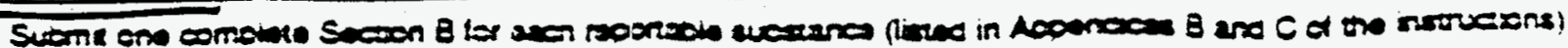

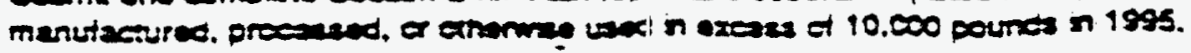

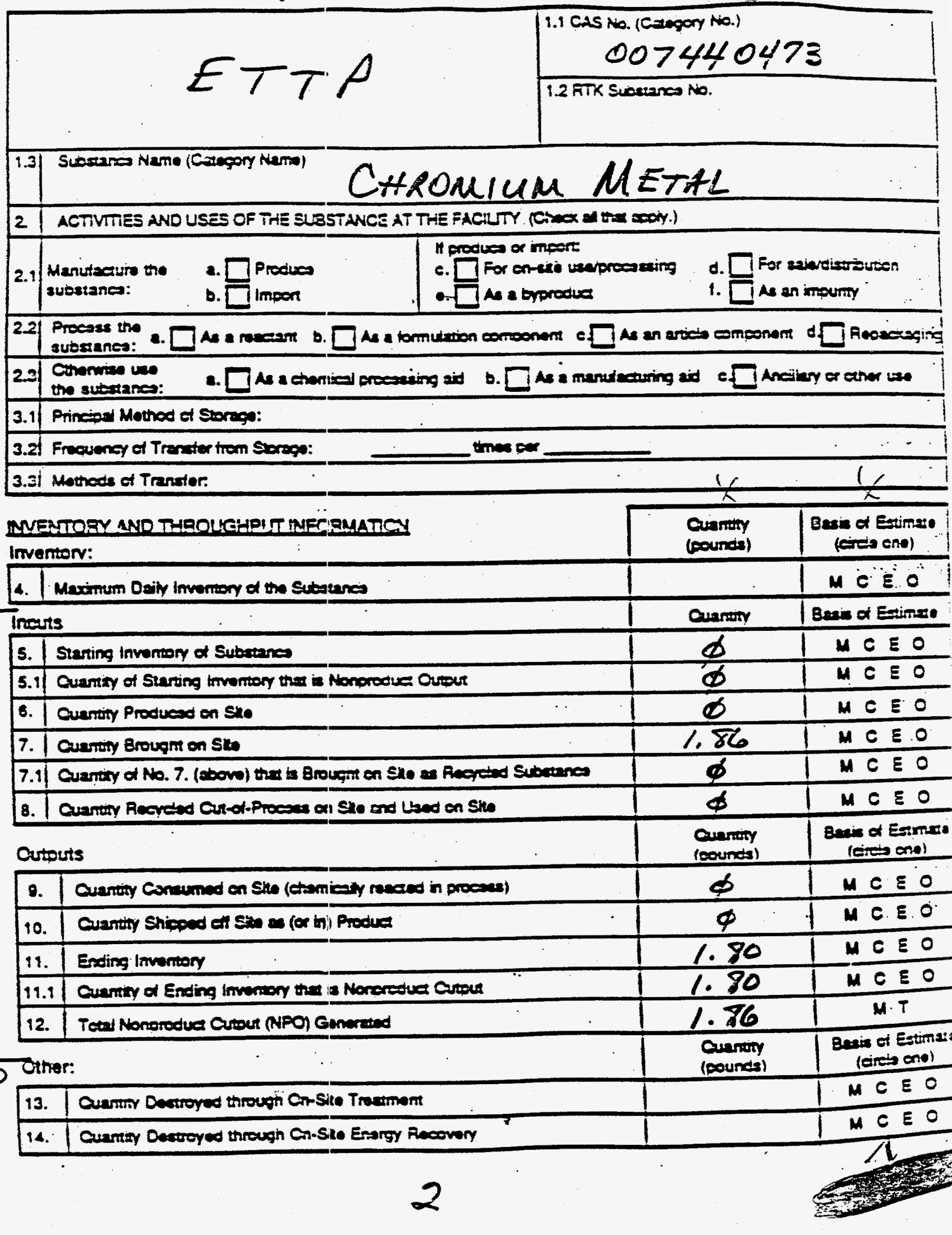




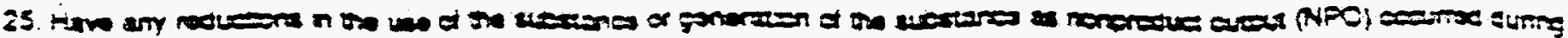

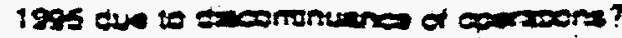

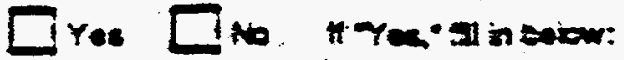

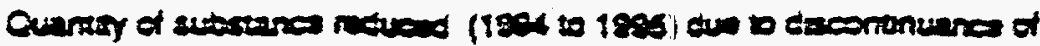

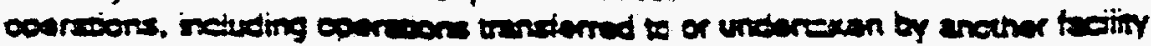

\begin{tabular}{|c|c|}
\hline 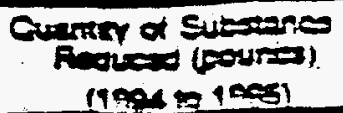 & $\begin{array}{l}\text { East } \\
\text { Et } \\
\text { Estinat }\end{array}$ \\
\hline & $M C E$ \\
\hline
\end{tabular}

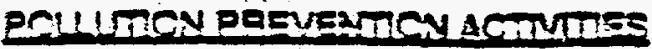

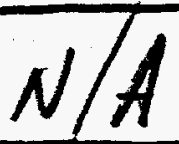

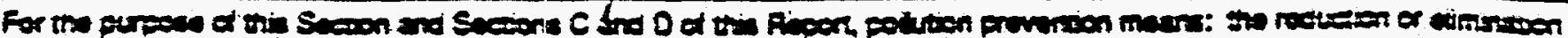

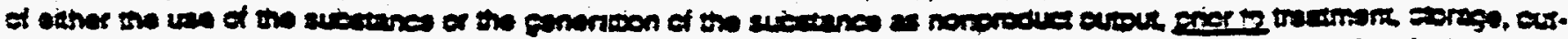

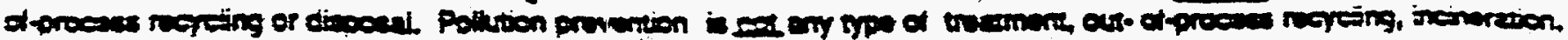

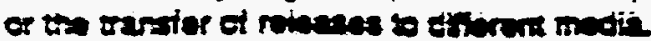

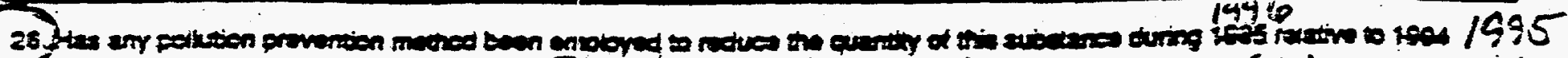

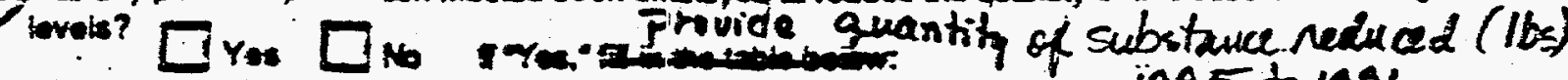
1995 to 1995

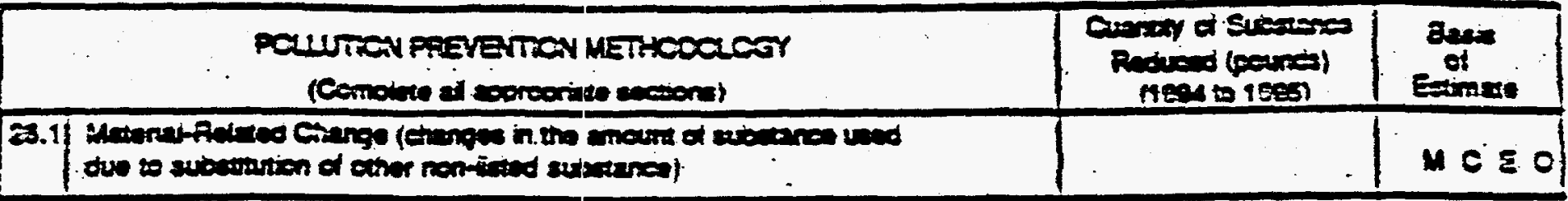

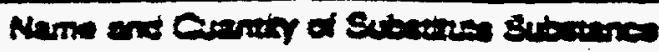

coser.:20

Erastans

cravmin mal

)

b)

c)

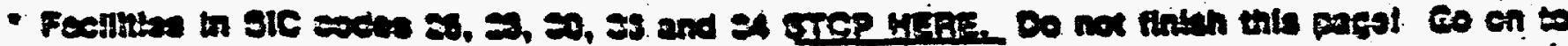

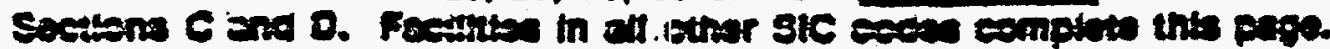

\begin{tabular}{|c|c|c|}
\hline ca2 & 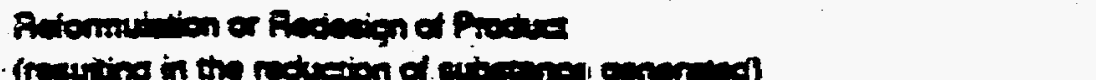 & Ne $=0$ \\
\hline 233 & 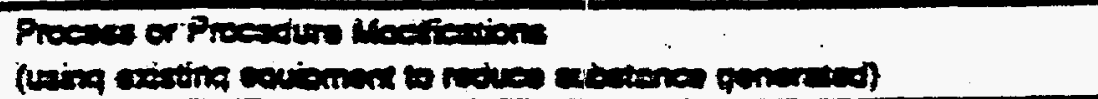 & \\
\hline $23: 4$ & 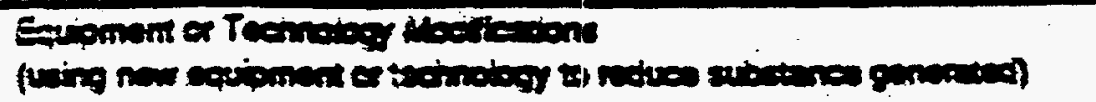 & 14. $=0$ \\
\hline 20.5 & 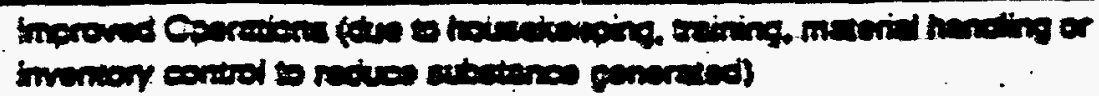 & $M e \geq 0$ \\
\hline
\end{tabular}

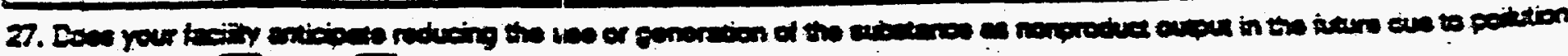

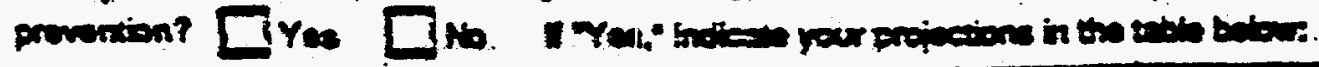

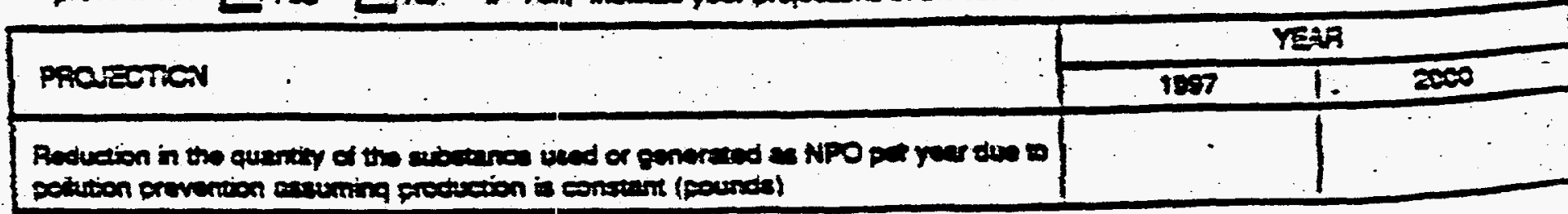




\section{New Jersey Form S}

\section{E.TTP CHROMIUM METAL}

\subsection{Starting Inventory of Substance on Site:}

Zero. All offsite waste incinerated cluring the year is assumed to have been received during the same year. Although there may have been other chromium inventory onsite at the beginning of 1997, it was most likely exempt from TRI reporting as an ingredient in solid articles (extremely difficult to determine after-the-fact if any would have lost its article exemption during the year); there also may have been chromium metal in other waste management activities that are not nearly as quantifiable as that treated by incineration.

\subsection{Starting Inventory that is NPO: Zero.}

6. Quantity Produced on Site: Zero

7. Quantity Brought on Site: $1.86 \mathrm{lbs}$ of chromium metal that was in waste treated at the incinerator was from offsite

7.1 Quantity Brought on Site as Recycled Substance: Zero

8. Quantity Recycled Out-of-Process on Site and Used on Site: Zero

\section{Quantity Consumed on Site: Zero}

10. Quantity Shipped off Site as (ior in) Product: Zero

11. Ending Inventory: $1.80 \mathrm{lbs}$ recovered in sludge, assumes $3 \%$ lost to air/water emissions.

\subsection{Quantity of Ending Inventory that is Nonproduct Output: $1.80 \mathrm{Ibs}$}

12. Total Nonproduct Output Generated: $1.86 \mathrm{lbs}$ considered nonproduct output, although there are problems applying the nonproduct definition [generated prior to treatment] to this situation, and subsequent sections |Environmental Releases and Offsite Transfers, which are Form $R$ entries] are more appropriate for tracking the waste ingredients.

NOTE: The remaining sections of the New Jersey reporting form are Not Applicable to incineration and other waste treatment activities, according to the introduction to Item \#26. 


\section{INTENTIONALLY BLANK}




\section{Distribution}

W. Garvey, U.S. EPA

C. C. Hill

R. L. Johnson, Jr./ R. A. Evans

R. Kingrea

R. Martin, DOE-ORO

F. Perez

J. Powers, DOE-HQ

A. D. Saunders

G. G. Worley

EC Document Center-RC

Y-12 Plant Records Service (1)/DOE-OSTI (2) 